\title{
Graphene and Graphene-Based Composites: A Rising Star in Water Purification - A Comprehensive Overview
}

\author{
Muniyappan Rajiv Gandhi, ${ }^{\text {[a] }}$ Subramanyan Vasudevan, ${ }^{[b]}$ Atsushi Shibayama, ${ }^{[c]}$ and \\ Manabu Yamada ${ }^{[\mathrm{d}]}$
}

\begin{abstract}
Graphene is an interesting two-dimensional carbon sheet possessing single-layered atom thickness that confers unique physical and chemical properties. The pristine graphene sheets have some limited applications in water purification, but the modification of graphene into the graphene composite by the incorporation of some functional groups or nanoparticles on the surface extensively increases its environmental applications. Recently, graphene nanocomposites have found to show very promising applications in all types of water purification. The present review highlights the recent developments in the applications of graphene and graphene-based composites as adsorbent, catalyst, photocatalyst, electrocatalyst, photo-
\end{abstract}

\section{Introduction}

Graphene, which is the most recent material of the carbon group, is considered as one of the greatest smart materials of the $21^{\text {st }}$ century. ${ }^{[1]}$ Graphene and graphene-based composites show numerous potential applications owing to their distinctive two-dimensional assembly and related band structure. Graphene has gained attention of many scientists since its innovation due to its exceptional large surface area $\left(2630 \mathrm{~m}^{2}\right.$ $\left.\mathrm{g}^{-1}\right)_{1}^{[2]}$ high electrical conductivity at room temperature ${ }^{[3,4]}$ (106 s cm $\left.{ }^{-1}\right)$, good mechanical properties ${ }^{[5]}(\sim 1.1 \mathrm{TPa})$, fracture strength $^{[5]}(125 \mathrm{GPa})$, breaking strength ${ }^{[6]}\left(42 \mathrm{~N} \mathrm{~m}^{-1}\right)$, excellent mobility as charge carriers ${ }^{[7]}\left(\sim 20 \mathrm{~m}^{2} \mathrm{~V}^{-1} \mathrm{~s}^{-1}\right)$, superior thermal conductivity $\left.(\sim 5000 \mathrm{~W} \mathrm{~m} \mathrm{~K})^{-1}\right)^{[6]}$ high carrier density $\left(\sim 10^{12}\right.$

\section{[a] Dr. M. R. Gandhi}

Venture Business Laboratory

Akita University

1-1 Tegatagakuen-machi, Akita 010-8502, Japan

E-mail: rajivgandhi85@gmail.com

[b] Prof. S. Vasudevan

CSIR-Central Electrochemical Research Institute Karaikudi-630006, India

[c] Prof. A. Shibayama

Department of Earth Resource Engineering and Environmental Science, Graduate School of International Resource Sciences

Akita University

1-1 Tegatagakuen-machi, Akita 010-8502, Japan

[d] Prof. M. Yamada

Research Center for Engineering Science, Graduate School of Engineering Science

Akita University

1-1 Tegatagakuen-machi, Akita 010-8502, Japan

Supporting information for this article is available on the WWW under http://dx.doi.org/10.1002/slct.201600693 electrocatalyst, and disinfection and desalination agent in comprehensive water purification systems. We primarily focus on the environmental engineering applications of graphene nanocomposites as sorbent materials for the elimination of toxic inorganic (cationic and anionic), organic, and mixed/multiple pollutants, and as catalysts for the degradation of toxic organic contaminants using catalytic oxidation, photocatalytic oxidation, electrocatalytic oxidation, and photoelectrocatalytic oxidation. We have also discussed the use and feasibility of graphene nanocomposites in water disinfection and desalination. Finally, the future challenges and perspectives are discussed.

$\left.\mathrm{cm}^{-2}\right){ }_{1}^{[8]}$ good optical transmittance $(\sim 97.7 \%),{ }^{[0]}$ specific magnetism, and chemical stability. ${ }^{[1]}$ Graphene and its composites are widely used in sensors, transistors, electronics, composite materials, photonics, bioengineering, energy production, and storage. ${ }^{[10]}$ Pure graphene is hydrophobic in nature and cannot be dispersed in aqueous solutions, ${ }^{[11]}$ therefore this factor limits its application in water purification. Chemically converted graphene, namely graphene oxide and reduced graphene oxide, can be easily synthesized ${ }^{[12]}$ and have shown numerous potential applications in water purification. ${ }^{[13]}$ For example, graphene oxide consists of many oxygen functional groups for example carboxyl, ketone, epoxy, and hydroxyl groups at their basal as well as edge planes. Moreover, graphene oxide is hydrophilic in nature with large negative charge surface that helps effectively remove cationic impurities (heavy metal cations and cationic dyes) by electrostatic interaction. ${ }^{[13,14]}$ Graphene oxides are capable to act as adsorbent for various heavy metals. ${ }^{[15]}$ Graphene oxides undergo transformations in water over a period of several months, which limits its application in water treatment. ${ }^{[15]}$ Reduced graphene oxide possesses large surface area, but does not possess large negative charge, and shows effective removal of anionic impurities (anionic dyes, $\mathrm{As}(\mathrm{III}), \mathrm{As}(\mathrm{V})$, and $\mathrm{Cr}(\mathrm{VI})$ ). ${ }^{[14,15]}$ In order to improve the efficiency of graphene, graphene oxide, and reduced graphene oxide in environmental applications, graphene nanocomposites are prepared by anchoring them with specific functional groups and various nanomaterials. ${ }^{[13,16]}$ Therefore, the prepared graphene-based nanocomposites show superior water purification applications compared with unmodified graphene, graphene oxide, and reduced graphene oxide. ${ }^{[13,15,17]}$ The graphene-based composites show great improvements in their performance toward adsorption capacity, catalytic/photocatalytic/electrocatalytic/photoelectrocatalytic 
activity, and disinfection and desalination ability in water purification applications. ${ }^{[13-15,17-20]}$ Many reviews have compiled environmental applications of graphene on specific fields. ${ }^{[13-15,17-20]}$ Majority of the review articles included experiments on the adsorptive/photocatalytic remediation of metal ions or dyes. However, none of them reviewed all applications of graphenebased materials as adsorbents, catalysts, and in water disinfection and desalination. Thus, in this present review an attempt has been made to discuss briefly graphene-based composites and their preparations and properties. Recent advances have been shown in the adsorptive remediation of graphenebased composites as toxic inorganic (cationic and anionic) contaminants, organic contaminants (dyes, micro-organic contaminants, polychlorinated biphenyls, personal-care products, pharmaceuticals, pesticide, herbicides, etc.), and mixed contaminants. We focused on the catalytic application of graphene-based nanocomposites considering the above-mentioned organic contaminants by using catalytic oxidative degradation, photocatalytic oxidative degradation, electrocatalytic oxidative degradation, and photoelectrocatalytic oxidative degradation. In addition, the critically reviewed applications of graphene-based composites included water disinfection against different kinds of disease causing microorganisms and the feasibility of water desalination $(\mathrm{NaCl}, \mathrm{KCl}$, $\mathrm{Na}_{2} \mathrm{SO}_{4}, \mathrm{MgSO}_{4}, \mathrm{MgCl}_{2}, \mathrm{As}(\mathrm{III}), \mathrm{As}(\mathrm{V})$, and dyes). Finally, the potential upcoming research work on high-efficient graphene- based nanomaterials and future challenges and perspectives are discussed considering the challenges in near-future water purification applications. We believe that the present review would help the researchers and environmental engineers understand the current needs and challenges to produce highly efficient graphene-based materials for all kinds of water purification in commercial applications.

\section{Preparations and properties of graphene and graphene - based composites}

\section{Graphene}

In 2004, Novoselov et al. ${ }^{[21]}$ synthesized very stable monocrystalline graphene films with a thickness of few atoms by mechanical exfoliation from pyrolytic graphite. In 2010, the Nobel Prize in physics was awarded jointly to Geim and Novoselov (University of Manchester, USA) for ground-breaking experiments considering the two-dimensional graphene material. This was the first highly recognized method used for the preparation of high quality graphene by using the top-down approach. Various methods have been reported to prepare graphene. Until now, two primary approaches are applied for the preparation of graphene using different carbon materials: the top-down chemical approach, in which graphitic materials are used as starting materials, and the bottom-up approach, in

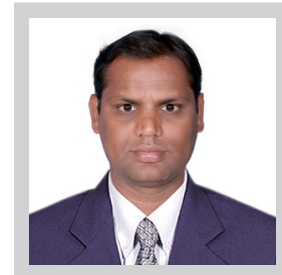

Muniyappan Rajiv Gandhi is Post-Doctoral Researcher (Center of Excellence Researcher) at Venture Business Laboratory, Akita University, Japan. He obtained his M.Sc. degree in Chemistry (2007) and Ph. D. degree in Chemistry (2012) from Gandhigram Rural Institute, India. In 2013, he joined as Post-Doctoral Researcher at Research Center for Engineering Science in tenure-track program for young faculty members, Akita University, Japan. He has been awadred JSPS Postdoctoral Fellowship in 2016 under Overseas Researchers Program of Japan Society for the Promotion of Science. His research mainly focuses on water/wastewater treatment, development of novel functional adsorbents/macrocyclic extractants, and recycling of rare metals from secondary resources.

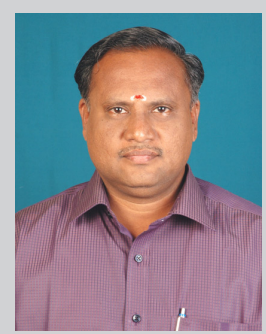

S. Vasudevan is Professor at AcSIR and Principal Scientist at Central Electrochemical Research Institute, India. He has been working in diverse areas of electrochemistry for the past 20 years. His research primarily focused on the areas of electrochemical water treatment, hydrogen generation by water electrolysis, materials electrochemistry and electro-catalysis. He has published more than
100 research papers in reputed peer reviewed journals and written seven book chapters. He is the recipient of several honors and awards.

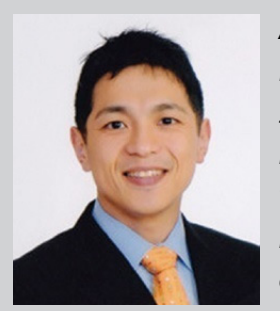

Atsushi Shibayama is Professor and Vice Dean of Graduate School of International Resource Sciences at Akita University, Japan. He received his D. Eng. degree from Kyushu University, Japan in 1999. His research activity mainly focused on advanced mineral processing, development of rare metals recycling technology, removal of hazardous impurities from resources and environmental engineering related to wastewater treatment.

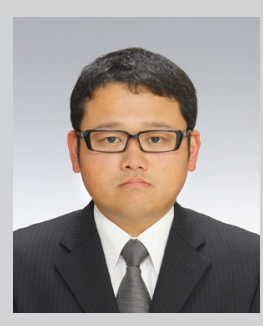

Manabu Yamada is Assistant Professor of Research Center for Engineering Science, Graduate School of Engineering Science at Akita University, Japan. He obtained Ph.D. degree from Akita University, Japan in 2010. His research primarily focused on the areas of development of novel functional extractants/adsorbents for rare metals separation from secondary resources and organiccrystal materials possessing adsorption properties for gaseous/vaporous organic compounds. 
which small carbon-based molecules are used as precursor for the synthesis of graphene. ${ }^{[22]}$ The methods of Schafhäutl (1840), ${ }^{[23]}$ Brodie (1859), ${ }^{[24]}$ Staudenmaier (1898), ${ }^{[25]}$ and Hummer's and Offeman (1958) ${ }^{[26]}$ used the top-down approach for the preparation of graphite oxides by the oxidative exfoliation of graphite. Currently, Hummer's method ${ }^{[26 a-e]}$ and the modified Hummer's method ${ }^{[27]}$ are primarily used as common techniques for the preparation of graphene oxide (GO). In these techniques, graphite is oxidized into GO using strong acids and the produced GO is dispersed in water. The top-down approach is cost-effective but limited at a laboratory scale only. ${ }^{[2]}$ In the top-down approach, graphene sheets are prepared by exfoliation peeling, cleaving, or separation from graphite, ${ }^{[26]}$ graphite oxide (GO), and graphite fluoride. ${ }^{[29]}$ Researchers have successfully fabricated a few layers of graphene sheets using the topdown approach.

Marcano et al. ${ }^{[27]}$ reported improved methods for synthesis of graphene oxide. They used Hummer's methods, modified Hummer's methods and new improved methods for preparation of graphene oxide. They compared the yield, quality, and advantages of the process. In Hummer's method, $69 \mathrm{~mL}$ of $\mathrm{H}_{2}$ $\mathrm{SO}_{4}, 3 \mathrm{~g}$ of graphite power (1 wt. equiv.) and $\mathrm{NaNO}_{3}(1.5 \mathrm{~g}, 0.5$ wt. equiv.) were cooled to $0{ }^{\circ} \mathrm{C} . \mathrm{KMnO}_{4}(9.0 \mathrm{~g}, 3$ wt. equiv.) was added to the mixture slowly and solution temperature increased to $20^{\circ} \mathrm{C}$. The reaction mixture was heated to $35^{\circ} \mathrm{C}$ and stirred for $30 \mathrm{~min}$. Additional water was added to reaction mixture heated to $98^{\circ} \mathrm{C}$ for $15 \mathrm{~min}$ and the reaction mixture was cooled to room temperature. Further, additional water and $30 \%$ of $\mathrm{H}_{2} \mathrm{O}_{2}(3 \mathrm{~mL})$ were added to the mixture and then the mixture was purified using washing, filtration, drying, etc. The final product was found to be $1.2 \mathrm{~g}$. In the modified Hummer's methods, 6 wt. equivalent of $\mathrm{KMnO}_{4}$ was used and same experiment conditions were used. The final product was $4.2 \mathrm{~g}$. They further improved the modified Hummer's method using 9: $1 \mathrm{H}_{2} \mathrm{SO}_{4} / \mathrm{H}_{3} \mathrm{PO}_{4}$ and obtained $5.8 \mathrm{~g}$ of the final product. The advantages of this method include no generation of any toxic gas $\left(\mathrm{NO}_{x}\right)$ and the control of temperature. In this method the graphene oxide is more oxidized than the Hummer's methods and modified Hummer's method. The improved synthesis of graphene oxide is very important for the large-scale production and applications. In recent years, serval modified Hummer's method have been developed. For example, Chen et al. ${ }^{[26 \mathrm{~b}]}$ reported an improved Hummer's method for environment friendly synthesis of graphene oxide. They reported synthesis of graphene oxide without using $\mathrm{NaNO}_{3}$ and obtained the same yield with conventional Hummer's method. The main advantages of the reported method is does not produce the toxic gas i.e. $\mathrm{NO}_{2}$ and $\mathrm{N}_{2} \mathrm{O}_{4}$, simplifies the wastewater disposal and hence it decreases the cost of production. Frankberg et al. ${ }^{[26 c]}$ synthesized graphene oxide using modified Hummer's methods from graphite powder. They proposed new procedure for exfoliation, in order to improve the yield of modified Hummer's synthesis. They carried out graphene oxide exfoliation via repeated ionexchanged water dilution and sonication in different amplitudes. They improved the yield of the graphene oxide up to $70 \%$ using their proposed exfoliation method. Kang et al. ${ }^{[26 \mathrm{~d}]}$ developed second oxidation step of Hummer's method. The first oxidation step is as usual with conventional Hummer's method and the second oxidation were conducted with different time length and temperatures. The second oxidation step influences the graphene oxide size, defects with in the layer, thermal stability, functional group on the surface, etc. Further, Abdolhosseinzadeh et al. ${ }^{[26]}$ reported fast and fully-scalable one pot synthesis of reduced graphene oxide. They reported that simultaneous oxidation as well as exfoliation, improved the yield of few layer of graphene oxides and they reduced the graphene oxide with ascorbic acid (eco-friendly reducing agents). The developed protocols were highly suitable for large scale production of graphene oxide.

Generally, numerous mechanical processes have been reported for producing the high-quality defect-free graphene. The common methods of the preparation are the exfoliation of graphite, electrochemical exfoliation, thermal exfoliation, sonication, acid dissolution of graphite, chemical reduction of $\mathrm{GO}$, and few more. Many researchers have extensively reviewed the synthesis of graphene using various methods, which provide a detailed understanding of the top-down approach. ${ }^{[10,22,30]}$ The top-down method is extensively used for the preparation of graphene at laboratory level with high-quality properties and low yield. The main disadvantage of the top-down approach is that graphene structures contain a vast number of defects on the graphene surface and it uses hazardous and toxic reagents, which limits the practical utilization of prepared graphene in several research fields. ${ }^{[31]}$

In the bottom-up approach, a large number of small molecules (hydrocarbons and silicon carbides) are decomposed into graphitic materials in the presence of catalyzed metal surfaces. The SiC substrate is generally used for epitaxial growth of graphene and the decomposition of $\mathrm{SiC}$ produces graphene layers. ${ }^{[22]}$ For example, graphene can be prepared using an epitaxial growth method by heating silicon carbide. ${ }^{[33]}$ Epitaxial graphene is synthesized by thermal decomposition of SiC using vacuum graphitization technique. ${ }^{[34]}$ The thermal decomposition of the $\mathrm{SiC}$ forms millimeter-sized constant graphene planes after the vaporization of silicon. ${ }^{[35]}$ The chemical vapor deposition (CVD) process is used to prepare graphene on a metal substrate under ultrahigh vacuum and at high temperatures. In the CVD method, a gaseous hydrocarbon material is heated $(1073 \mathrm{~K})$ and then graphene is deposited on the metal surface. The control and stability in the graphene scale are potentially high in the CVD process. ${ }^{[15]}$ The other standard techniques, such as arc discharge, chemical conversion of $\mathrm{CO}$ reduction, plasma discharge etching of graphite, carbon nanotube unzipping, chemical reduction of graphene oxides, and self-organization of surfactants, have been previously described for the preparation of graphene and their derivatives. ${ }^{[10,22,30]}$ The bottom-up approach has several advantages, such as graphene film is free from impurities, contains less defects, graphenecontrolled initiation, and the growth of the product, which is tailored through the precise choice of the initial substrate. The disadvantages of this approach are as follows: difficult for bulk production, high-temperature requirement, use of sophisticated instruments, and expensive materials. ${ }^{[31,35]}$ However, the bottom-up approach is widely preferred process for the prepa- 
ration of graphene due to control of atomic size, shape, composition, stability, and edge structure. ${ }^{[22]}$

Pristine graphene is hydrophobic in nature and very hard to disperse in aqueous solution to remove the contaminant. ${ }^{[36]}$ In order to improve the dispersibility of graphene, graphene surface is functionalized through chemical modification. The $\pi-\pi$ interaction between organic pollutant and graphene plays a vital role in the water treatment. The aggregation of the graphene in aqueous solution is the major drawbacks in the water treatment. To avoid aggregation of the graphene sheets, oxygen groups are introduced by oxidation. Oxygen groups on graphene layers reduce the aggregation and improve the removal capacity of the pollutant. Graphene oxide is conjugated in the graphene plane and possesses many functional groups (epoxide, carboxyl, hydroxyl, carbonyl, etc.) on the surface. ${ }^{[36]}$ These oxygen functional groups present on the graphene oxide surface act as an adsorbent and strongly interact with metal ions, cationic dye, and pharmaceuticals in aqueous solutions. Further, the reduction of graphene oxide is typically carried out by using reducing agents such as hydrazine, sodium borohydride, vitamin $C$, etc. ${ }^{[37-40]}$ The reduced graphene oxide possesses a large surface area, lacks of negative charge, and shows a high water cleanup efficacy toward anionic dyes, metal anions, and other contaminants. ${ }^{[14]}$ Pristine graphene, graphene oxide, and reduced graphene oxide exhibit moderate performance in the water treatment. ${ }^{[3,14]}$ Therefore, they are modified into various forms, such as nanocomposites, nanoparticles, membranes, etc., and used as adsorbents, catalysts, photocatalysts, photoelectrocatalysts, disinfectants, and in desalination in water treatment.

\section{Graphene - based composites}

\section{Polymer - graphene composites}

Generally, the compatibility of graphene and organic polymers is very poor and it is difficult to prepare homogeneous composites. ${ }^{[41]}$ In contrast, graphene oxides (GO) are more compatible with organic polymers. In order to synthesize functionalized graphene sheets, at first GO is reduced and then functionalized with various organic polymers for various applications. Song et al. ${ }^{[36]}$ synthesized tea polyphenols functionalized graphene nanosheets by using eco-friendly tea polyphenols as a reducing and functionalizing reagent. The advantage of this method is that tea polyphenols are utilized as a green reducing agent, additional functionalizing reagents are not necessary for functionalization of graphene oxide and thus it is environmental friendly, simple, and inexpensive. In this method, graphene oxide is synthesized from graphene using an ultrasonic exfoliation method. First, graphite oxide is dispersed in water and sonicated about $1 \mathrm{~h}$ for thorough exfoliation, and after that the graphite oxide dispersion is centrifuged in order to remove any nonexfoliated material. Finally the exfoliated GO sheets are collected from the supernatant liquid. In the GO sheet dispersion, an aqueous solution of tea polyphenol powder is added and stirred, and then sonicated. Furthermore, the solution is moved to a stainless-steel autoclave and temperature kept at $80^{\circ} \mathrm{C}$ for
$8 \mathrm{~h}$. The products of the reaction are washed with water through centrifugation and then dialyzed to remove unreacted tea polyphenols and other oxidation impurities. The synthesized tea polyphenol-graphene oxide has predominant single sheets, very stable, high surface area, and shows very good dispersibility in water. The average thickness of the synthesized GO nanosheets was $1.2 \mathrm{~nm}$ and the thickness of the tea polyphenol-graphene oxide sheets was about 1.7-2.2 nm. The increase in the thickness could be attributed to the functionalization of tea polyphenols/oxidized polyphenol on both sides of the graphene sheets.

Zhang et al. ${ }^{[42]}$ made water-soluble magnetic polyacrylic acid/graphene oxide/ $\mathrm{Fe}_{3} \mathrm{O}_{4}$ composites (PPA/GO/Fe $\mathrm{O}_{4}$ ). In this method, azide precursor (2-(Phosphonooxy)ethyl 2-azido-2methylpropanoate) is added to $\mathrm{Fe}_{3} \mathrm{O}_{4}$ nanoparticles in order to produce the azide-modified maghemite nanoparticles. Then, propargyl-amine-modified $\mathrm{GO}$ is prepared as follows. $\mathrm{GO}$ is suspended in $\mathrm{SOCl}_{2}$ and agitated at $65^{\circ} \mathrm{C}$ for 1 day. After that unreacted $\mathrm{SOCl}_{2}$ is removed, and then propargyl amine $\mathrm{CHCl}_{3}$ and anhydrous triethanolamine are added dropwise and the mixture stirred for $1 \mathrm{~h}$ at $0^{\circ} \mathrm{C}$ and then for $24 \mathrm{~h}$ at room temperature. The solid product is isolated using centrifugation and the obtained solid product again redispersed using THF and then product separated through further centrifugation and redispersed in $\mathrm{H}_{2} \mathrm{O}$. Graphene oxide/ $/ \mathrm{Fe}_{3} \mathrm{O}_{4}\left(\mathrm{GO} / \mathrm{Fe}_{3} \mathrm{O}_{4}\right)$ composites are prepared by a $\mathrm{CuSO}_{4}$ catalyzed azide alkyne cycloaddition reaction. Azide-modified $\mathrm{Fe}_{3} \mathrm{O}_{4}$ nanoparticles are mixed with a solvent (4:1 DMSO and $\mathrm{H}_{2} \mathrm{O}$ ) and sonicated. Copper sulfate and sodium ascorbate are mixed to the solution and stirred. Furthermore, propargyl-amine-modified GO is also mixed and stirred overnight. The final material is separated using magnet and completely washed with phosphate buffer solution. PPA/GO/ $\mathrm{Fe}_{3} \mathrm{O}_{4}$ nanocomposites are prepared by $\mathrm{GO} / \mathrm{Fe}_{3} \mathrm{O}_{4}$ nanocomposites and polyacrylic acid using carbodiimide under sonication at $0^{\circ} \mathrm{C}$ and then the final product is separated by a permanent magnet and thoroughly washed with phosphate buffer solution. $\mathrm{PAA} / \mathrm{GO} / \mathrm{Fe}_{3} \mathrm{O}_{4}$ nanocomposites exhibit good dispersibility in water. The obtained thickness of $\mathrm{GO}$ ranges from 1.0 to $2.0 \mathrm{~nm}$ and the height of the $\mathrm{GO}$ nanosheet is $\sim 1.6 \mathrm{~nm}$. The saturated magnetization of PAA/GO/ $/ \mathrm{Fe}_{3} \mathrm{O}_{4}, \mathrm{GO} / \mathrm{Fe}_{3} \mathrm{O}_{4}$, and $\mathrm{Fe}_{3} \mathrm{O}_{4}$ is 30,43 , and 62 emu g ${ }^{-1}$, respectively. $\mathrm{Fe}_{3} \mathrm{O}_{4} / \mathrm{GO}$ composites show less saturated magnetization than $\mathrm{Fe}_{3} \mathrm{O}_{4}$ and PAA/ $\mathrm{GO} / \mathrm{Fe}_{3} \mathrm{O}_{4}$ because of a reduction in the quantity of the $\mathrm{Fe}_{3} \mathrm{O}_{4}$ in the composites. Magnetic $\beta$-cyclodextrin/graphene oxide nanocomposite (MCGN) was synthesized by Fan et al. ${ }^{[43]}$ At first, $\mathrm{Fe}_{3}$ $\mathrm{O}_{4}$ is mixed with an aqueous solution of $\mathrm{NH}_{2}-\beta$-cyclodextrin and ammonia solution. Further, $\mathrm{Fe}_{3} \mathrm{O}_{4}$ and $\mathrm{NH}_{2}-\beta$-cyclodextrin are cross-linked with glutaraldehyde at $50^{\circ} \mathrm{C}$ for $0.5 \mathrm{~h}$. Homogeneous graphene oxide dispersion is added to this mixture and shaken for a few minutes at $60^{\circ} \mathrm{C}$ and further stirred for $3 \mathrm{~h}$ and $30 \mathrm{~min}$. Then, the final material is recovered by magnet and then dried. The carboxyl groups present in the $\mathrm{GO}$ react with the $-\mathrm{NH}_{2}$ groups of $\mathrm{NH}_{2}-\beta$-cyclodextrin and a strong bond is formed between magnetic cyclodextrin and GO. The obtained MCGN shows magnetic saturation of $50.1 \mathrm{emu} \mathrm{g}^{-1}$ and is considered an environment-friendly biosorbent for water treatment applications. Similarly, Fan et al. ${ }^{[44]}$ also synthesized water- 
dispersible magnetic chitosan/graphene oxide composites by using an environment-friendly biosorbent. Wang et al. ${ }^{[45]}$ made magnetic polyethylenimine-modified magnetic mesoporous silica composites. The amine groups present in the polyethyleneimide interact with the carboxyl groups on GO sheets via chemical conjugation. The average diameter of the microspheres is $260 \mathrm{~nm}$ and the saturation magnetization is found to be 7.5 emu g $^{-1}$.

Hu et al. ${ }^{[46]}$ produced GO membrane by the layer-by-layer deposition method from $\mathrm{GO}$ nanosheets, and then cross-linked it with 1,3,5-benzenetricarbonyltrichloride on a polysulfone support. The obtained height of GO nanosheets was found to be 1-2 nm, showing that the GO nanosheets contain both single and double layers. All these prepared graphene-based polymer composites show better application than the individual graphene and polymers. Their detailed applications in water treatment are explained in the next section. Numerous graphene-based polymer nanocomposites, such as polystyrene/ graphene, polyaniline/graphene, Nafion/graphene, polyvinyl alcohol/graphene, polycarbonate/graphene, polypropylene/graphene, reduced graphene oxide/polymethylmethacrylate, etc., have been reported. ${ }^{[45,47]}$ These graphene-based polymer nanocomposites are primarily used in the drug, gene delivery, cancer therapy, bioimaging, actuators, fuel cells/capacitors, and chemical and biological sensors. ${ }^{[4,30,48]}$

\section{Metal/metal oxide - graphene composites}

Generally, graphene acts as a good electron acceptor as well as possess transport properties. ${ }^{[4,10]}$ Metal/metal oxide-graphene composites absorb light on illumination and cause the photoexcitation of electron. The excited electrons move from the valence band to the conduction band by an electronic excitation between graphene materials and metal oxide. This process initiates the electron-hole pair charge separation between metal oxide and graphene. Graphene is a potential electron acceptor and possesses two-dimensional $\pi$-conjugation structures that effectively suppress the recombination of photogenerated $\bar{e}-\mathrm{h}^{+}$ pairs. ${ }^{[49]}$ The photoexcited ē in the conduction band travels on the surface of metal oxide/graphene composite and yields a huge volume of very reactive oxyradicals, e. g., superoxide radicals $\left(\mathrm{O}_{2}^{-}\right)$and hydroxyl radicals $\left({ }^{\circ} \mathrm{OH}\right)$. The produced radicals travel on the surface of metal oxide-graphene composites. These oxyradicals readily degrade the organic pollutants, microorganisms, etc., and convert them into harmless substances $\left(\mathrm{CO}_{2}\right.$ and $\left.\mathrm{H}_{2} \mathrm{O}\right) .{ }^{[18,49]}$ Graphene, reduced graphene oxide, and graphene oxide were modified using several metal/metal oxides, for example $\mathrm{ZnO}, \mathrm{TiO}_{2}, \mathrm{Mn}_{2} \mathrm{O}, \mathrm{Mn}_{3} \mathrm{O}_{4} \mathrm{Ag}_{3} \mathrm{PO}_{4}, \mathrm{COFe}_{2}, \mathrm{BiVO}_{4}$, $\mathrm{Bi}_{2} \mathrm{Fe}_{4} \mathrm{O}_{9} \mathrm{CuO} / \mathrm{TiO}_{2}, \mathrm{Ag} / \mathrm{ZnO}, \mathrm{Ag} / \mathrm{Ag}_{3} \mathrm{PO}_{4}, \mathrm{BiOl}, \mathrm{BiOBr}, \mathrm{WO}_{3} \mathrm{Cu}_{2} \mathrm{O}$, $\mathrm{ZnFe}_{2} \mathrm{O}_{4}, \mathrm{La} / \mathrm{TiO}_{2}, \mathrm{CdSe}-\mathrm{TiO}_{2}, \mathrm{ZnFe}_{2} \mathrm{O}_{4}, \mathrm{ZnO} / \mathrm{ZnFe}_{2} \mathrm{O}_{4}, \mathrm{La}_{2} \mathrm{Ti}_{2} \mathrm{O}_{7}$, $\mathrm{Fe}_{2} \mathrm{O}_{3} / \mathrm{ZnO}, \quad \mathrm{Cu}_{2} \mathrm{O} / \mathrm{SnO}_{2}, \quad \mathrm{Bi}_{5} \mathrm{Nb}_{3} \mathrm{O}_{15}, \quad \mathrm{ZnFe}_{2} \mathrm{O}_{4}, \quad \mathrm{SnO}_{2} \quad \mathrm{CuFe}_{2} \mathrm{O}_{4}$, $\mathrm{ZnWO}_{4}, \mathrm{Nd} / \mathrm{TiO}_{2}, \mathrm{~W}_{18} \mathrm{O}_{49}, \mathrm{BaCrO}_{4}, \alpha-\mathrm{SnWO}_{4}, \mathrm{Bi}_{2} \mathrm{WO}_{6}, \mathrm{Ta}_{2} \mathrm{O}_{5}$, and $\mathrm{ZnFe}_{2} \mathrm{O}_{4}$, which were employed as photocatalysts for toxic organic pollutants degradation, chemical reactions, fuel cells, etc. ${ }^{[18,49-52]}$ The advantage of using metal (Ag, $\mathrm{La}, \mathrm{Fe}$, etc.) in the graphene/metal oxide composites is to increase the photocatalytic activity of the composites by prolonging the lifetime of charged radicals and capturing the photoexcited electrons and to further reduce the recombination of produced charged radical ions. ${ }^{[18]}$ Among the metal oxides, $\mathrm{ZnO}$ and $\mathrm{TiO}_{2}$ are considered the most extensively used UV-light-driven photocatalysts due to their too large band gap of 3-3.32 eV, and they utilize solar energy of $<5 \%$ only. ${ }^{[53,54]}$ Whereas $\mathrm{ZnFe}_{2} \mathrm{O}_{4}$ (band gap $=1.9 \mathrm{eV}$ ), ${ }^{[55,56]}$ and $\mathrm{BiVO}_{4}$ (band gap $=2.2 \mathrm{eV}$ ) act as an excellent visible light active photocatalyst. ${ }^{[5]]}$ Depending on the band gap of metal/metal oxide in the graphene composite, they can be utilized as UV/visible light induced photocatalysts. For example, Wang et al. ${ }^{[58]}$ synthesized reduced graphene oxide- $\mathrm{TiO}_{2}$ nanocomposite, which showed excellent photocatalytic activity. At first, graphene oxide is prepared from graphite powder by Hummer's oxidation process. Then, RGO$\mathrm{TiO}_{2}$ nanocomposites are synthesized using various weight ratios (1:100,1:40, 1:20, 1:10, and 1:3) of graphene oxide and $\mathrm{TiO}_{2}$ (commercial P25) using a hydrothermal reaction and then heated to $400^{\circ} \mathrm{C}$ for $2 \mathrm{~h}$ under argon gas. In the hydrothermal reaction, the $\mathrm{GO}$ is reduced to graphene and simultaneously $\mathrm{TiO}_{2}$ is deposited onto the graphene layers. GO synthesized in this way was characterized by AFM using the tapping mode; and the images showed sheets of size $\sim 5 \mathrm{~mm}$, and the thickness $<$ $6.9 \mathrm{~nm}$ indicating the formation of a few layers of GO.

Ameen et al. ${ }^{[59]}$ made $\mathrm{ZnO}$-graphene oxide nanohybrid and effectively used it as a photocatalyst. In this process, GO is dissolved in water. Aqueous solutions of hydrazine monohydrate and zinc nitrate hexahydrate are added to the GO dispersion under stirring. Then, the $\mathrm{NH}_{3}$ aqueous solution is also mixed and stirred for $30 \mathrm{~min}$. Finally, the reaction mixture is moved to a flask and placed in an oven at $90^{\circ} \mathrm{C}$ for $12 \mathrm{~h}$. After $12 \mathrm{~h}$, the produced $\mathrm{ZnO}-\mathrm{GO}$ nanocomposite is centrifuged and thoroughly washed with water and then dried.

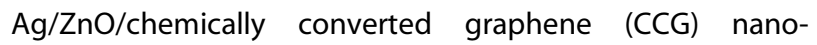
composites were synthesized by Yoo et al. ${ }^{[37]}$ using solutionbased method. In this method, graphene oxide is prepared from graphite powder by Hummer's oxidation process, further graphene oxide is reduced using hydrazine monohydrate, and finally the chemically converted graphene (CCG), i.e., reduced graphene oxide, is obtained. Further, CCG dispersion is sprayed onto a quartz plate and the CCG film is obtained. The CCG film is soaked with zinc acetate dehydrate in an ethanol solution. The CCG film covered by zinc acetate thin layer is annealed at $350^{\circ} \mathrm{C}$ in oxygen atmosphere for $30 \mathrm{~min}$ and $\mathrm{ZnO}$ nanorods are obtained. Further, the CCG film is treated with zinc nitrate hexahydrate and methanamine in a hot oven at $90^{\circ} \mathrm{C}$ for $2 \mathrm{~h}$. The produced $\mathrm{Ag}$ nanoparticles are spray coated with $\mathrm{ZnO} / \mathrm{CCG}$ and then annealed at $150^{\circ} \mathrm{C}$ for the complete removal of the solvent. The composites showed $\mathrm{ZnO}$ nanorods with Ag nanoparticles of size $10-20 \mathrm{~nm}$. Ag/ZnO/CCG showed very high photodegradation activity compared with $\mathrm{ZnO} / \mathrm{CCG}$ and Ag/ $\mathrm{ZnO}$ because the excited electrons are first moved to graphene and then transferred to Ag attached to graphene.

Various methods, such as hydrothermal/solvothermal method, sol-gel method, solution mixing method, self-assembly, and microwave irradiation, have been reported for the preparation of metal/metal oxide-graphene composites. ${ }^{[18,49,52-59]}$ Metal/metal oxide-graphene composites were widely used in water split- 
ting for hydrogen generation, photodegradation of pollutants, etc. $^{[60-62]}$

\section{Nanoparticle - graphene composites}

Nanoparticle-graphene composites show enhanced properties due to the synergistic effect between graphene materials and the firmly fixed nanoparticles. ${ }^{[63,64]}$ The existence of oxygen groups and defects on the surface of $\mathrm{GO}$ and $\mathrm{rGO}$ provide them an excellent platform for the attachment of nanoassemblies. In general, nanoparticles of $\mathrm{Ag}, \mathrm{Au}, \mathrm{Pt}, \mathrm{ZnO}, \mathrm{CdS}$, $\mathrm{TiO}_{2}$, and $\mathrm{NiO}$ are firmly fixed on $\mathrm{GO} / \mathrm{rGO}$ surfaces for various applications. $^{[31,63-69]}$ The nanoparticle-graphene composites are synthesized by reagent reduction, chemical method, microwave irradiation, self-catalysis reduction, solution synthesis, and electrochemical deposition. ${ }^{[63-69]}$

Wang et al. ${ }^{[66]}$ made carbon nanoparticle/graphene composites using the chemical reduction method. At first, the graphene oxide sheets are widely dispersed in water and mixed with the nanocarbons. The mixture is agitated for about $30 \mathrm{~min}$ and then sonicated for $60 \mathrm{~min}$. Then, the hydrazine solution is poured to the mixture and heat treated at $100^{\circ} \mathrm{C}$ for $24 \mathrm{~h}$. Further, the mixture is filtered and washed with water and dried in a vacuum oven at $60^{\circ} \mathrm{C}$ for $24 \mathrm{~h}$. The functionalized carbon nanoparticles are firmly fixed on graphene surfaces. The carbon nanoparticles are neatly packed between graphene layers and appear as porous layer structure with a specific surface area of $1256 \mathrm{~m}^{2} \mathrm{~g}^{-1}$. The size of the functionalized nanocarbon particles was found to be in the range of 5-50 nm.

Du et al. ${ }^{[67]}$ synthesized metal nanoparticle/graphene hydrogel (MNP@GHG) composites using nickel foam as substrate via electroless deposition method. Initially, the reduced graphene hydrogel is deposited on the porous nickel foam substrate. Then, the graphene-hydrogel-coated nickel foam is immersed in different metal chloride solutions $\left(\mathrm{HAuCl}_{4}, \mathrm{H}_{2} \mathrm{PtCl}_{6}, \mathrm{H}_{2} \mathrm{PdCl}_{4}\right.$, and $\mathrm{CuCl}_{2}$ ) for different times. Further, metal nanoparticles are deposited on the 3D reduced graphene oxide hydrogels by a galvanic cell reaction and MNP@GHG composites are produced. In this method, $\mathrm{Au}, \mathrm{Pt}, \mathrm{Pd}$, and $\mathrm{Cu}$ nanoparticles are all successfully deposited on graphene hydrogels.

Graphene/Au nanoparticle composites were prepared by Zhuo et al. ${ }^{[50]}$ using a self-catalysis reduction method. Gold nanoparticle/graphene composites were fabricated by Hong et al. ${ }^{[68]}$ using a self-assembly method. Wang et al. ${ }^{[69]}$ synthesized $\mathrm{Ni}$ nanocrystals of $\mathrm{GO} / \mathrm{rGO}$ by a hydrothermal reaction. Nanoparticle-graphene composites are widely used in catalysis, photocatalysis, photovoltaic devices, sensors, supercapacitors, clean energy applications, and so on. ${ }^{[63-69]}$

\section{Ceramic - graphene composites}

Graphene possesses an outstanding mechanical property and is widely used as a good reinforcement material in ceramic composites. ${ }^{[70]}$ Ceramics are widely used in high-temperature applications but have poor toughness. Graphene is used to enhance the toughness of bulk ceramics materials. It is also used as nanofiller in ceramic composite materials owing to its excep- tional large surface area, fracture toughness, and extraordinary mechanical, electrical, and thermal properties. Several studies proved that ceramic-based matrix incorporated graphene fillers have significantly better mechanical properties and electrical and thermal conductivities. ${ }^{[0]}$ Ceramic-graphene composites are widely used in different applications, such as heat transfer and thermal energy storage, oxygen reduction, dielectric behavior, reinforced sensors, solar cells as electrode materials, Liion batteries, as catalysts and in water treatments. ${ }^{[1,70]}$ Currently, ceramic-graphene composites are mainly prepared using the techniques such as powder processing, colloidal processing, sol-gel processing, pressure chemical vapor deposition, in situ synthesis, solvothermal, spark plasma sintering, and the dip-coating method. ${ }^{[70-77]}$

Zhou et al. ${ }^{[71]}$ made highly conductive porous graphene/ceramic composites using ambient pressure chemical vapor deposition. They formed 3D graphene architecture on aluminum oxide and porous $\mathrm{Al}_{2} \mathrm{O}_{3}$ ceramics using the heat transfer and thermal energy storage. The formation of graphene was based on the carbothermic reduction on $\mathrm{Al}_{2} \mathrm{O}_{3}$ surface, which initiated the nucleation and growth of graphene.

Walker et al. ${ }^{[72]}$ fabricated graphene platelets on silicon nitride ceramics and densified them at $\sim 1650^{\circ} \mathrm{C}$ using a spark plasma sintering method. The platelets on average contain $\sim 3-$ 4 graphene sheets with a thickness of less than $2 \mathrm{~nm}$. The grain size is found to be $\sim 500 \mathrm{~nm}$, and the grains are uniform throughout the fracture surfaces. The addition of 1.5 vol\% graphene in the silicon nitride ceramics increases toughness to about $235 \%$. Similarly, Fernández-García et al. synthesized $\mathrm{Al}_{2}$ $\mathrm{O}_{3}$ /graphene and $\mathrm{BaTiO}_{3} /$ graphene composites by a spark plasma sintering method and studied their dielectric properties.

Lou et al. ${ }^{[73]}$ prepared graphene oxide/ceramic composite membrane on a silane-modified ceramic support using a dipcoating method. In this approach, an $\mathrm{Al}_{2} \mathrm{O}_{3}$ support (pore size average $\sim 110 \mathrm{~nm}$ and porosity about $\sim 35 \%$ ) is immersed in a glycidoxypropyltrimethoxysilane/ethanol solution for $30 \mathrm{~min}$ at $40^{\circ} \mathrm{C}$. Then, the silane-modified $\mathrm{Al}_{2} \mathrm{O}_{3}$ support is heated for $4 \mathrm{~h}$ at $110^{\circ} \mathrm{C}$. The silane-modified ceramic support is dip-coated with graphene oxide solution. The thickness of graphene oxide nanosheets is $0.7-1.5 \mathrm{~nm}$ and the lateral size is $200-1000 \mathrm{~nm}$. The GO/ceramic composite membrane is crack free and exhibits selectivity for the pervaporation of ethanol/water mixtures.

$\mathrm{Wu}$ et al. ${ }^{[74]}$ synthesized graphene oxide/ZrB 2 nanocomposite; and then Pt nanoparticles were deposited on reduced graphene oxide/ $/ \mathrm{rB}_{2}$ composite using a simple solvothermal method. $\mathrm{RGO} / \mathrm{ZrB}_{2}$ nanocomposite supported $\mathrm{Pt}$ nanoparticles show very high catalytic activity as compared with graphene oxide/ $/ \mathrm{ZB}_{2}$. Nanoconductive $\mathrm{ZrB}_{2}$ ceramic is wedged between the $\mathrm{Pt}$ nanoparticle-supported graphene sheets that act as a highly efficient catalyst for oxygen reduction.

Liu et al. ${ }^{[75]}$ studied the effect of graphene platelet on toughening of $\mathrm{ZrO}_{2}$ and $\mathrm{Al}_{2} \mathrm{O}_{3}$ composites. Various ratios of ceramic materials $\left(\mathrm{ZrO}_{2}\right.$ and $\left.\mathrm{Al}_{2} \mathrm{O}_{3}\right)$ with graphene platelet were sintered at various temperatures $\left(1450-1650^{\circ} \mathrm{C}\right)$ via a spark plasma sintering method. Graphene platelets (thickness of 
6-8 $\mathrm{nm}$ and level dimensions of $15-25 \mathrm{~nm}$ ) were mixed well with the ceramic materials; and even the material was found to be intact after sintering at very high temperature. Ramirez et al. ${ }^{[76]}$ made conducting graphene/silicon nitride $\left(\mathrm{Si}_{3} \mathrm{~N}_{4}\right)$ composites using spark plasma sintering. The produced graphene/ $\mathrm{Si}_{3} \mathrm{~N}_{4}$ composites exhibited good electrical conductivity bestowed by the existence of reduced graphene.

Fan et al. ${ }^{[77]}$ carried out the synthesis of graphene nanosheet $/ \mathrm{Al}_{2} \mathrm{O}_{3}$ composites by using spark plasma sintering technique. The prepared material showed much improved electrical properties compared with most of the carbon nanotube $/ \mathrm{Al}_{2} \mathrm{O}_{3}$ composites. Watcharotone et al. ${ }^{[78]}$ synthesized graphene-silica composite thin films using a sol-gel method and used them as transparent conductors. Ceramic-graphene composites show limited applications in water treatment. Porwal et al. ${ }^{[70]}$ reviewed the synthesis and properties of graphene based ceramic composites in detail. A limited research work has focused on graphene ceramic matrix composites as compared with polymer composites.

\section{Role of graphene and graphene - based materials in the water treatment applications}

\section{Application of graphene and graphene - based materials as} an adsorbent

\section{Adsorption of inorganic (cationic and anionic) contaminants}

Many kinds of graphene-based materials were used for the removal of toxic inorganic (cationic and anionic) pollutants from aqueous media. Graphene-based materials have great potential to adsorb variety of inorganic contaminants via electrostatic attraction, various $\pi$-interactions, and functional groups present in the graphene surfaces. This section, overview the various graphene-based materials reported for the removal of cationic and anionic heavy metal pollutants. Graphene-based materials were classified based on preparation method, surface area, thickness, metal ions removed, sorption method, $\mathrm{pH}$, contact time, temperature, adsorption capacity $(\mathrm{mg} / \mathrm{g})$ and regeneration/reusability were given in the supporting information Table S1. ${ }^{[3,38,42-44,79-97]}$

Huang et al. fabricated graphene nanosheets (GNSs) from graphite oxide using an exfoliation process. ${ }^{[79]}$ The sorption of $\mathrm{Pb}$ (II) ions from aqueous solutions on pristine GNSs and thermally modified GNSs was studied. The adsorption of lead ions was better enhanced by heat treatment than pristine GNSs. They concluded that the heat treatment of graphene favors adsorption through lead ions (Lewis acid), which increases the Lewis basicity and electrostatic attraction of graphene. The drawback of the prepared graphene nanosheets is that it requires ultrasonication for a good dispersion of graphene in metal solutions and after sorption it also requires filtration through microsyringe to separate the GNS/solution mixture. Generally, graphene-based sorbents possess hydrophobicity, which, to some extent, restricts the sorption efficiency of heavy metal ions in water treatment. To avoid such bottleneck, Song et al. ${ }^{[36]}$ fabricated stable and water-dispersible polyphenols functionalized graphene nanosheets. The systematic prepara- tion of tea polyphenols functionalized graphene nanosheets is shown in Figure 1a. The advantages of tea polyphenols include water-solubility, low toxicity, biodegradability, and green reagent. Graphene nanosheets functionalized by tea polyphenols show very good water dispersibility and superior $\mathrm{Pb}(\mathrm{II})$ sorption capacity $(1126 \mathrm{mg} / \mathrm{g}$ ) and $\mathrm{Pb}(\mathrm{II})$ selectivity to $\mathrm{Cu}(\mathrm{II}), \mathrm{Ni}(\mathrm{II}), \mathrm{Cr}(\mathrm{III})$, $\mathrm{Co}(\mathrm{II})$, and $\mathrm{Cd}(\mathrm{II})$ in aqueous solution. The regeneration and reusability of this adsorbent are also very efficient with $0.1 \mathrm{M} \mathrm{HCl}$ and the $\mathrm{Pb}(\mathrm{II})$ desorption capacity was found to be $85-90 \%$. The limitation of this process is that it requires micron level filter to separate sorbents and metal solutions. Fan et al. ${ }^{[43]}$ synthesized a magnetic $\mathrm{NH}_{2}-\beta$-cyclodextrin/graphene oxide nanocomposite (MCGN) using the reaction between amine groups of magnetic $\mathrm{NH}_{2}-\beta$-cyclodextrin and the carboxyl groups of $\mathrm{GO}$. The preparation of MCGN and their $\mathrm{Cr}(\mathrm{IV})$ removal mechanism are shown in Figure $1 \mathrm{~b}$ and $\mathrm{c}$. The prepared MCGN composite possesses $50.13 \mathrm{emu} / \mathrm{g}$ of saturation magnetization, which allows a rapid recovery of the MCGN from aqueous solution. The MCGN exhibited quick sorption of $\mathrm{Cr}(\mathrm{VI})$ from waste solutions with the sorption capacity of $120 \mathrm{mg} / \mathrm{g}$. The MCGN was reused by desorbing from $\mathrm{Cr}(\mathrm{VI})$ sorbed $\mathrm{MCGN}$ using aqueous $\mathrm{NaOH}$.

Zhao et al. ${ }^{[80]}$ made graphene oxide nanosheets and studied their $\mathrm{Cd}(\mathrm{II})$ and $\mathrm{Co}$ (II) adsorption from aqueous solutions. They prepared graphene oxide nanosheets showing sorption efficiencies of $106.3 \mathrm{mg} / \mathrm{g}$ for Cd(II) and $68.2 \mathrm{mg} / \mathrm{g}$ for Co(II). The general heavy metal removal sorption mechanism is shown in Figure $1 \mathrm{~d}$. After the metal adsorption experiments, graphene oxide nanosheets were recovered by membrane filters. In order to avoid the membrane filters to separate adsorbent/aqueous solutions and for easy separation of adsorbent/aqueous solution, the superparamagnetic reduced $\mathrm{GO}-\mathrm{Fe}_{3} \mathrm{O}_{4}$, reduced $\mathrm{GO}$ $\mathrm{Fe}(0)-\mathrm{Fe}_{3} \mathrm{O}_{4}$, and reduced $\mathrm{GO}-\mathrm{Fe}(0)$ composites were prepared. Among these, the prepared reduced $\mathrm{GO}-\mathrm{Fe}(0)-\mathrm{Fe}_{3} \mathrm{O}_{4}$ showed a high $\mathrm{As}$ (III) sorption capacity of $44 \mathrm{mg} / \mathrm{g}$, whereas the reduced GO- $\mathrm{Fe}_{3} \mathrm{O}_{4}$ and GO-Fe(0) showed capacities of $37 \mathrm{mg} / \mathrm{g}$ and $21 \mathrm{mg} / \mathrm{g}$, respectively. The sorption efficiency of reduced GO$\mathrm{Fe}(0)-\mathrm{Fe}_{3} \mathrm{O}_{4}$ composites was determined for toxic heavy metal elements such as $\mathrm{Cr}(\mathrm{VI}), \mathrm{Pb}(\mathrm{II}), \mathrm{Cd}(\mathrm{II}), \mathrm{Hg}(\mathrm{II})$, and arsenic-contaminated natural water. The results showed that the prepared reduced $\mathrm{GO}-\mathrm{Fe}(0)-\mathrm{Fe}_{3} \mathrm{O}_{4}$ adsorbed $31.2 \mathrm{mg} / \mathrm{g}$ of $\mathrm{Cr}(\mathrm{Vl}), 22 \mathrm{mg} / \mathrm{g}$ of $\mathrm{Hg}(\mathrm{II}), 19.2 \mathrm{mg} / \mathrm{g}$ of $\mathrm{Pb}(\mathrm{II})$, and $1.91 \mathrm{mg} / \mathrm{g}$ of $\mathrm{Cd}(\mathrm{II})$. The reduced $\mathrm{GO}-\mathrm{Fe}(0)-\mathrm{Fe}_{3} \mathrm{O}_{4}$ composite showed $>90 \%$ of As sorption, which indicates that the reduced $\mathrm{GO}-\mathrm{Fe}(0)-\mathrm{Fe}_{3} \mathrm{O}_{4}$ can be realistically utilized for the purification of drinking water. The initial arsenic concentration ranges between 0.98 and $4.82 \mathrm{ppb}$ for real-field arsenic-contaminated natural water. Because the prepared composites are superparamagnetic, they are easily separated from the solutions with a magnet. Similarly, Zhang et al. ${ }^{[42]}$ prepared polyacrylic acid modified graphene oxide/ $\mathrm{Fe}_{3}$ $\mathrm{O}_{4}\left(\mathrm{GO} / \mathrm{Fe}_{3} \mathrm{O} 4\right)$ composites. The prepared magnetic PAA/GO/Fe $\mathrm{O}_{4}$ nanocomposites showed a sorption capacity of $0.75,0.85$, 0.9 , and $0.85 \mathrm{mg} / \mathrm{g}$ for $\mathrm{Cd}(\mathrm{II}), \mathrm{Cu}(\mathrm{II})$, and $\mathrm{Pb}(\mathrm{II})$, respectively.

Madadrang et al. ${ }^{[82]}$ synthesized graphene oxide, $\mathrm{N}$-(trimethoxysilylpropyl) ethylenediaminetriacetic acid linked graphene oxide (EDTA-GO) and reduced EDTA-GO. They studied it for the sorption of $\mathrm{Pb}$ (II) from water, and reported that EDTA-GO showed a high $\mathrm{Pb}(\mathrm{II})$ sorption capacity of $476 \mathrm{mg} / \mathrm{g}, \mathrm{GO}$ 


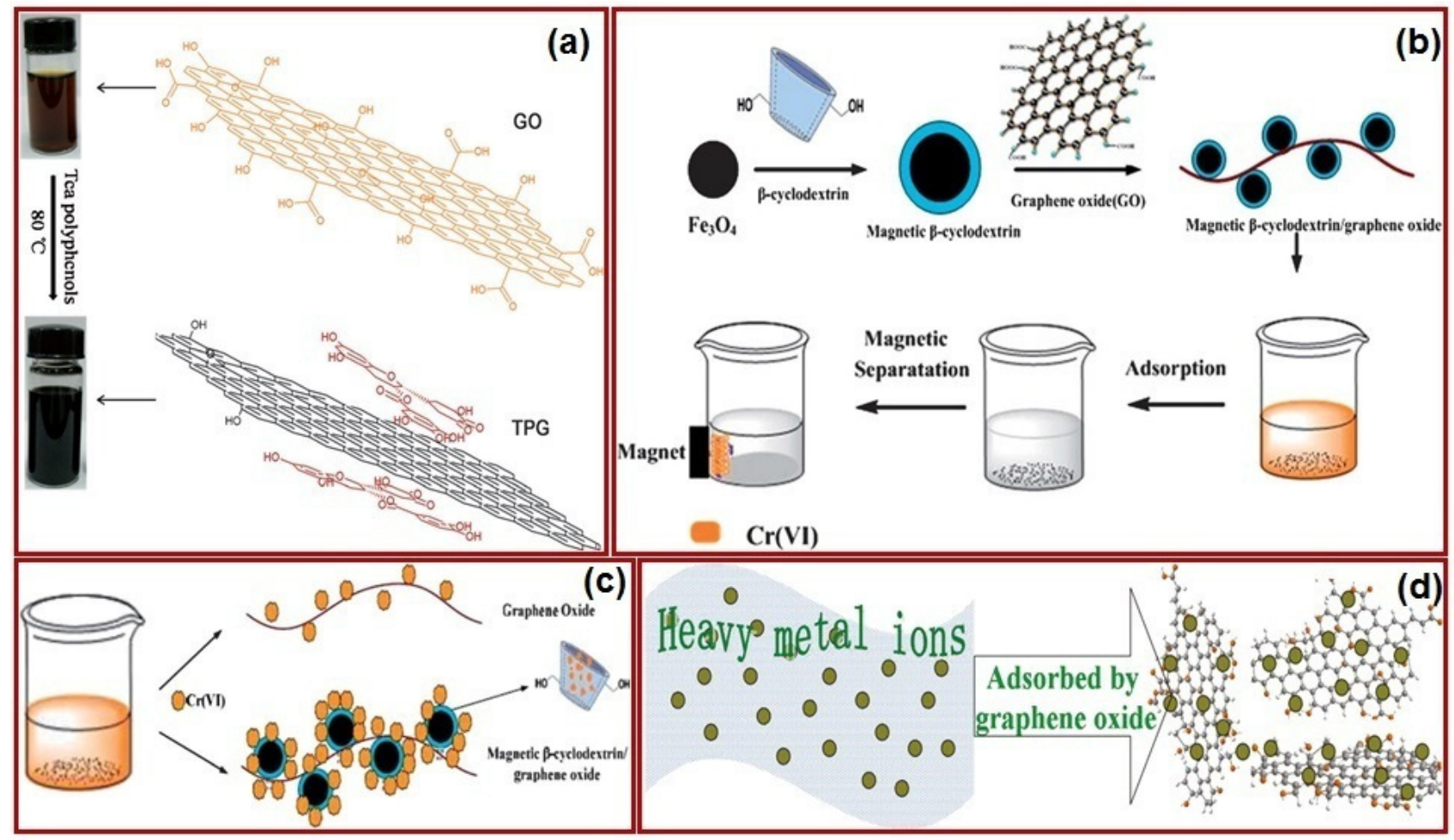

Figure 1. a) The systematic preparation of tea polyphenols functionalized graphene nanosheets. Reproduced with permission. ${ }^{[36]}$ Copyright 2012, Wiley. b) and c) Preparation of MCGN and their Cr(IV) removal mechanism. Reproduced with permission. ${ }^{[43]}$ Copyright 2012, Royal Society of Chemistry. d) General heavy metal removal sorption mechanism of graphene oxide nanosheets. Reproduced with permission. ${ }^{[80]}$ Copyright 2011, American Chemical Society.

showed $367 \mathrm{mg} / \mathrm{g}$ for $\mathrm{Pb}(\mathrm{II})$, whereas reduced EDTA-GO showed only $228 \mathrm{mg} / \mathrm{g}$. The schematic diagram of EDTA-GO and its removal of metal ions are shown in Figure 2a. In addition, EDTA-GO can be regenerated and reused for a continuous process. Cong et al. ${ }^{[83]}$ produced graphene hydrogels via the reduction of graphene oxide. They incorporated $\alpha$-FeOOH nanorods onto graphene sheets and assembled macroscopic graphene monoliths. The macroscopic 3D graphene $/ \alpha-\mathrm{FeOOH}$ hydrogel showed maximum adsorption capacities of $373.8 \mathrm{mg} /$ $\mathrm{g}$ and 139.2 for $\mathrm{Pb}(\mathrm{II})$, and $\mathrm{Cr}(\mathrm{VI})$ respectively. The high adsorption capacity of the $3 \mathrm{D}$ graphene $/ \alpha-\mathrm{FeOOH}$ hydrogels was obtained by the ion exchange, electrostatic attraction, and surface complexation between $\alpha-\mathrm{FeOOH}$ and heavy metal ions and also by the oxygen functional groups of the graphene and metal ions. Water-dispersible magnetite-reduced graphene oxide composites were synthesized and used for the removal of $\mathrm{As}(\mathrm{V})$ and $\mathrm{As}(\mathrm{III})$ by Chandra et al. ${ }^{[38]}$ They synthesized two different $\mathrm{Fe}_{3} \mathrm{O}_{4}$ reduced grapheme oxide (RGO) composites with low and high concentrations of magnetite M-RGO 1 and $M$ RGO 2, respectively. The $A s(V)$ and $A s(I I I)$ sorption capacity of M-RGO was 5.27 , and $10.20 \mathrm{mg} / \mathrm{g}$, respectively, whereas $M$ RGO2 showed the sorption capacity of 5.83 and $13.10 \mathrm{mg} / \mathrm{g}$ for $\mathrm{As}(\mathrm{V})$ and $\mathrm{As}(\mathrm{III})$, respectively. The magnetite M-RGO composites are superparamagnetic at room temperature and therefore easily separated using magnets. The composites showed an excellent and complete removal of $\mathrm{As}(\mathrm{III})$ and $\mathrm{As}(\mathrm{V}) \quad(<$ 99.9\%) within $1 \mathrm{ppb}$. Therefore, M-RGO was practically used for arsenic separation from water. Liu et al. ${ }^{[84]}$ synthesized a magnetite/graphene oxide (M/GO) composite and studied the sorption of $\mathrm{Co}(\mathrm{II})$. The sorption capacity of $\mathrm{Co}$ (II) was found to be $12.98 \mathrm{mg} / \mathrm{g}$. M/GO-adsorbed Co(II) was quickly recovered from a solution using external magnets. The $\mathrm{Co}$ (II) sorption of $\mathrm{M} / \mathrm{GO}$ composite is influenced by foreign ions such as $\mathrm{NO}_{3}{ }^{-}, \mathrm{ClO}_{4}^{-}$, $\mathrm{Cl}^{-}, \mathrm{K}^{+}, \mathrm{Na}^{+}$, and $\mathrm{Mg}^{2+}$. For the removal of $\mathrm{Cr}(\mathrm{VI}), \mathrm{Ma}$ et al. ${ }^{[85]}$ synthesized ethylenediamine-reduced graphene oxide (EDRGO). The schematic of the preparation of ED-RGO is shown in Figure $2 \mathrm{~b}$. They used ED-RGO sorption of $\mathrm{Cr}(\mathrm{VI})$ from aqueous solution at low $\mathrm{pH}$. ED-RGO effectively reduced highly toxic $\mathrm{Cr}(\mathrm{VI})$ to 300 times less toxic $\mathrm{Cr}$ (III) by an electrostatic attraction and coupled reduction mechanism through pronated amine groups of ED-RGO and carboxylic electron donors of ED-RGO. The proposed $\mathrm{Cr}(\mathrm{VI})$ sorption mechanism of ED-RGO is shown in Figure 2c. ED-RGO showed a sorption capacity of $4.90 \mathrm{mg} / \mathrm{g}$ for $\mathrm{Cr}(\mathrm{VI})$. The present method is quite different from the previously reported graphene-based sorbent for $\mathrm{Cr}(\mathrm{VI})$.

Vasudevan et al..$^{[95,96]}$ synthesized graphene and used it for the removal of phosphate and perchlorate. The prepared graphene showed phosphate adsorption capacity of $89.37 \mathrm{mg} / \mathrm{g}$ and perchlorate adsorbent capacity of $0.024 \mathrm{mg} / \mathrm{g}$. The results showed that graphene is an excellent adsorbent for removal of $\mathrm{PO}_{4}{ }^{3-}$ and $\mathrm{ClO}_{4}{ }^{-}$from aqueous solution. Kumar et al. ${ }^{[97 a]}$ prepared L-cystine-functionalized graphene oxide and used for the sorption of $\mathrm{Hg}(\mathrm{II})$. L-Cystine-functionalized $\mathrm{GO}$ showed $79.36 \mathrm{mg} / \mathrm{g}$ of $\mathrm{Hg}$ (II) sorption and unmodified graphite showed 


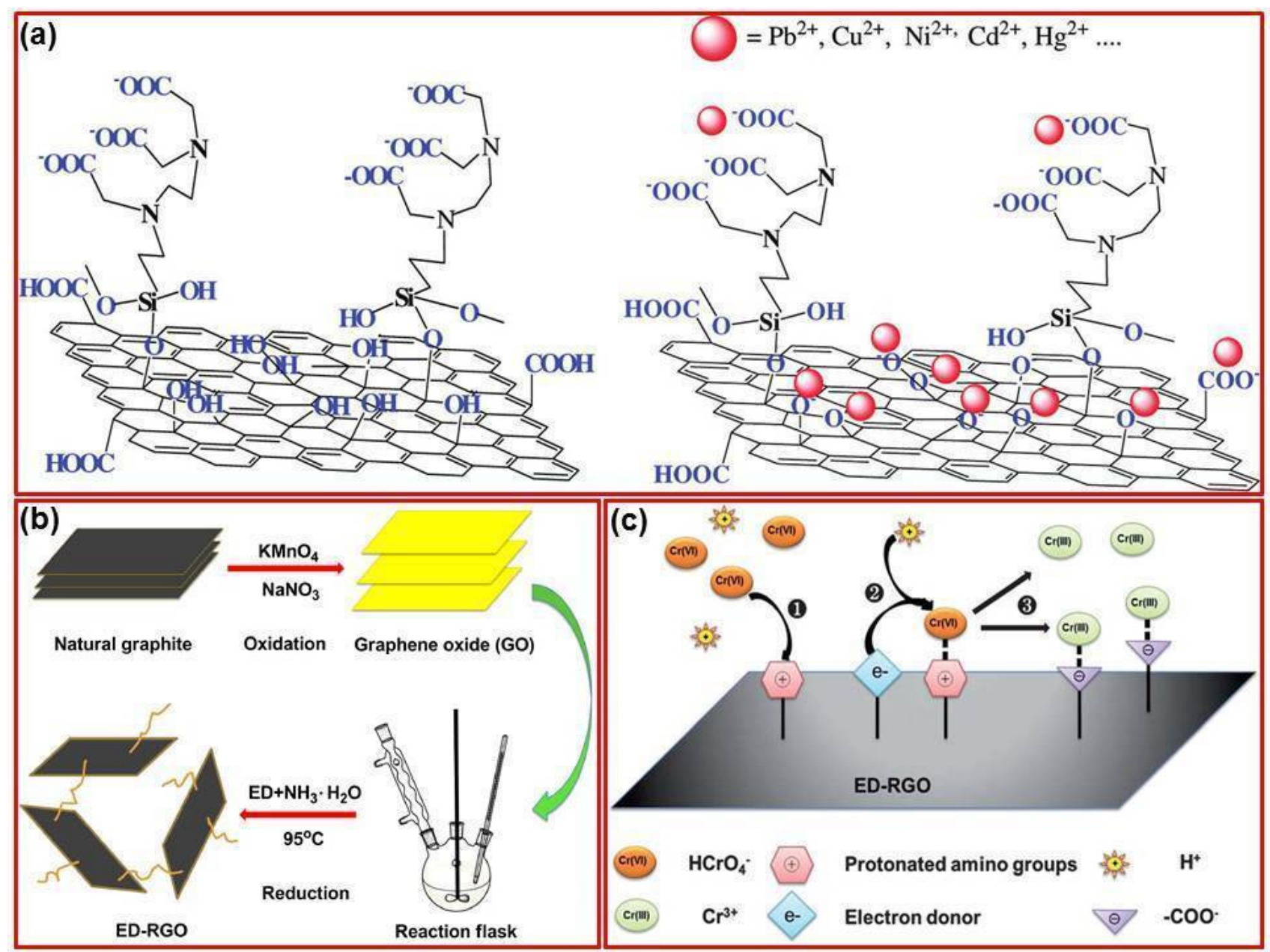

Figure 2. a) The schematic diagram of EDTA-GO and its removal efficiency for metal ions. Reproduced with permission ${ }^{[82]}$ Copyright 2012, American Chemical Society. b) Schematic of the preparation of ED-RGO. Reproduced with permission. ${ }^{[8]}$ Copyright 2012, Royal Society of Chemistry. c) Proposed mechanism of the $\mathrm{Cr}(\mathrm{VI})$ removal by ED-RGO. Reproduced with permission. ${ }^{[85]}$ Copyright 2012, Royal Society of Chemistry.

only $12.49 \mathrm{mg} / \mathrm{g}$ of $\mathrm{Hg}$ (II) sorption. The sorbent showed a good sorption capacity even in the existence of various other metal cations $\mathrm{Cd}^{2+}, \mathrm{Co}^{2+}, \mathrm{Cu}^{2+}, \mathrm{Ni}^{2+}, \mathrm{Pb}^{2+}, \mathrm{Se}^{2+}, \mathrm{Zn}^{2+}$, and $\left.\mathrm{Au}^{+}\right)$and other metal anions $\left(\mathrm{PO}_{4}{ }^{3-}, \mathrm{NO}_{3}{ }^{-}, \mathrm{SO}_{4}{ }^{2-}\right.$, and $\left.\mathrm{Cl}^{-}\right)$. The adsorbent was reused for four cycles of adsorption/desorption and the adsorbent showed the same sorption capacity even after four cycles. Similarly, Rajesh et al. ${ }^{[97 \mathrm{~b}-\mathrm{d}]}$ prepared many graphene based sorbents for the adsorption of fluoride and chromium from aqueous solution.

\section{Adsorption of organic pollutants}

Graphene-based materials act as an excellent adsorbent material for the removal of various organics dyes, pharmaceutical drugs, toxic chemicals, pesticides, solvents, and oils (vegetable oil, paraffin oil, gasoline etc.). The major mechanisms of removal of organic pollutants on the graphene-based materials were $\pi-\pi$ interaction, anion- $\pi$ interaction and cation- $\pi$ interaction and functional group interactions. In this section, we briefly outlined the most recent graphene-based materials utilised for organic pollutants.

The summary of various graphene-based materials used for the sorption of various organic pollutants is shown in supporting information Table S2. ${ }^{[14,98-122]}$ Fan et al. ${ }^{[98]}$ fabricated magnetic chitosan and graphene oxide (MCGO) composite for the sorption of anionic dye methyl blue from aqueous solution. The fabrication of MCGO and their methylene blue removal mechanism is shown in Figure 3a. The maximum methyl blue sorption ability was found to be $95.16 \mathrm{mg} / \mathrm{g}$ for MCGO, $43.5 \mathrm{mg} / \mathrm{g}$ for graphene oxide, $60.4 \mathrm{mg} / \mathrm{g}$ for magnetic chitosan, and $46.23 \mathrm{mg} / \mathrm{g}$ for natural chitosan membranes. At acidic $\mathrm{pH}$, anionic dye methyl blue was adsorbed via protonated amino groups of MCGO by ionic interactions. The dye desorption values of $\mathrm{H}_{2} \mathrm{O}, \mathrm{HCl}$, and $\mathrm{NaOH}$ were $1.4,5.1$, and $95.0 \%$, respectively. The advantages of MCGO include stability, magnetic separation, and easy regeneration, and its high methyl blue dye sorption efficiency is about $90-80 \%$ even after five cycles.

Ramesha et al. ${ }^{[14]}$ synthesized graphene oxide and reduced graphene oxide $(\mathrm{rGO})$ for the sorption of cationic dyes, i.e., 

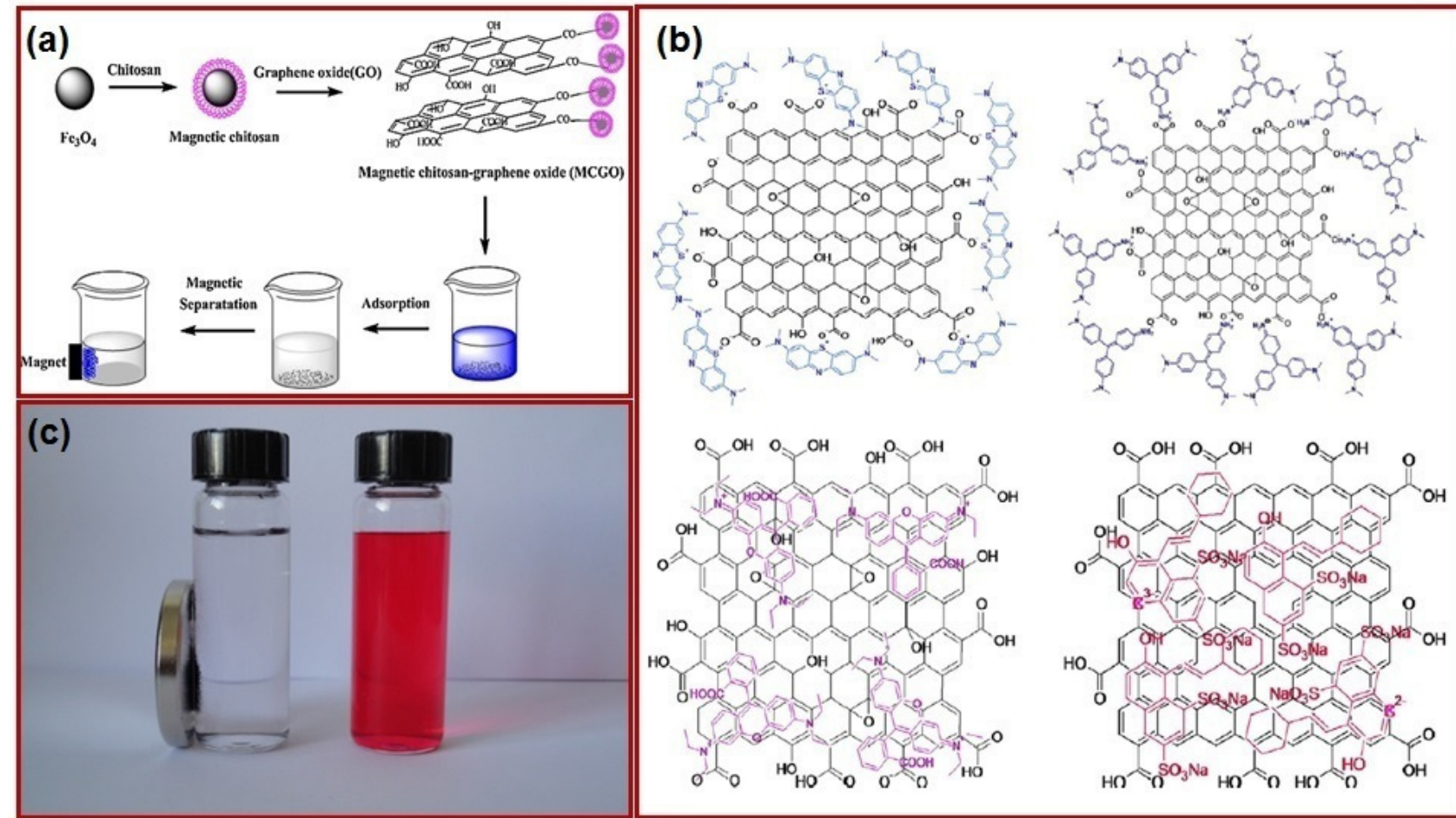

Figure 3. a) Fabrication of MCGO and its methylene blue removal mechanism. Reproduced with permission. ${ }^{[98]}$ Copyright 2012, Elsevier. b) Schematics of probable interaction of studied dye with graphene oxide and reduced graphene oxide. Reproduced with permission. ${ }^{[14]}$ Copyright 2011, Elsevier. c) Picture of fuchsine dye solution, after sorption with $\mathrm{G} / \mathrm{Fe}_{3} \mathrm{O}$ and their magnetic separation of $\mathrm{G} / \mathrm{Fe}_{3} \mathrm{O}$. Reproduced with permission. ${ }^{[99]} \mathrm{Copyright} 2011$, Elsevier.

methyl violet, rhodamine $B$, methylene blue, and Orange $G$ (anionic dye) from aqueous media. They reported that graphene oxide contains many oxygen functional groups (epoxy, carboxyl, hydroxyl groups, and ketone) and it is hydrophilic in nature with a large negatively charged surface that helps in the effective adsorption of cationic dyes (methylene blue $(17.3 \mathrm{mg} /$ $\mathrm{g})$, methyl violet $(2.47 \mathrm{mg} / \mathrm{g})$, rhodamine B $(1.24 \mathrm{mg} / \mathrm{g})$. Graphene oxide showed negligible adsorption capacity for Orange $\mathrm{G}$ (anionic dye). In contrast, the reduced graphene oxide with a large surface area and less negatively charged surface removed $95 \%$ of Orange G $(5.98 \mathrm{mg} / \mathrm{g})$ and about $50 \%$ of cationic dyes. The schematics of probable interaction of studied dye with graphene oxide and reduced graphene oxide are shown in Figure $3 \mathrm{~b}$. After the adsorption, the sorbent was precipitated and separated by centrifugal force. Wang et al. ${ }^{[99]}$ made magnetic graphene nanocomposites $\left(\mathrm{G} / \mathrm{Fe}_{3} \mathrm{O}\right)$ for the removal of fuchsine (cationic dye). The dye sorption was rapid and achieved the maximum dye sorption within 30 min with a sorption efficiency of $89.4 \mathrm{mg} / \mathrm{g}$. The picture of fuchsine dye solution, after sorption with $\mathrm{G} / \mathrm{Fe}_{3} \mathrm{O}$ and their magnetic separation of $\mathrm{G} / \mathrm{Fe}_{3} \mathrm{O}$ are shown in Figure 3c. The $\mathrm{G} / \mathrm{Fe}_{3} \mathrm{O}$ nanocomposite was a highly efficient adsorbent for fuchsine and could easily be desorbed by using acidic ethanol. The sorbent was recycled easily and used continuously and separated using the magnetic field separation.

Graphene/iron oxide hydrogels were prepared by Cong et al. ${ }^{[83]}$ by using reduction of graphene oxide. The schematic preparations of graphene $/ \alpha-\mathrm{FeOOH}$ and graphene $/ \mathrm{Fe}_{3} \mathrm{O}_{4}$ hy- drogels are shown in Figure 4a. Graphene/ $\alpha-\mathrm{FeOOH}$ hydrogels showed maximum of $92 \%$ adsorption capacity of gasoline owing to its strong well interconnected architecture and good porous nature. The Graphene/ $\alpha-\mathrm{FeOOH}$ hydrogels also showed good adsorption capacity towards many nonpolar organic solvents and oils, namely, cyclohexane, toluene, paraffin oil vegetable oil, and phenoxin. The w/w adsorption capacity of the hydrogels was about 27 times. The images of gasoline adsorption and its recycling are shown in Figure $4 \mathrm{~b}$. The adsorption performance of graphene/ $\alpha$-FeOOH hydrogels up to 8 cycles are shown in Figure 4c. The adsorption capacity towards many nonpolar organic solvents and oils are shown in Figure $4 \mathrm{~d}$. The main advantages of oil adsorbed graphene $/ \alpha-\mathrm{FeOOH}$ hydrogels is that when burn they are converted into $\alpha-\mathrm{Fe}_{2} \mathrm{O}_{3}$ (hematite) (Figure 4e). The extraordinary oil adsorption capacity of graphene hydrogels could be attributed to the hydrophobic nature of hydrogels and $\pi-\pi$ stacking of the prepared hydrogels. Another advantage of the hydrogels is that they can easily be separated using external magnets and reused for many cycles.

Graphene nanosheet (GNS)/magnetite $\left(\mathrm{Fe}_{3} \mathrm{O}_{4}\right)$ composites $\left(\mathrm{GNS} / \mathrm{Fe}_{3} \mathrm{O}_{4}\right)$ were prepared by $\mathrm{Ai}$ et al. ${ }^{[100]}$ using a solvothermal process. The schematic preparation of $\mathrm{GNS} / \mathrm{Fe}_{3} \mathrm{O}_{4}$ composites and their methylene blue adsorption are shown in Figure 5a. After dye sorption the magnetic $\mathrm{GNS} / \mathrm{Fe}_{3} \mathrm{O}_{4}$ composite was separated with an external magnet and its maximum monolayer adsorption ability was $43.82 \mathrm{mg} / \mathrm{g}$. The composite showed good adsorption capacity for methylene blue in five successive cycles of desorption-adsorption. Similarly, many researchers 


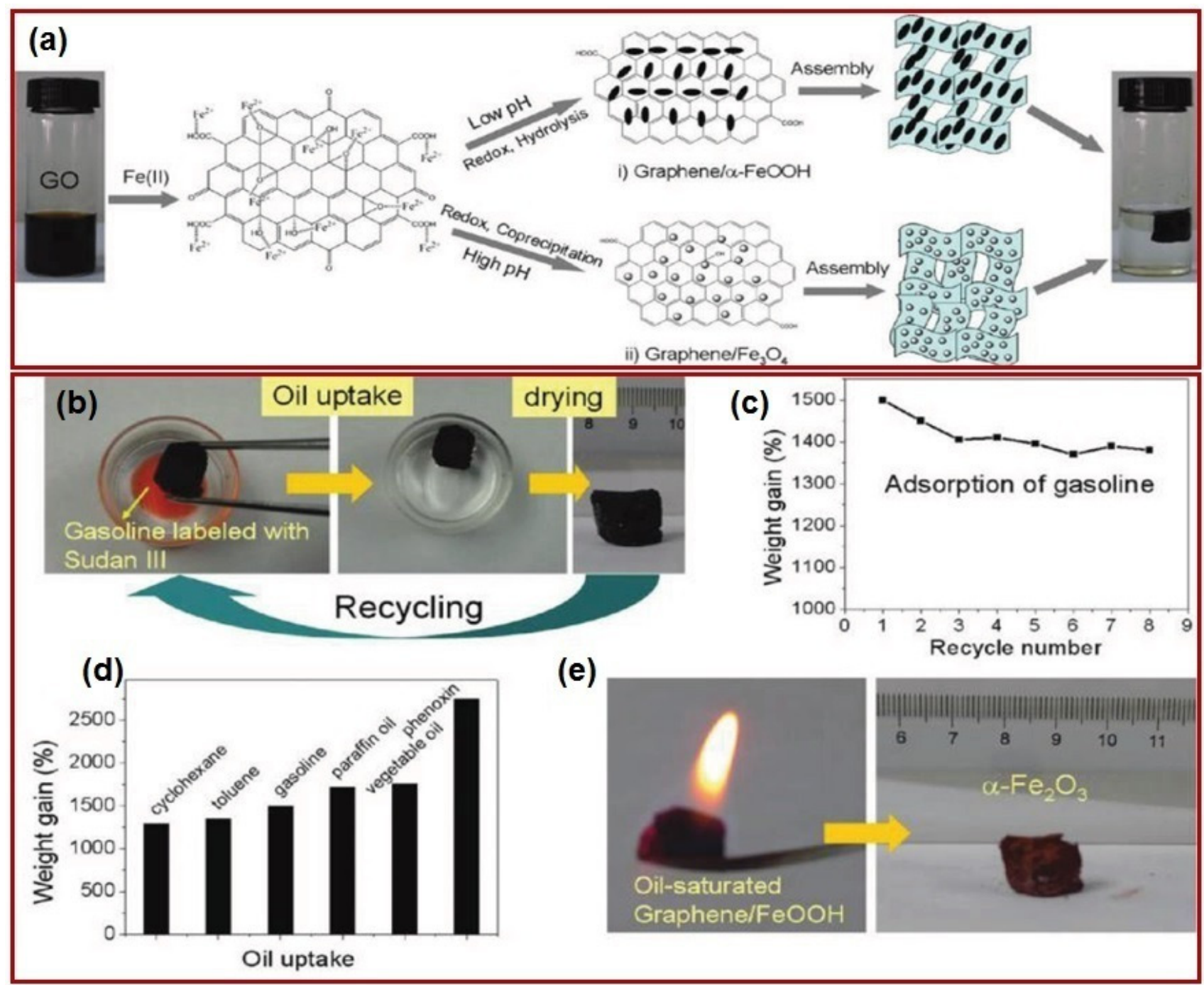

Figure 4. a) Schematic preparations of graphene/ $\alpha-\mathrm{FeOOH}$ and graphene/Fe $\mathrm{O}_{4}$ hydrogels. b) The images of gasoline adsorption and its recycling onto graphene $/ \alpha$-FeOOH gels. c) Sorption performance of gasoline onto graphene $/ \alpha-F e O O H$ hydrogels. $d$ ) The adsorption capacity towards many nonpolar organic solvents and oils onto graphene/ $\alpha-\mathrm{FeOOH}$ hydrogel. e) The image of oil adsorbed graphene $/ \alpha-\mathrm{FeOOH}$ hydrogels burning and its conversation into $\alpha-\mathrm{Fe} \mathrm{O}_{3}$ (hematite). Reproduced with permission. ${ }^{[83]}$ Copyright 2012, American Chemical Society.

synthesized various graphene composites that were prepared by the removal of methylene blue and showed a very high dye sorption capacity. ${ }^{[101-103]}$

Li et al. ${ }^{[104 a]}$ produced tri-isocyanate reinforced graphene aerogel (RGA). RGA showed excellent crude oil sorption capacity $(\sim 169 \mathrm{mg} / \mathrm{g})$. They reported that RGA can be considered as an effective absorbent with ease of storage and cleanup, and offers very safe removal of organic contaminants. The prepared aerogels adsorbed crude oil by $\pi-\pi$ stacking interactions and abundant pore structures. The synthesis of three-dimensional graphene architectures such as gelation based graphene organo gels, hydrogels, aerogels and their recent developments has been reviewed by Min et al. ${ }^{[104 b]}$ Further, Zhao et al. ${ }^{[104 c]}$ also reviewed preparation of various 3D graphene based hydrogels, aerogels and their applications including water purification.
Kabiri et al. ${ }^{[104 d]}$ reported graphene-carbon nanotube (CNT) aerogels for continuous oil removal. They prepared grapheneCNT aerogels using graphene oxide, acid treated CNTs, and ferrous sulfate as reducing agents. The prepared graphene-CNT hybrid hydrogels were freeze dried in order to get grapheneCNT aerogels. The graphene-CNT aerogels showed very good adsorption of various pure oils, such as vegetable oil, paraffin, gasoline, tetrahydrofuran (THF), and toluene, with an adsorption capacity of about $30 \mathrm{~g} / \mathrm{g}$. In the presence of water the adsorption capacity slightly decreased due to competitive sorption of water along with oil. The graphene-CNT aerogels showed very high recycling performance towards gasoline. The sorption capacity of gasoline even after $8^{\text {th }}$ cycle was about $22 \mathrm{~g} / \mathrm{g}$. The high oil removal capacity was attributed to the well interconnected 3D architecture of graphene-CNT aerogel and their superoleophilic/superhydrophobic properties. 

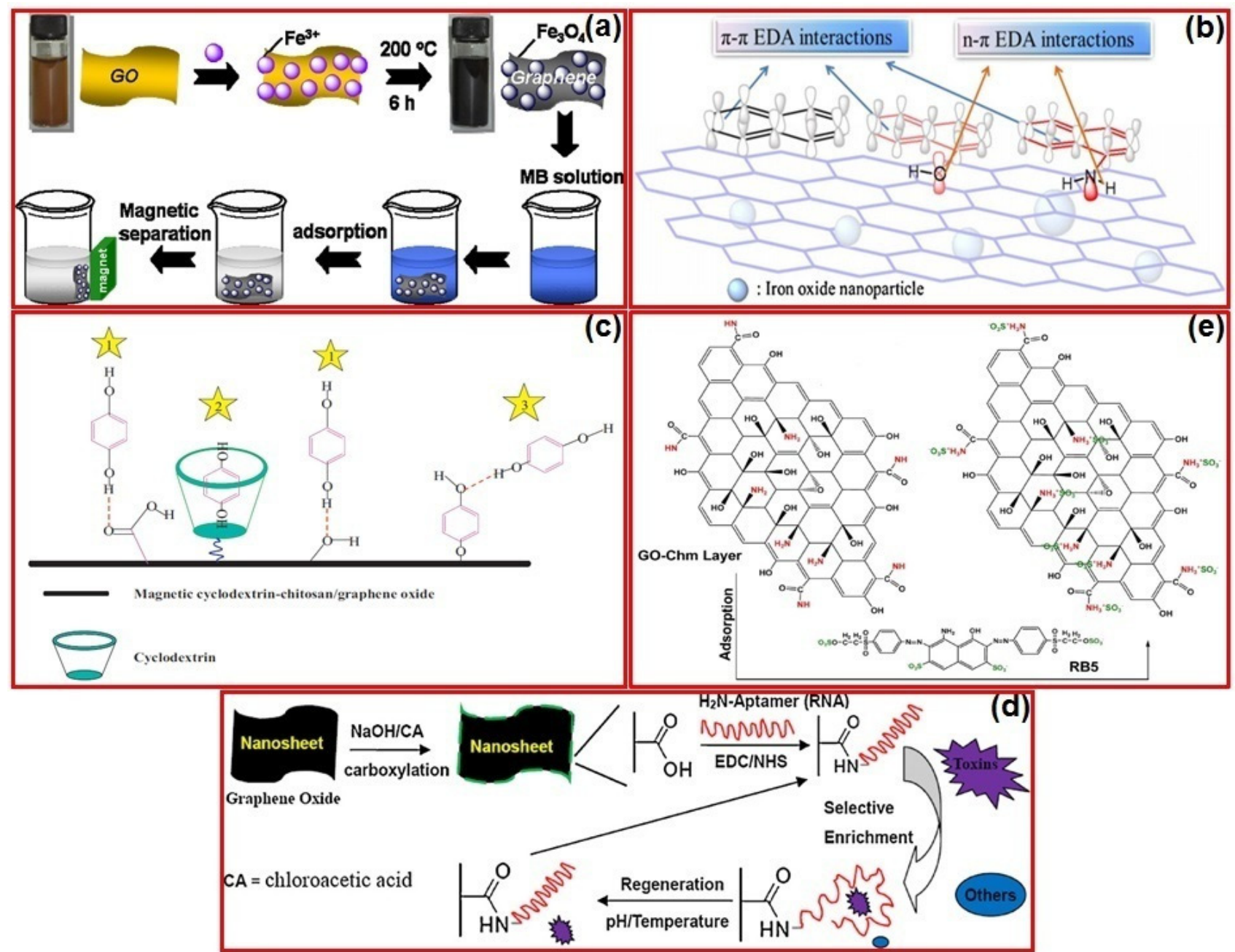

Figure 5. a) Schematic of the preparation of $\mathrm{GNS} / \mathrm{Fe}_{3} \mathrm{O}_{4}$ composites and their methylene blue adsorption. Reproduced with permission. ${ }^{[100]}$ Copyright 2011 , Elsevier. b) Schematic removal mechanism of 1-naphthylamine, 1-naphthol, and naphthalene. Reproduced with permission. ${ }^{\text {[105] }}$ Copyright 2012, Elsevier. c) Schematic representation of the proposed removal mechanism of hydroquinone by CCGO. Reproduced with permission. ${ }^{\text {[108] }}$ Copyright 2013 , Elsevier. d) Schematic preparation method of RNA-GO nanosheets and their peptide toxin removal mechanism. Reproduced with permission. ${ }^{[114]}$ Copyright 2012, Elsevier. e) Schematic adsorption of reactive black 5 onto GO-Chm. Reproduced with permission. ${ }^{[121]}$ Copyright 2013, American Chemical Society.

Similarly, polydimethylsiloxane (PDMS)-graphene sponges fabricated by Tran et al. ${ }^{[104 e]}$ showed very high removal capacity towards gasoline, hexane, dimethylformamide (DMF), toluene, tetrahydrofuran (THF), and vegetable oil. PDMS-graphene sponges removed $4.5 \mathrm{~L}$ of hexane within 30 min using a nonturbulence pressure assisted oil-water system. PDMS-graphene sponges showed oil sorption capacity from $220-800 \mathrm{wt} \%$ towards studied oils and organic solvents.

Guo et al. ${ }^{[104 f]}$ prepared graphene oxide/polyethylenimine hydrogels (GO/PEI) and studied for the adsorption of methylene blue and rhodamine B dye. GO/PEl hydrogels exhibited $323 \mathrm{mg} / \mathrm{g}$ of methylene blue adsorption and $114 \mathrm{mg} / \mathrm{g}$ of rhodamine $B$ adsorption. Graphene oxide and polyethylenimine interact well in the hydrogel due to the hydrogen bonding and electrostatic interaction between amine groups of PEI and graphene oxide.
Ma et al. ${ }^{[104 g]}$ reported preparation of porous graphene hydrogel and used for the removal of ciprofloxacin drug from water. They used hydrothermal reduction method and ascorbic acid as a reducing agent for the preparation of 3D porous graphene hydrogel sorbents. The graphene hydrogel showed $235 \mathrm{mg} / \mathrm{g}$ of ciprofloxacin removal from aqueous solution. The major removal mechanism of ciprofloxacin was attributed to $\pi$ $\pi$ interactions, hydrogen bonding between hydrogel and ciprofloxacin and hydrophobic interactions. The hydrogel was also capable of removing methanol and ethanol from water. Graphene hydrogel granules showed high sorption capacity than the graphene hydrogel blocks.

Yang et al. ${ }^{[105]}$ synthesized reduced graphene oxide/iron oxide (GO/FeO $\cdot \mathrm{Fe}_{2} \mathrm{O}_{3}$ ) composites. They used $\mathrm{GO} / \mathrm{FeO} \cdot \mathrm{Fe}_{2} \mathrm{O}_{3}$ for removal of naphthalene, 1-naphthol, and 1-naphthylamine. The adsorption capacity was as follows: 1-naphthylamine $(4.96 \mathrm{mmol} / \mathrm{g})>1$-naphthol $(2.70 \mathrm{mmol} / \mathrm{g})>$ naphthalene 
(2.85 mmol/g). The schematic removal mechanism of naphthalene, 1-naphthol, and 1-naphthylamine is presented in Figure $5 \mathrm{~b}$. The main mechanism involved in the sorption of naphthalene, 1-naphthol, and 1-naphthylamine was electron-donoracceptor interaction and the sorption efficiency depended on the dipole moment. They compared the sorption capacity of $\mathrm{GO} / \mathrm{FeO} \cdot \mathrm{Fe}_{2} \mathrm{O}_{3}$ with multiwalled carbon nanotubes/iron oxide (MWCNTs/FeO $\cdot \mathrm{Fe}_{2} \mathrm{O}_{3}$ ) and reported that the structural arrangement of sorbents is very important for effective sorption of aromatic compounds. The magnetic cyclodextrin-chitosan/graphene oxide (CCGO) prepared by Li et al. ${ }^{[108]}$ showed a sorption capacity of $458.72 \mathrm{mg} / \mathrm{g}$ for hydroquinone. The schematic representation of the proposed removal mechanism of hydroquinone by CCGO is presented in Figure $5 c$. The adsorbed hydroquinone was removed from CCGO by washing with ethanol and it can be recycled.

Lin et al. ${ }^{[111]}$ reported a rapid and extremely efficient method for tetracycline sorption from natural water by graphene oxide functionalized magnetic particles (GO-MPs). They used GOMPs for the removal of tetracycline, oxytetracycline, chlortetracycline, and doxycycline, and their sorption capacity was found to be $39.1,45.0,42.6$, and $35.2 \mathrm{mg} / \mathrm{g}$, respectively. They used acetonitrile, methanol, acetone, formic acid, acetic acid, and oxalic acid as an eluent for the removal of adsorbed tetracyclines, but could not be able to remove them from GO-MPs. Hu et al. ${ }^{[114]}$ immobilized RNA on graphene oxide nanosheets (RNA-GO nanosheets) and used the adsorption of microgram level peptide toxins (microcystin-LR) from drinking water samples. The schematic preparation method for RNA-GO nanosheets and their peptide toxin removal mechanism are shown in Figure $5 \mathrm{~d}$. The maximum sorption of microcystin-LR onto RNA-GO nanosheets was found to be $1.44 \mathrm{mg} / \mathrm{mg}$ and adsorbed trace peptide toxin was removed by hot water $\left(50^{\circ} \mathrm{C}\right)$ and reused. The reported RNA-GO nanosheets were potentially useful materials for removal of biomacromolecule, and other toxic small biomolecules. Maliyekkal et al. ${ }^{[115]}$ studied the effective sorption of pesticides, malathion (ML), endosulfan (ES), and chlorpyrifos (CP) using graphene oxide (GO) and reduced graphene oxide (RGO) from aqueous solution. The chlorpyrifos sorption capacity on RGO was found to be about $\sim 1200 \mathrm{mg} / \mathrm{g}$. The chlorpyrifos sorption capacity of GO was $10-20 \%$ less than that of RGO. They reported that RGO is an effective sorbent for the sorption of pesticides than GO. The sorption of endosulfan and malathion onto RGO was 1100 and $800 \mathrm{mg} / \mathrm{g}$, respectively. They also removed $90 \%$ adsorbed chlorpyrifos from RGO using $n$-hexane and reused. The study revealed the interactions of graphene with various pesticides and highlighted the importance of graphene based sorbents in eco-friendly applications. Graphite oxide-magnetic chitosan composite (GO-Chm) was synthesized by Travlou et al..$^{[121]}$ and used for the removal of reactive black 5 (anionic dye). The schematic adsorption of reactive black 5 onto GO-Chm is shown in Figure 5e. The maximum dye removal capacity was found to be 391, 401, and $425 \mathrm{mg} / \mathrm{g}$, at 25,45 , and $65^{\circ} \mathrm{C}$ respectively. GO-Chm showed a high adsorption capacity in acidic media $(\mathrm{pH} 3)$ and a high desorption capacity in alkaline media ( $\mathrm{pH} 12)$.

\section{Adsorption of multiple and mixed contaminants}

The application of graphene-based materials for the adsorption of various types of multiple and mixed contaminants were discussed in this section. The graphene-based material possesses multifunctional characteristics and it simultaneously capable of removing organic dyes, metals ions, organic chemicals and pesticides via adsorption. Pioneering and most important graphene-based materials used for the removal of mixed contaminants and mechanism of removal etc. were discussed.

Graphene-based adsorbents reported for the removal of multiple and mixed pollutants are given in supporting information Table S3..$^{[45,123-130]}$ Sui et al. ${ }^{[123]}$ reported an eco-friendly method for the preparation of carbon nanotube-graphene hybrid aerogels and applied for various water decontamination applications. They synthesized graphene-CNT hybrid aerogel (graphene-MWCNT) by heating graphene oxide, carbon nanotubes, and vitamin $C$ via supercritical carbon dioxide drying method. GO-MWCNT and GO-c-MWCNT were used as capacitive deionization (CDI) electrodes for brackish water desalination. GO-c-MWCNT and GO-MWCNT showed a highest desalination capacity of 521.6 and $633.3 \mathrm{mg} / \mathrm{g}$, respectively. GO-c-MWCNT and GO-MWCNT were also utilized for the sorption of transition metals and dyes, i.e., $\mathrm{Cu}(\mathrm{II}), \mathrm{Hg}(\mathrm{II}), \mathrm{Ag}(\mathrm{I}), \mathrm{Pb}(\mathrm{II})$, fuchsin, acid fuchsin, rhodamine $\mathrm{B}$, and methylene blue. The dyes adsorbed by GO-MWCNT were removed by cetyl trimethylammonium bromide and reused. The prepared hybrid aerogels displayed an excellent efficiency in water treatment such as $\mathrm{CDI}$ of $\mathrm{NaCl}$, the removal of heavy metal ions and dyes. Reduced graphene oxide-silver composites (RGO@Ag) prepared by Gupta et al. ${ }^{[124]}$ exhibited excellent dehalogenation as well as very good removal capacity for organochlorine based pesticides from aqueous solution. RGO@Ag converted the persistent organochlorine pesticide, lindane $\left(\mathrm{C}_{6} \mathrm{H}_{6} \mathrm{Cl}_{6}\right)$, into different isomers of trichlorobenzenes (TCBs, $\mathrm{C}_{6} \mathrm{H}_{3} \mathrm{Cl}_{3}$ ), whereas the reduced graphene oxide (RGO) and $\mathrm{Ag}$ nanoparticles alone failed to do so. The RGO composite showed the highest adsorption capability of lindane as $827 \mathrm{mg} / \mathrm{g}$. The sorption of lindane on RGO@Ag occurs via physisorption, but the sorption of dehalogenated lindane is performed by $\pi-\pi$ interactions. RGO@Ag adsorbed pesticides were removed using hexane and were dispersed in aqueous $\mathrm{NH}_{3}$ solution. The efficiency of RGO@Ag was decreased to $70-75 \%$ after the $5^{\text {th }}$ sorption and desorption cycles. The study showed a new type of removal process for toxic halocarbons and also provided an innovative technique for removal of halocarbons from water.

Koushik et al. ${ }^{[125]}$ used RGO@Ag for sequential dehalogenation of organohalides (aliphatic halocarbons and pesticides) by adsorption during degradation. The RGO@Ag composite showed a very high adsorption for the groups of pesticides (chlorpyrifos $(765 \mathrm{mg} / \mathrm{g})$, endosulfan $(622 \mathrm{mg} / \mathrm{g})$, and dichlorodiphenyldichloroethylene $(631 \mathrm{mg} / \mathrm{g}))$, chlorocarbons (carbon tetrachloride $(997 \mathrm{mg} / \mathrm{g})$, chloroform $(132 \mathrm{mg} / \mathrm{g}$ ), dichloromethane $(121 \mathrm{mg} / \mathrm{g})$, and 1,1,1,3,3,3-hexafluoro-2-propanol $(1534 \mathrm{mg} / \mathrm{g})$, and $1,1,1,2,2,3,3,4,4,5,5,6,6,7,7,8,8$-heptadeca fluoro-10-iodo decane $(498 \mathrm{mg} / \mathrm{g})$. The schematic removal of the pesticides and organohalides is shown in Figure 6a and 


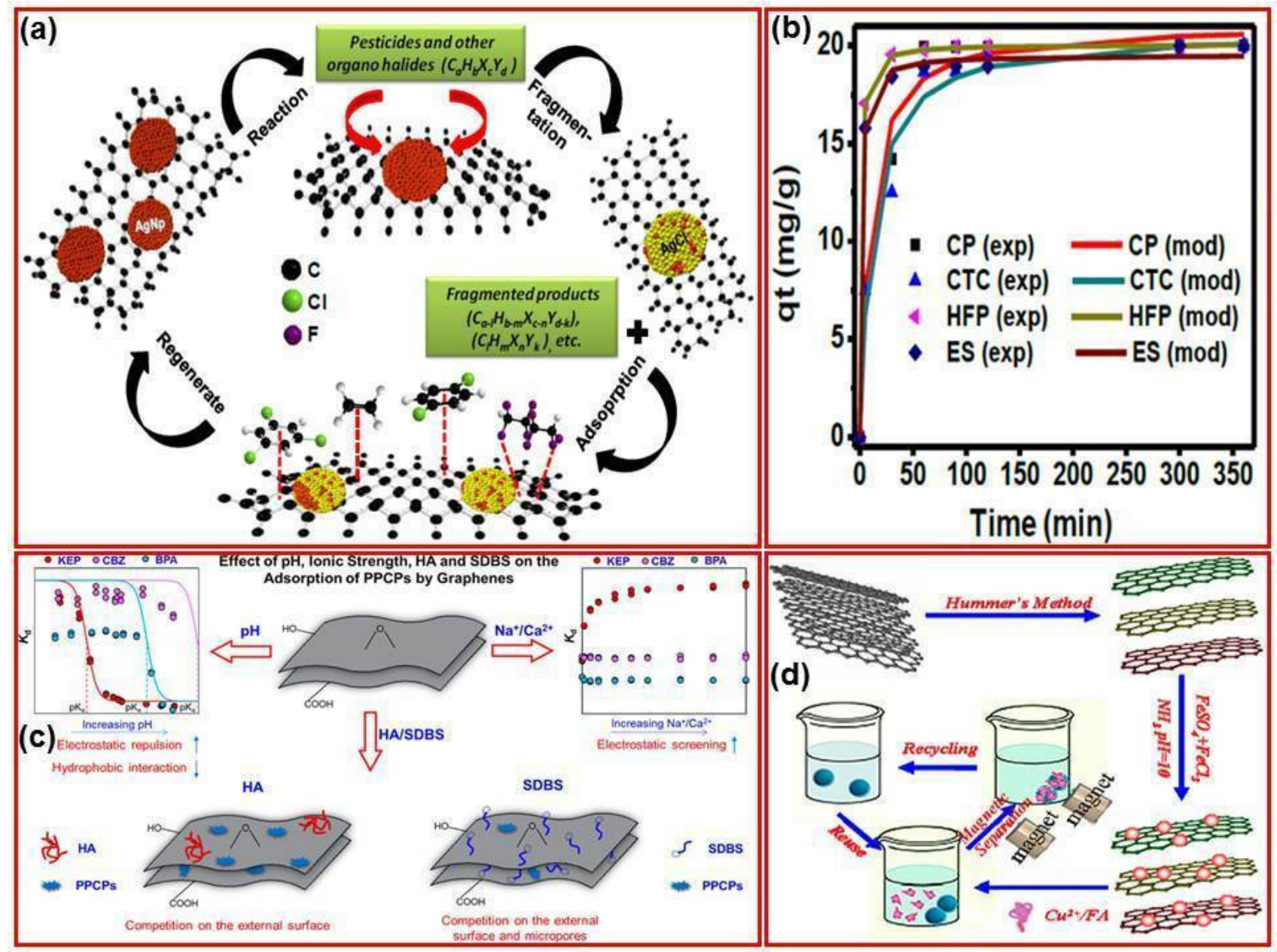

Figure 6. a) Schematic removal of the pesticides and organohalides. Reproduced with permission. ${ }^{[125]}$ Copyright 2016, Elsevier. b) Pseudo second-order kinetic parameter for various pollutants. Reproduced with permission. ${ }^{[125]}$ Copyright 2016, Elsevier. c) Schematic preparation of reduced graphene oxides and the removal mechanism of their pharmaceuticals and personal-care products. Reproduced with permission. ${ }^{[126]}$ Copyright 2014, American Chemical Society. d) Preparation of $\mathrm{GO} / \mathrm{Fe}_{3} \mathrm{O}_{4}$ and the removal mechanism of copper/fulvic acid. Reproduced with permission. ${ }^{[127]}$ Copyright 2012, American Chemical Society.

their pseudo second-order kinetic parameters for various pollutants are shown in Figure $6 \mathrm{~b}$. Liu et al. ${ }^{[126]}$ studied the removal of pharmaceutical drugs and cosmetics by graphene materials and various carbon nanotubes materials. They used reduced graphene oxides ( $\mathrm{rGO} 1$ and $\mathrm{rGO} 2$ ), graphene, graphite, single wall carbon nanotubes (SWCNTs), and multiwall carbon nanotubes (MWCNTs) for the removal of ketoprofen, carbamazepine, and bisphenol A. The schematic preparation of reduced graphene oxides and the sorption mechanism of pharmaceuticals and personal care products are shown in Figure $6 c$. The maximum sorption capacity of ketoprofen, carbamazepine, and bisphenol A onto rGO1 was $62.5,115$, and $152 \mathrm{mg} / \mathrm{g}$, respectively. The sorption capacity of pharmaceuticals and personal care products followed the order of SWCNTs $>$ rGO1 $>$ rGO2 $>$ MWCNTs $>$ graphene $>$ graphite, which is consistent with the orders of their surface areas and micropore volumes. The graphene composites exhibited an excellent sorption capacity for the removal of pharmaceuticals and personal care products.
$\mathrm{Li}$ et al. ${ }^{[127]}$ synthesized graphene oxide nanosheets decorated with $\mathrm{Fe}_{3} \mathrm{O}_{4}$ nanoparticles $\left(\mathrm{GO} / \mathrm{Fe}_{3} \mathrm{O}\right)$ and used for the sorption of $\mathrm{Cu}(\mathrm{II})$ and fulvic acid (natural organic substance). The copper removal capacity of $\mathrm{GO} / \mathrm{Fe}_{3} \mathrm{O}$ was found to be $18.26 \mathrm{mg} /$; and in the presence of fulvic acid it was increased and reached to $19.9 \mathrm{mg} / \mathrm{g}$. Furthermore, the $\mathrm{GO} / \mathrm{Fe}_{3} \mathrm{O}$ composite recovered more than $80 \%$ of fulvic acid from aqueous solutions. The preparation of $\mathrm{GO} / \mathrm{Fe}_{3} \mathrm{O}_{4}$ and the removal mechanism of copper/fulvic acid are shown in Figure $6 \mathrm{~d}$. The desorption of $\mathrm{Cu}(\mathrm{II})$ sorbed $\mathrm{GO} / \mathrm{Fe}_{3} \mathrm{O}_{4}$ was carried out using $\mathrm{HNO}_{3}(\mathrm{pH} \sim 2)$ and then $\mathrm{GO} / \mathrm{Fe}_{3} \mathrm{O}_{4}$ was reused for many times. The $\mathrm{Cu}$ (II) adsorption capacity of reused $\mathrm{GO} / \mathrm{Fe}_{3} \mathrm{O}_{4}$ was decreased by $<5 \%$ after five cycles of sorption/desorption, showing that $\mathrm{GO} / \mathrm{Fe}_{3} \mathrm{O}_{4}$ has a good reusability. Similarly, reduced graphene oxide/iron oxide composite were used for the adsorption of 1-naphthylamine, $\mathrm{Pb}$ (II), and 1-naphthol. ${ }^{[128]}$

In general, graphene oxide nanosheets/aerogels and various functionalized graphene oxide showed high adsorption of heavy metal ions. The native graphene oxide possess many 
functional groups namely, carboxyl, hydroxyl, carbonyl, etc. which captures the heavy metals/cationic dyes from aqueous solution via electrostatic attraction. Further, varies ligands (amine, EDTA) functionalized graphene oxide showed very high heavy metal sorption capacity compared to graphene oxide. Graphene, reduced graphene oxide and functionalized/metal oxides incorporated reduced graphene oxide showed high adsorption capacity towards toxic anions ( $\mathrm{As}(\mathrm{III} / \mathrm{V}), \mathrm{Cr}(\mathrm{VI}), \mathrm{PO}_{4}{ }^{3-}$, $\mathrm{ClO}_{4}^{-}$) and anionic dyes. These materials possess lacks of negative charge on the surface and hence showed high sorption capacity towards various toxic anions and anionic dyes. In the adsorption of chemical compounds, oil, pharmaceuticals and pesticide, the physical interactions (various $\pi$ interactions) playing major role for the removal. Graphene based materials showed very high sorption capacity compared to other carbonaceous adsorbents (activated carbon, fly ash, and carbon nanotubes etc.)

\section{Graphene based materials for catalytic oxidative degradation of organic contaminants}

Graphene and graphene-based materials were wieldy used as catalyst for the degradation of organic contaminations from water. The graphene based materials act as an adsorbent material for organic contamination and activates the oxidizing agent $\left(\mathrm{H}_{2} \mathrm{O}_{2}, \mathrm{KIO}_{4}\right.$, and Oxone) for the successful degradation. In the presence of graphene based materials, the degradation performances of oxidizing agent many fold increases. The present topic summarises the various graphene materials used for the catalytic oxidative degradation of organic contaminants and current development in the field.

Graphene-based materials reported for catalytic oxidative degradation of various types of organic contaminants are enumerated in supporting information Table S4. ${ }^{[131-141]} \mathrm{Xu}$ et al. ${ }^{[131]}$ used graphene- $\mathrm{CoFe}_{2} \mathrm{O}_{4}\left(\mathrm{G}-\mathrm{CoFe} \mathrm{O}_{4}\right)$ composite to activate the oxidizing agent, peroxymonosulfate (PMS), for the degradation of dimethyl phthalate (DMP). $\mathrm{G}-\mathrm{CoFe}_{2} \mathrm{O}_{4}$ was found to be an efficient and better activating agent for PMS than $\mathrm{CoFe}_{2} \mathrm{O}_{4}$. A graphene content of $22 \%$ showed optimum degradation of DMP and excess graphene percentage led to very high sorption of DMP as well as inadequate degradation. $\mathrm{G}-\mathrm{CoFe} \mathrm{O}_{4}$ was found to be a good activator for PMS at pH 4.08.3. In the catalytic oxidative degradation of $\mathrm{DMP}, \mathrm{G}-\mathrm{CoFe}_{2} \mathrm{O}_{4}$ acts a supporting material to enhance the sorption of DMP instead of catalyst. DMP decomposition performances of various catalyst systems are shown in Figure 7a. Further, DMP was desorbed by PMS ions and oxidized the DMP. The DMP degradation was mainly done by the $\mathrm{OH}^{*}$ and $\mathrm{SO}_{4} \cdot$ radicals. G-CoFe $\mathrm{O}_{4}$ degraded $\sim 24 \%$ of total organic carbon (TOC) within $1 \mathrm{~h}$. The initial reduction of TOC may be due to degradation of aliphatic chains in DMP. Thangavel et al. ${ }^{[132]}$ synthesized graphene-oxide$\mathrm{Fe}^{3+}$ hybrid nanosheets $\left(\mathrm{GO}-\mathrm{Fe}^{3+}\right.$ ) and used for the effective oxidation of Reactive Red 120 using a sonocatalytic method. The commercial oxidants, such as potassium periodate $\left(\mathrm{KIO}_{4}\right)$, peroxodisulfate (PDS), hydrogen peroxide $\left(\mathrm{H}_{2} \mathrm{O}_{2}\right)$, and peroxymonosulfate (PMS), were used as catalyst to enhance the sonocatalytic degradation. Reactive Red 120 degradation was many fold enhanced with commercial oxidants $\left(\mathrm{KIO}_{4}<\mathrm{PDS}<\right.$ $\mathrm{H}_{2} \mathrm{O}_{2}<\mathrm{PMS}$ ). During degradation, the addition of $\mathrm{SO}_{4}{ }^{2-}, \mathrm{Cl}^{-}$, and $\mathrm{H}_{2} \mathrm{PO}_{4}^{-}$decreased the degradation efficiency, whereas $\mathrm{HCO}_{3}{ }^{-}$increased the degradation efficiency. The decrease in the degradation efficiency in the presence of inorganic ions was caused by the electrostatic interaction between inorganic anions and $\mathrm{GO}-\mathrm{Fe}^{3+}$. During dye degradation, the inorganic ions interact with $\mathrm{Fe}^{2+}-\mathrm{Fe}^{4+}$ and thus produce less active radicals than $\mathrm{OH}^{\circ}$. Overall, the oxidants reacted with $\mathrm{Fe}(\mathrm{II})$ and promoted the Reactive Red 120 degradation through active radicals. The schematic diagram of Reactive Red 120 degradation using $\mathrm{GO}-\mathrm{Fe}^{3+}$ hybrid is shown in Figure $7 \mathrm{~b}$.

Yao et al. ${ }^{[133]}$ produced magnetic $\mathrm{MnFe}_{2} \mathrm{O} 4$-reduced graphene oxide ( $\mathrm{rGO}$ ) hybrids and $\mathrm{MnFe}_{2} \mathrm{O}_{4}$ nanoparticles and used them as catalysts to activate peroxymonosulfate to oxidatively degrade rhodamine $\mathrm{B}$, methylene blue, methyl violet, methyl orange, and orange II in water. The mechanism of $\mathrm{SO}_{4}{ }^{-}$ activation by $\mathrm{MnFe}_{2} \mathrm{O}_{4}$-rGO/PMS is shown in Figure $8 \mathrm{a}$. $\mathrm{MnFe}_{2} \mathrm{O}_{4}$ and $\mathrm{MnFe}_{2} \mathrm{O} 4-\mathrm{rGO}$ hybrids showed excellent fenton-like activities, could be separated using magnets, and showed high durability in the degradation of organic pollutants even after four repeated uses. $\mathrm{MnFe}_{2} \mathrm{O}_{4}-\mathrm{rGO}$ hybrid activates the primary radical $\mathrm{SO}_{4}{ }^{-}$and oxidizing organic pollutants. $\mathrm{MnFe}_{2} \mathrm{O} 4-\mathrm{rGO}$ hybrid showed a good catalytic performance in the oxidation of Orange II dye than pure $\mathrm{MnFe}_{2} \mathrm{O}_{4}$, endorsing the roles of graphene. The $\mathrm{MnFe}_{2} \mathrm{O}_{4}-\mathrm{rGO}$ hybrid showed a highly stable performance and was considered a good candidate for environmental applications as catalytic materials. Li et al. ${ }^{[136]}$ synthesized reduced graphene oxide ( $\mathrm{rGO}$ ) and used for the catalytic oxidative transformation of 1,4-hydroquinone to 1,4benzoquinone. The prepared $\mathrm{rGO}(33.3 \mathrm{mg} / \mathrm{L})$ oxidized more than $76 \%$ of 1,4 -hydroquinone to 1,4-benzoquinone within $36 \mathrm{~h}$ without addition of any external oxidizing agents. They proposed that the dissolved oxygen in the aqueous solution reacts with rGO and generates molecular oxygen intermediates at graphene surface. The oxygen intermediates entrap hydrogen ions from 1,4-hydroquinone and enable the production of semiquinone radicals. The produced semiquinone radicals transfer an electron to oxygen intermediates to generate super oxide radicals $\left(\mathrm{O}^{2-}\right)$. The super oxide radical $\left(\mathrm{O}^{2-}\right)$ again react with 1,4-hydroquinone and generate a superoxide radical and hydrogen peroxide. The prepared $\mathrm{rGO}$ acts as a very good adsorbent for 1,4-hydroquinone as well as promotes the catalytic conversion of 1,4-hydroquinone to 1,4-benzoquinone at graphene surface. Sun et al. ${ }^{[138]}$ prepared reduced graphene oxide and used as a catalyst for the degradation of methylene blue, 2,4-dichlorophenol, and phenol in water. The reduced graphene oxide exhibited very high catalytic performance compared to graphene oxide, graphite, carbon nanotube, and commercial activated carbons and was also superior to popular $\mathrm{CO}_{3}$ $\mathrm{O}_{4}$ (transition metal oxide). The enhanced catalytic property of RGO was very high for aqueous organic pollutants studied because of structure-defective graphene, which effectively activated the peroxymonosulfate and produced active sulfate radicals. The activation of peroxymonosulfate by graphene and the mechanism of the phenol degradation are shown in Figure 8b. The catalytic performance of different carbon materials was in 

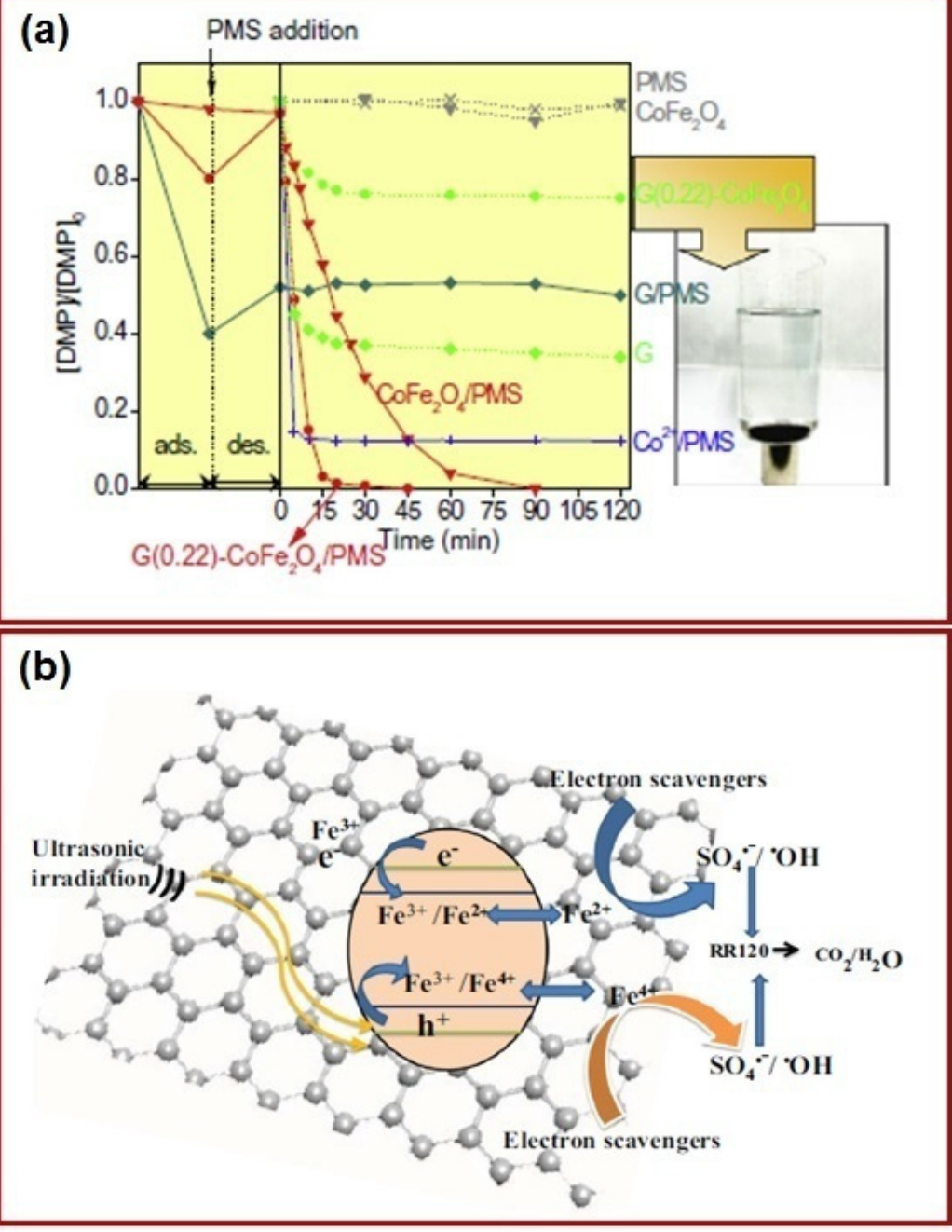

Figure 7. a) DMP decomposition performances of various catalyst systems. Reproduced with permission. ${ }^{[131]}$ Copyright 2015, Elsevier. b) Schematic diagram of Reactive Red 120 degradation using $\mathrm{GO}-\mathrm{Fe}^{3+}$ hybrid. Reproduced with permission. ${ }^{[132]}$ Copyright 2015, Elsevier. the order of RGO > multiwall carbon nanotube $>$ graphite powder $>$ graphene oxide.

Sun et al. ${ }^{[140]}$ synthesized nitrogen-doped reduced graphene oxide $(\mathrm{G}-\mathrm{N})$ and nitrogen-boron-codoped reduced graphene oxide (G-N-B) and used as a metal free catalysts for phenol degradation from aqueous solution. G-N (5.61\%) exhibited very high catalytic performance by activating $\mathrm{HSO}_{5}{ }^{-}$during the degradation of phenol. Nitrogen-boron-codoped reduced graphene oxide further improved the catalytic performance towards oxidation of phenol. Reduced graphene oxide showed only $52.5 \%$ decomposition of phenol in $180 \mathrm{~min}$, whereas G-N and $\mathrm{G}-\mathrm{N}-\mathrm{B}$ showed $100 \%$ degradation in $45 \mathrm{~min}$. In the second cycle, $\mathrm{G}-\mathrm{N}$ and $\mathrm{G}-\mathrm{N}-\mathrm{B}$ showed $56.0 \%$ and $86.0 \%$ of phenol decomposition in $180 \mathrm{~min}$, respectively, showing good reusability. The prepared metal free graphene based catalysts showed a potential application in wastewater treatment and seemed to be a good alternate of the widely used commercial metal based catalysts. Peng et al. ${ }^{[141]}$ produced porous reduced graphene oxide and used as an adsorbent as well as catalyst for the degradation of organic pollutant from aqueous solution. They activated reduced graphene oxide by used $\mathrm{CO}_{2}$ in order to get porous graphene catalysts. They used $\mathrm{CO}_{2}$ activated re- duced graphene oxide for the sorption of phenol and as catalyst for the degradation of methylene blue. The $\mathrm{CO}_{2}$ activated reduced graphene oxide showed high catalytic ability by activation of $\mathrm{HSO}_{5}^{-}$to generate $\mathrm{SO}_{4}^{-}$radicals for the effective decomposition of methylene blue. The 60 -min $\mathrm{CO}_{2}$-activated reduced graphene oxide (A-RGO-60) showed the highest surface area of $1200 \mathrm{~m}^{2} / \mathrm{g}$ and $100 \%$ degradation of methylene blue in $1 \mathrm{~h}$. The surface area of 25-min $\mathrm{CO}_{2}$-activated RGO (A-RGO-25), 75-min $\mathrm{CO}_{2}$-activated RGO (A-RGO-75), and reduced graphene oxide (RGO) were found to be 400,900 , and $200 \mathrm{~m}^{2} / \mathrm{g}$, respectively, and took $2.0 \mathrm{~h}, 1.5 \mathrm{~h}$, and $4 \mathrm{~h}$, respectively, for $100 \%$ degradation of methylene blue. The RGO and activated RGO also showed good catalytic properties through activation of $\mathrm{HSO}_{5}{ }^{-}$in the absence of a transition metal for degradation of methylene blue. They reported that the prepared activated RGO materials could be used as an eco-friendly sorbent as well as a catalyst for waste water treatment. 


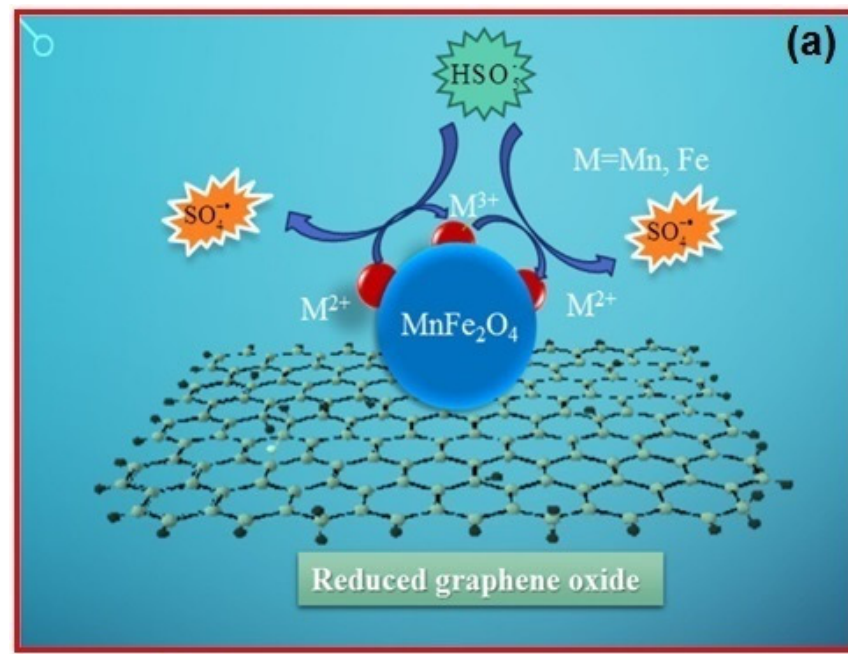

(a)
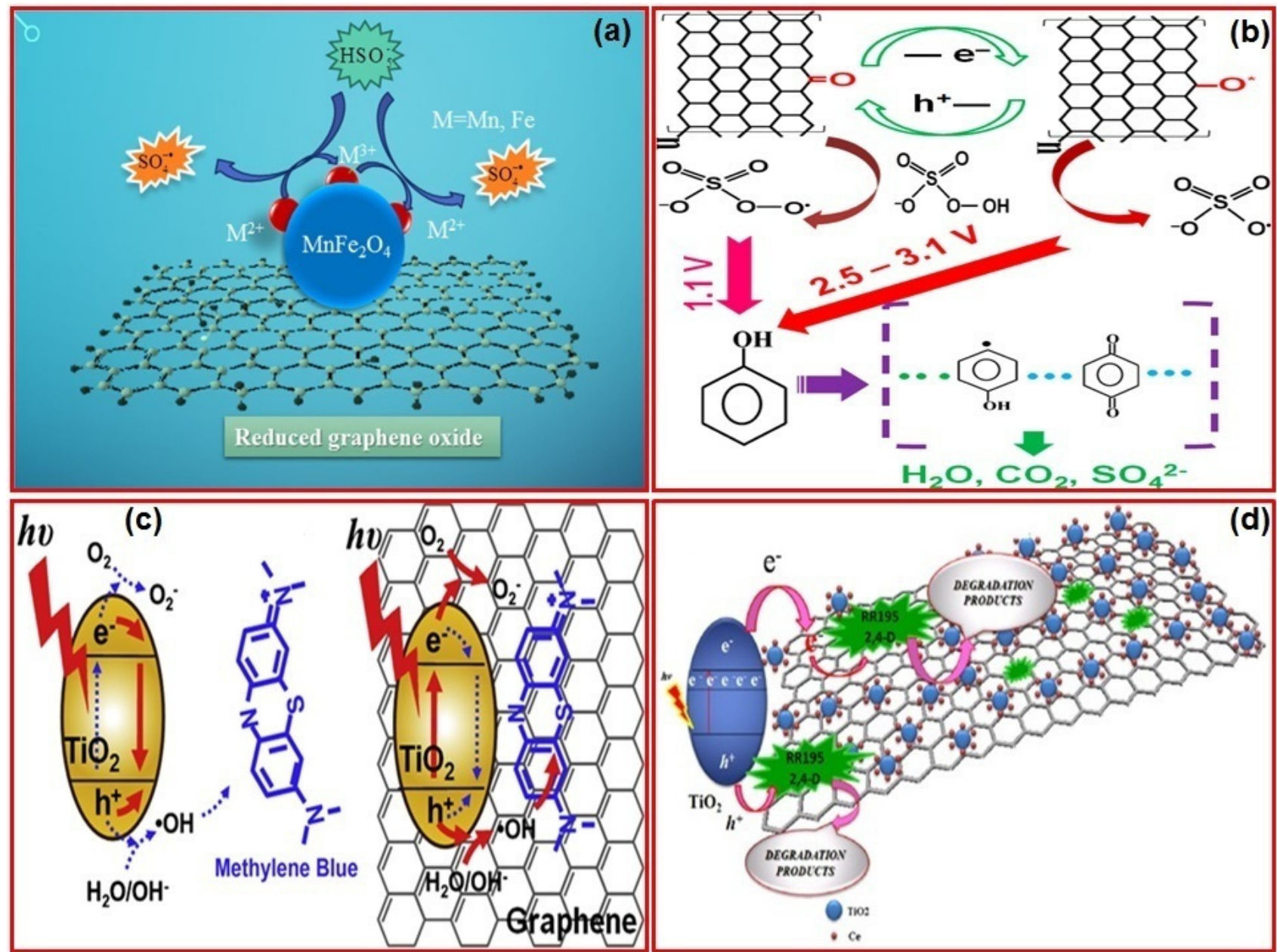

Figure 8. a) Mechanism of $\mathrm{SO}_{4}^{-\bullet}$ activation by $\mathrm{MnFe}_{2} \mathrm{O}_{4}-\mathrm{rGO} / \mathrm{PMS}$. Reproduced with permission. ${ }^{[133]}$ Copyright 2014, Elsevier. b) Activation of peroxymonosulfate by graphene and the mechanism of the phenol degradation. Reproduced with permission. ${ }^{[138]}$ Copyright 2012, American Chemical Society. c) Schematic sketch of the methylene blue photodegradation process with pristine $\mathrm{TiO}_{2}$ nanorods and TNGSs. Reproduced with permission. ${ }^{[145]}$ Copyright 2012 , Elsevier. d) Schematic diagram of the $\mathrm{CeO}_{2}-\mathrm{TiO}_{2}$-graphene nanocomposite and the photodegradation of the contaminants. Reproduced with permission. ${ }^{[154]}$ Copyright 2012, Elsevier.

\section{Application of graphene - based materials in photocatalytic oxidative degradation of organic impurities}

Graphene and graphene-based materials are well known for its electron acceptor and transport properties. Graphene and graphene metal nanocomposites possess very high photo catalytic properties via generation of electron-hole pair in the present of light sources. Graphene materials were used as photocatalyst for the degradation of organic dyes, drugs and toxic chemicals. This section discussing the various graphene-based materials investigated for the photocatalytic oxidative degradation of organic pollutants and recent advances were highlighted. The complete literature survey of various applications of graphenebased materials in photocatalytic oxidative degradation of organic impurities is given in supporting information Table S5. ${ }^{[5-59,142-161]} \mathrm{Ai}$ et al. ${ }^{[142]}$ synthesized various graphitic carbon nitride $\left(\mathrm{g}-\mathrm{C}_{3} \mathrm{~N}_{4}\right), \mathrm{RGO}$ composites and used as hybrid photocatalysts. Among them, the prepared $\mathrm{g}-\mathrm{C}_{3} \mathrm{~N}_{4} / 0.6 \mathrm{~g}$ graphene ( $\mathrm{CN}-\mathrm{G}-0.4)$ showed $100 \%$ photo-oxidation of methylene blue and $87 \%$ photo-oxidation of phenol in water solutions under UV-visible irradiation. In the visible light of a wavelength greater than $390 \mathrm{~nm}$, it showed $86 \%$ methylene blue decomposition; and at a wavelength greater than $430 \mathrm{~nm}$, it showed only $41 \%$ methylene blue decomposition. The methylene blue decomposition highly depends on the intensity of light source. The graphitic carbon nitride $\left(\mathrm{g}-\mathrm{C}_{3} \mathrm{~N}_{4}\right)$ showed very less photooxidation efficiency compared with the prepared graphene-carbon nitride hybrids. $\mathrm{TiO}_{2}$ P25-10\% graphene composite (P25$10 \% \mathrm{GN}$ ) was prepared by Li et al..$^{[144]}$ which showed $>90 \%$ degradation of reactive black 5 in 160 min under UV irradiation. $\mathrm{TiO}_{2}$ nanorod decorated $5 \%$ GO sheets (TNGS) were synthesized by Lee et al. ${ }^{[145]}$ The sheets showed complete methylene blue decomposition in the presence of visible light irradiation in $3 \mathrm{~h}$. The schematic sketch of the methylene blue photodegradation process with pristine $\mathrm{TiO}_{2}$ nanorods and TNGSs is shown in Figure 8c. They reported that high photocatalytic activity of TNGS was due to the high surface area, enhanced dye 
adsorption efficiency, high electron transport properties and their two dimensional architecture.

$\mathrm{Ai}$ et al. ${ }^{[150]}$ synthesized the $\mathrm{BiOBr}$-graphene nanocomposite and used for the removal of NO using visible light. They prepared various $\mathrm{BiOBr}$-graphene composites by varying graphene and bismuth molar ratios between 1:10 (BGC-10), 1:20 (BGC-20), 1:50 (BGC-50), and 1:100 (BGC-100). Among the prepared composites, BGS-50 exhibited maximum of $40.3 \%$ of NO removal in $40 \mathrm{~min}$ with visible light. Based on the characterization results, they proposed that the improved photocatalytic performance of the BGC composites can be attributed to the excellent charge transfer and separation in between graphene and $\mathrm{BiOBr}$. Kamegawa et al. ${ }^{[152]}$ prepared $\mathrm{TiO}_{2}$ nanoparticles on a mesoporous silica surface selectively coated with $0.15 \mathrm{wt} \%$ graphene ( $\mathrm{TiO}_{2} / \mathrm{MCM}-41 /$ graphene) and used them as UV light photocatalysts for the degradation of 2-propanol. $\mathrm{TiO}_{2} / \mathrm{MCM}-41 /$ graphene showed the complete degradation of 2-propanol in $24 \mathrm{~h}$ under UV light. They stated that the selective graphene coating led to the enhanced photocatalytic abilities of $\mathrm{TiO}_{2} / \mathrm{MCM}-41$ for the degradation of 2-propanol from aqueous solution. Wang et al. ${ }^{[153 a]}$ synthesized various graphene- $\mathrm{Bi}_{2} \mathrm{MoO}_{6}$ hybrids and used them as visible light photocatalysts for the decomposition of reactive brilliant red $\mathrm{X}-3 \mathrm{~B}$ dye and phenol. They prepared five different samples with initial $\mathrm{GO}$ weight of $0.5 \%\left(\mathrm{G}^{-\mathrm{Bi}_{2}}\right.$ $\left.\mathrm{MoO}_{6}-1\right), 1.0 \%\left(\mathrm{G}-\mathrm{Bi}_{2} \mathrm{MoO}_{6}-2\right), 2.5 \%\left(\mathrm{G}-\mathrm{Bi}_{2} \mathrm{MoO}_{6}-3\right), 5 \%\left(\mathrm{G}-\mathrm{Bi}_{2}\right.$ $\left.\mathrm{MoO}_{6}-4\right)$, and $10 \%\left(\mathrm{G}-\mathrm{Bi}_{2} \mathrm{MoO}_{6}-2\right)$. Among the prepared composites, $\mathrm{G}_{-} \mathrm{Bi}_{2} \mathrm{MoO}_{6}-3$ hybrid showed $>90 \%$ photodegradation of reactive brilliant red $\mathrm{X}-3 \mathrm{~B}$ dye and phenol within 90 min under excellent visible light. The photodegradation of reactive brilliant red dye $\mathrm{X}-3 \mathrm{~B}$ onto the graphene-titania composite showed only $39 \%$ photodegradation in $90 \mathrm{~min}$. Graphene- $\mathrm{Bi}_{2}$ $\mathrm{MoO}_{6}$ showed higher photocatalytic activity compared with pure $\mathrm{Bi}_{2} \mathrm{MoO}_{6}$ under visible light. The study clearly showed that high loading of $\mathrm{GO}$ does not favor the photodegradation of reactive brilliant red dye $\mathrm{X}-3 \mathrm{~B}$.

Jiao et al. ${ }^{[153 b]}$ fabricated reduced graphene oxide/chitosan/ silver nanoparticle hydrogel and used as photo catalyst for the degradation of methylene blue and rhodamine B dye. The hydrogel showed about $100 \%$ methylene blue degradation under UV light within $70 \mathrm{~min}$, but the degradation was low in the absence of UV light. In case of rhodamine B, it showed $90 \%$ decomposition under UV light, and only $70 \%$ in the absence of UV light. The high photocatalytic dye decomposition performance of the hydrogel was due to the presence of silver nanoparticle on the reduced graphene sheets, and the chitosan worked as a gelation medium.

A ZnO-graphene oxide nanohybrid ( $\mathrm{ZnO}-\mathrm{GO}$ ) was prepared by Ameen et al ${ }^{[59]}$ for the decomposition of crystal violet using UV light. The prepared ZnO-GO showed $98 \%$ degradation in $85 \mathrm{~min}$ that could be attributed to GO nanosheets and high charge separation in the presence of UV light irradiation. Ghasemi et al. ${ }^{[154]}$ synthesized $\mathrm{CeO}_{2}-\mathrm{TiO}_{2}-5$ wt $\%$ graphene composite, which showed $90 \%$ decomposition of Reactive Red 195 and $67 \%$ decomposition of 2,4-dichlorophenoxyacetic acid in $100 \mathrm{~min}$ in UV light. The schematic diagram of the $\mathrm{CeO}_{2}-\mathrm{TiO}_{2}-$ graphene nanocomposite and the photodegradation of the contaminants are shown in Figure 8d. $\mathrm{CeO}_{2}-\mathrm{TiO}_{2}$-graphene ex- hibited very high photodecomposition ability compared with $\mathrm{CeO}_{2}-\mathrm{TiO}_{2}$ and $\mathrm{TiO}_{2}$. The photocatalytic performance of $\mathrm{CeO}_{2}-$ $\mathrm{TiO}_{2}$-graphene decreased with an increase in graphene content. They reported that $\mathrm{CeO}_{2}-\mathrm{TiO}_{2}$-graphene exhibited higher photocatalytic activity than $\mathrm{CeO}_{2}-\mathrm{TiO}_{2}$-carbon nanotube or activated carbon due to their structural architecture and electron transport properties.

$\mathrm{Li}$ et al. ${ }^{[155]}$ synthesized mesoporous graphene- $\mathrm{TiO}_{2} / \mathrm{SiO}_{2}$ composites using sol-gel technique and applied for the photodecomposition of endocrine-disrupting compound atrazine. The schematics structure of CT-GR nanocomposites and their photodegradation pathways are shown in Figure 9a. The three prepared component junction (graphene- $\mathrm{TiO}_{2} / \mathrm{SiO}_{2}$ ) photocatalysts showed excellent photocatalytic degradation performance for atrazine in sunlight.

Tang et al. ${ }^{[156]}$ fabricated reduced graphene oxide codecorated $\mathrm{TiO}_{2}$ nanotube assembly ( $\mathrm{Ag} / \mathrm{RGO}-\mathrm{TiO}_{2} \mathrm{NTs}$ ) and used them as photocatalysts for the removal of 2,4-dichlorophenoxyacetic acid (herbicide) from aqueous solution in a solar light irradiation. The Ag/RGO-TiO ${ }_{2} \mathrm{NTs}$ (mixed catalyst) showed complete photodecomposition of 2,4-dichlorophenoxyacetic acid. $\mathrm{Ag} / \mathrm{RGO}-\mathrm{TiO}_{2} \mathrm{NTs}$ showed $\sim 11$ fold higher photodecomposition rate than $\mathrm{TiO}_{2}$ nanotube assembly. Ag/RGO-TiO 2 NTs showed $97.3 \%$ degradation of herbicide even after 10 cycles with high stability and reusability. Neppolian et al. ${ }^{[158]}$ synthesized two photocatalysts, Pt-graphene oxide- $\mathrm{TiO}_{2}\left(\mathrm{Pt}-\mathrm{GO}-\mathrm{TiO}_{2}\right)$ and graphene oxide- $\mathrm{TiO}_{2}\left(\mathrm{GO}-\mathrm{TiO}_{2}\right)$ for the photodegradation of a commonly used anionic surfactant, dodecylbenzenesulfonate in an aqueous solution. Pt-GO-TiO ${ }_{2}$ showed $98 \%$ degradation at $\mathrm{pH} 5.0$ in $1 \mathrm{~h}$, whereas $\mathrm{GO}-\mathrm{TiO}_{2}$ showed only $78 \%$ degradation at $\mathrm{pH} 5.0$ in $1 \mathrm{~h}$. The Pt-GO-TiO ${ }_{2}$ exhibited excellent photodegradation of dodecyl benzenesulfonate under UV as well as visible light irradiation. The sorption of dodecylbenzenesulfonate onto the catalyst under light irradiation plays a very significant role for the photocatalytic oxidation of dodecylbenzenesulfonate. The Pt-GO-TiO ${ }_{2}$ catalyst degraded dodecylbenzenesulfonate rapidly with very high decomposition rate than commercial P-25 and synthesized $\mathrm{GO}^{-\mathrm{TiO}_{2}}$ or $\mathrm{TiO}_{2}$ photocatalysts. Platinum-doped $\mathrm{GO}^{-} \mathrm{TiO}_{2}$ showed an enhanced dodecylbenzenesulfonate oxidation. Wang et al. ${ }^{[159]}$ prepared $\mathrm{Cu}_{2} \mathrm{O} / \mathrm{SnO}_{2} /$ graphene and $\mathrm{SnO}_{2} /$ graphene nanocomposite for the photodegradation of pendimethalin (herbicide) using visible light. $\mathrm{Cu}_{2} \mathrm{O} / \mathrm{SnO}_{2} /$ graphene showed almost $99 \%$ degradation of pendimethalin, whereas $\mathrm{SnO}_{2} /$ graphene showed $85 \%$ degradation of pendimethalin under similar experimental conditions. The results revealed that when $\mathrm{Cu}_{2} \mathrm{O}$ was mixed with $\mathrm{SnO}_{2}$ /graphene materials the photodegradation activity was significantly improved by the transfer of light-induced electrons and holes between $\mathrm{Cu}_{2} \mathrm{O}$ and $\mathrm{SnO}_{2}$. They proposed that the mechanism of photocatalytic reaction was based on the energy band theory. Similarly, $0.6 \%$ Fe-doped $\mathrm{TiO}_{2}$ nanowire/graphene was used for the photodegradation of $17 \beta$-estradiol, an endocrine-disrupting hormone that is commonly released into aquatic environments. ${ }^{[161]}$ Visible light solar irradiation of $0.6 \%$ Fe-doped $\mathrm{TiO}_{2}$ nanowire/graphene showed $95 \%$ degradation of $17 \beta$-estradiol. Hou et al. ${ }^{[56]}$ made $\mathrm{ZnFe}_{2} \mathrm{O}_{4}$ multiporus microbrick/RGO hybrid $\left(\mathrm{ZnFe}_{2} \mathrm{O}_{4}-\mathrm{MM} / \mathrm{RGO}\right)$ that completely degraded 


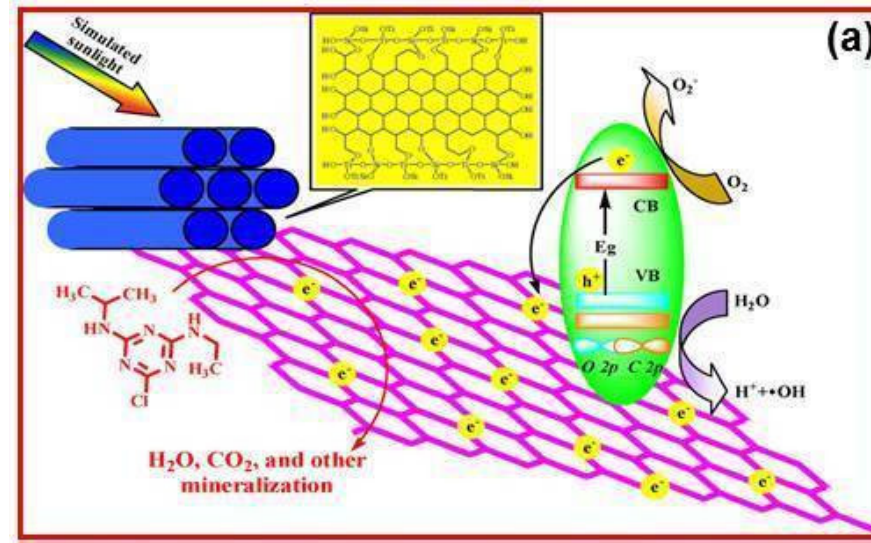

(a)
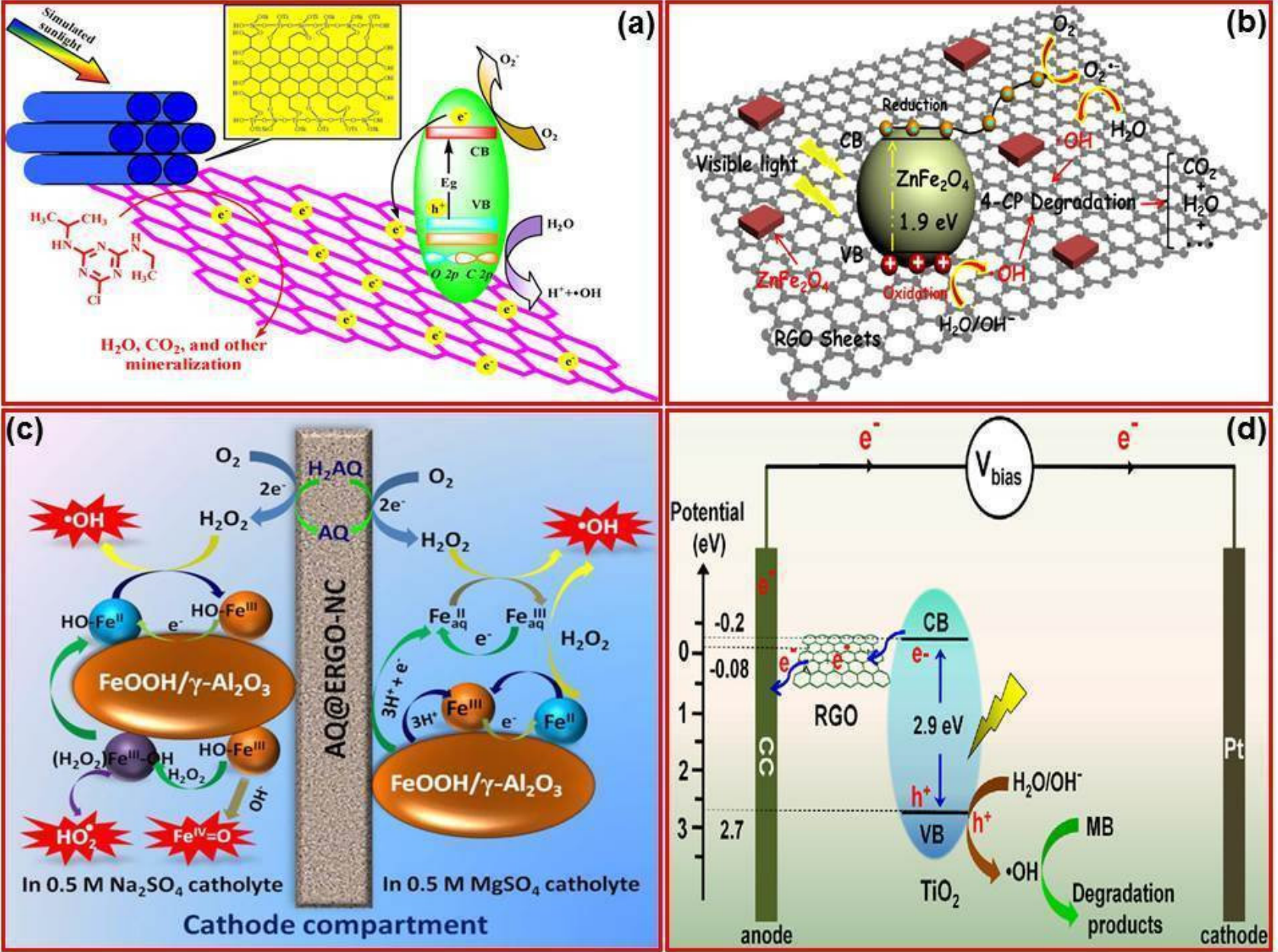

Figure 9. Schematics structure of CT-GR nanocomposites and their photodegradation pathways. Reproduced with permission. ${ }^{[155]}$ Copyright 2013 , Elsevier. b) The feasible mechanism of the photodecomposition of $p$-chlorophenol using $\mathrm{ZnFe} \mathrm{O}_{4}-\mathrm{MM} / \mathrm{RGO}$ hybrid with visible light source. Reproduced with permission. ${ }^{[56]}$ Copyright 2013, Elsevier. c) Schematic illustration of the probable electrocatalytic oxidation mechanism of AQ@ERGO-NC electrode in $\mathrm{MgSO}_{4}$ and $\mathrm{Na}_{2}$ $\mathrm{SO}_{4}$ catholytes. Reproduced with permission. ${ }^{[164]}$ Copyright 2015, The Electrochemical Society. d) Schematic diagram of the RGO/TiO $/$ /CC electrode system and their photoelectrocatalytic degradation process of methylene blue in the presence of visible light. Reproduced with permission. ${ }^{[163]}$ Copyright 2013 , Elsevier.

p-chlorophenol from water under visible light. The $\mathrm{ZnFe}_{2} \mathrm{O}_{4}$ $\mathrm{MM} / \mathrm{RGO}$ exhibited very high photocatalytic performance than the pristine $\mathrm{ZnFe}_{2} \mathrm{O}_{4}$ porous materials and nanoparticles with visible light. The feasible mechanism of the photodecomposition of $p$-chlorophenol using $\mathrm{ZnFe}_{2} \mathrm{O}_{4}-\mathrm{MM} / \mathrm{RGO}$ hybrid with visible light source is shown in Figure $9 \mathrm{~b}$.

\section{Graphene - based materials for the electrocatalytic oxidative degradation of organic contaminants}

Many graphene based materials have been successfully applied as an electrocatalyst for the oxidative degradation of organic contaminants. In this method, electro active oxidants were generated using graphene materials modified electrode for the degradation of various toxic organic compounds from wastewater. Various research investigations was carried out with graphene modified electrodes. The electrocatalytic oxidative degradation is an alternative technique for the photocatalytic degradation. In the case of electrocatalytic oxidation, electron- hole pair generated with an applied voltage. Recent research work published on the topic and the mechanisms of organic contaminants degradation were given in this section. Graphene-based catalysts used for the electrocatalytic oxidative degradation of organic contaminants are shown in supporting information Table S6. ${ }^{[162-168]}$ Reduced graphene oxide/ $/ \mathrm{TO}_{2} / \mathrm{car}-$ bon cloth $\left(\mathrm{RGO} / \mathrm{TiO}_{2} / \mathrm{CC}\right)$ electrodes were prepared and employed by Zhai et al. ${ }^{[163]}$ for the electrodegradation of methylene blue. The prepared $\mathrm{RGO} / \mathrm{TiO}_{2} / \mathrm{CC}$ electrode showed up to $15.6 \%$ degradation of methylene blue in $160 \mathrm{~min}$ with $0.9 \mathrm{~V}$ applied potential. Under the same conditions, the prepared RGO/ $\mathrm{TiO}_{2} / \mathrm{CC}$ showed $26.2 \%$ photodegradation of methylene blue in visible light and the combined electrocatalytic and photocatalytic process showed $41.8 \%$ decomposition of methylene blue. The photoelectrocatalytic degradation method showed higher degradation than the electrocatalytic and photocatalytic catalytic process for methylene blue. Zhang et al. ${ }^{[164]}$ fabricated anthraquinone@reduced graphene oxide nanohybrid cathodes (AQ@ERGO-NC) and used them for the electrodegradation of 
rhodamine $\mathrm{B}$ in $\mathrm{N}_{2}$ and $\mathrm{O}_{2}$ saturated solution. $\mathrm{AQ} @ E R G O-N C / \mathrm{N}_{2}$ and $\mathrm{AQ} @ E R G O N C / \mathrm{O}_{2}$ systems in $0.5 \mathrm{M} \mathrm{Na}_{2} \mathrm{SO}_{4}$ and $\mathrm{MgSO}_{4}$ solutions showed only $12 \%$ degradation of rhodamine $\mathrm{B}$ in $120 \mathrm{~min}$. The schematic illustration of the probable electrocatalytic oxidation mechanism of AQ@ERGO-NC electrode in $\mathrm{MgSO}_{4}$ and $\mathrm{Na}_{2} \mathrm{SO}_{4}$ catholytes is shown in Figure 9c. AQ@ERGONC showed about $100 \%$ degradation of rhodamine $\mathrm{B}$ using the $\mathrm{FeOOH} / \gamma-\mathrm{Al}_{2} \mathrm{O}_{3}$ catalyst for $60 \mathrm{~min}$ in $0.5 \mathrm{M} \mathrm{Na}_{2} \mathrm{SO}_{4}$ and $\mathrm{MgSO}_{4}$ electrolyte solution. The enhanced electrocatalytic degradation of rhodamine $\mathrm{B}$ was caused by the high activity of $\mathrm{FeOOH}$ nanoparticles and its capability to convert the electrogenerated $\mathrm{H}_{2} \mathrm{O}_{2}$ molecules into oxidative radicals. The $\mathrm{FeOOH}$-catalyzed heterogeneous electro-fenton system consisting AQ@ERGONC and $\mathrm{FeOOH} / \gamma-\mathrm{Al}_{2} \mathrm{O}_{3}$ nanoparticles showed a high degradation rate for rhodamine $\mathrm{B}$. The strong interfacial interactions of reduced graphene oxide nanosheets and anthraquinone molecules ensured the efficient cathodic electrogeneration of $\mathrm{H}_{2} \mathrm{O}_{2}$ and the degradation of rhodamine B. Similarly, Wang et al. ${ }^{[167]}$ produced $1.0 \mathrm{wt} \% \mathrm{RGO} / \mathrm{TiO}_{2}$ film (surface area $57.2 \mathrm{~m}^{2} \mathrm{~g}^{-1}$ and size $19.1 \mathrm{~nm}$ ) and studied the electrocatalytic decomposition of acid Orange II and rhodamine $\mathrm{B}$. The $1.0 \mathrm{wt} \% \mathrm{RGO} / \mathrm{TiO}_{2}$ film electrode showed a maximum of $12 \%$ degradation of rhodamine $\mathrm{B}$ and acid Orange II at an applied potential of $0.6 \mathrm{~V}$ at $\mathrm{pH} 6.0$ in 40 min. Further, $1.0 \mathrm{wt} \% \mathrm{RGO} / \mathrm{TiO}_{2}$ showed $72 \%$ degradation of rhodamine $\mathrm{B}$ and $45 \%$ degradation of Orange II under the photocatalytic method. They reported that the photoelectrocatalytic method is the best method for the complete degradation of dyes. Zhai et al. ${ }^{[168]}$ reported the electrocatalytic oxidation of methylene blue using reduced graphene oxide modified platinum nanoflower- $\mathrm{TiO}_{2}$ nanotube arrays (Pt-TNT/ RGO) under visible light. The ternary catalysts (Pt-TNTs/RGO) displayed very low electrocatalytic performance (10.8\%) for the degradation of methylene blue in $120 \mathrm{~min}$. However, the ternary electrode also displayed efficient photoelectrocatalytic degradation ability for methylene blue in visible light. In contrast, compared with other degradation processes, the photoelectrocatalytic degradation process showed $80.9 \%$ degradation efficiency, whereas the photocatalytic process degraded only $20.7 \%$ of methylene blue under similar conditions.

\section{Graphene based materials for photoelectrocatalytic oxidative degradation of organic contaminants}

Photoelectrocatalytic oxidative degradation is an advanced method for the organic pollutants degradation. The graphene materials induced by the lightsources as well as electricity for effective production of photogenerated oxidants and electrogenerated oxidants for the complete mineralization of organic pollutants. The organic pollutants degradation efficiency of photoelectrocatalytic oxidation is very high compared with photocatalytic oxidation and electrocatalytic oxidation with graphene materials. Currently, many organic dyes were degraded with this method in the present of UV light and visible light. We have reviewed few papers on photoelectrocatalytic oxidative degradation efficiency of graphene modified electrode and summarised the current trends in this section. Various graphene based materials developed for the photo- electrocatalytic oxidative decomposition of organic contaminants are shown in supporting information Table S7. ${ }^{[163,166-170]}$ Zhai et al. ${ }^{[166]}$ fabricated reduced graphene oxide modified $\mathrm{TiO}_{2}$ nanotube arrays (RGO-TNTs) for the photoelectrocatalytic oxidative degradation of methyl orange in the presence of visible light. The RGO-TNTs showed higher photocatalytic activity and charge transfer capacity than $\mathrm{TiO}_{2}$ nanotube arrays. RGO-TNTs showed $30 \%$ degradation of methyl orange with a bias potential of $1.0 \mathrm{~V}$ under visible-light illumination. RGO-TNTs electrode exhibited a steady and enhanced photoelectrocatalytic performance for the oxidative decomposition of methyl orange than $\mathrm{TiO}_{2}$ nanotube array electrode. The RGO-TNTs electrode showed high degradation efficiency compared with the electrocatalytic and photocatalytic methods because of the combined effect of both photocatalytic and electrocatalytic processes involved in the degradation.

Various reduced graphene oxide/ $\mathrm{TiO}_{2}$ composite films with 0.2-1.5 wt $\% \mathrm{RGO} / \mathrm{TiO}_{2}$ films were synthesized by Wang et al. ${ }^{[167]}$ and used for the photoelectrocatalytic degradation of Orange II and rhodamine $\mathrm{B}$ acid from aqueous solutions. Among them, the prepared $1.0 \mathrm{wt} \% \mathrm{RGO} / \mathrm{TiO}_{2}$ film electrode showed $\sim 100 \%$ degradation of rhodamine $B$ and $\sim 97 \%$ degradation of acid Orange II in $40 \mathrm{~min}$ using an applied voltage of $0.6 \mathrm{~V}$ under UV light. The $0.2,0.6$, and $1.5 \%$ graphene oxide $/ \mathrm{TiO}_{2}$ composites showed 70,83 , and $92 \%$ decomposition of rhodamine $\mathrm{B}$, respectively with similar experimental conditions. An $\mathrm{RGO} / \mathrm{TiO}_{2}$ film of 1 wt $\%$ showed about 4-5-fold improved photoelectrocatalytic degradation performance for acid Orange II rhodamine $\mathrm{B}$ than native $\mathrm{TiO}_{2}$ film. The higher photoelectrocatalytic activity was primarily produced by reduced graphene oxide through enhanced electron transfer onto RGO/ $\mathrm{TiO}_{2}$ film. Zhai et al. ${ }^{[163]}$ synthesized reduced graphene oxide/ $\mathrm{TiO}_{2}$ modified carbon cloth electrode $\left(\mathrm{RGO} / \mathrm{TiO}_{2} / \mathrm{CC}\right)$ and studied photoelectrocatalytic decomposition of methylene blue in visible light. The schematic diagram of the $\mathrm{RGO} / \mathrm{TiO}_{2} / \mathrm{CC}$ electrode system and the photoelectrocatalytic degradation process of methylene blue are showed in Figure $9 \mathrm{~d}$. The $\mathrm{RGO} / \mathrm{TiO}_{2} /$ CC electrode showed $89.9 \%$ decomposition of methylene blue photoelectrocatalytic with an applied voltage of $0.9 \mathrm{~V}$. They compared the degradation efficiency of $\mathrm{RGO} / \mathrm{TiO}_{2} / \mathrm{CC}$ applying the electrocatalytic and photocatalytic processes. A high degradation of methylene blue was obtained applying the photoelectrocatalytic degradation process. The improved photoelectrocatalytic performance of the electrode was attributed to enhanced transfer of photoinduced electrons and effective electron-hole separation in the presence of visible light. Moreover, the catalytic activity and recyclability of the $\mathrm{RGO} / \mathrm{TiO}_{2} / \mathrm{CC}$ electrode were very high even after five cycles and the photoelectrocatalytic performance did not change, which indicates that $\mathrm{RGO} / \mathrm{TiO}_{2} / \mathrm{CC}$ electrode is very stable and could be reused for many cycles. Zhai et al. ${ }^{[168]}$ synthesized $\mathrm{Pt} / \mathrm{TiO}_{2} /$ reduced graphene oxide (Pt-TNTs/RGO) and studied photoelectrocatalytic decomposition of methylene blue in visible light. The fabricated Pt-TNTs/RGO electrode showed $80.9 \%$ degradation of methylene blue with an applied voltage of $-0.3 \mathrm{~V}$ in $120 \mathrm{~min}$. They compared the catalytic activity of the Pt-TNTs/RGO elec- 
trode applying the electrocatalytic and photocatalytic processes. The photoelectrocatalytic process showed a high degradation compared with the electrocatalytic and photocatalytic methods under similar conditions. The reduced graphene oxide improves sunlight absorption and promotes charge separation during the catalytic process. Yang et al. ${ }^{[170]}$ prepared the $\mathrm{TiO}_{2} /$ graphene $/ \mathrm{Cu}_{2} \mathrm{O}$ mesh for the photoelectrocatalytic oxidation of bisphenol A. The prepared $\mathrm{TiO}_{2} /$ graphene/ $\mathrm{Cu}_{2} \mathrm{O}$ mesh showed $64 \%$ degradation of bisphenol $A$ under visible light in $250 \mathrm{~min}$.

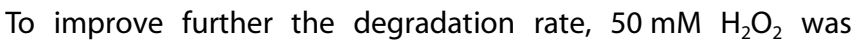
poured into reactor and bisphenol $\mathrm{A}$ degradation reaction was conducted under similar conditions, which showed $92 \%$ degradation in $250 \mathrm{~min}$. The complete degradation of bisphenol A was conducted under UV light irradiation. The $\mathrm{TiO}_{2} /$ graphene/ $\mathrm{Cu}_{2} \mathrm{O}$ mesh showed $100 \%$ degradation of bisphenol $\mathrm{A}$ under visible light in $150 \mathrm{~min}$. To further decrease the degradation time, about $50 \mathrm{mM} \mathrm{H}_{2} \mathrm{O}_{2}$ was poured into reactor and bisphenol A degradation reaction was conducted under similar conditions, which showed $100 \%$ degradation in $90 \mathrm{~min}$. The ternary $\mathrm{TiO}_{2} /$ graphene $/ \mathrm{Cu}_{2} \mathrm{O}$ catalyst exhibited very high photoelectrocatalytic activity for the decomposition of bisphenol $A$ with an aid of UV/visible irradiation compared with photocatalytic degradation.

Modified graphene oxide/reduced graphene oxide and metal oxide/reduced graphene oxide materials were widely used for catalytic oxidative degradation of organic pollutants. The graphene based materials act as adsorbent materials, on the surface of graphene the organic pollutants degradation occurs though oxidizing agent. In the case of photocatalytic oxidative degradation of organic pollutants, metal oxide incorporated graphene oxide/reduced graphene oxide were used as photocatalyst. Graphene based materials plays a vital role in the photocatalytic oxidative degradation of organic pollutants. The graphene based materials acts as an electron transporter and suppress the recombination of photogenerated $\bar{e}-\mathrm{h}^{+}$pairs. The excited electron travels on the surface of metal oxide/graphene composite and produce the very reactive superoxide radicals $\left(\mathrm{O}_{2}^{-}\right)$and hydroxyl radicals $\left({ }^{\circ} \mathrm{OH}\right)$. The produced radicals were degrading the organic pollutants and mineralize the pollutant. The photocatalytic oxidative degradation depends on the photolight sources and energy gap of the incorporated metal oxide. The photodegradation efficiency of graphene material incorporated metal oxides are many fold higher compared to the native metal oxide. Graphene/metal oxide modified electrode showed excellent electrocatalytic oxidative degradation of organic pollutants. Further, graphene materials/ metal oxide modified electrode showed superior organic pollutant degradation performances through photoelectrocatalytic oxidative degradation. The photoelectrocatalytic oxidative degradation of graphene based photoelectrocatalyst will be a power full tool for the organic pollutant degradation in near future.

\section{Application of graphene based materials in water disinfection}

Metal oxide incorporated graphene oxide/reduced graphene oxide, graphene oxide membranes/films, graphene nanorods and graphene nanowells etc. were widely used as water disinfection agents through direct contact or photolight irradiation. The graphene-based material inactivates/degrades the disease causing microorganism namely, Escherichia coli (E. coli), Staphylococcus aureus, Bacillus subtilis from water media. The inactivation/degradation of microorganism by graphene materials takes place through the breaking of cell walls by direct contact or photolight induced degradation. Application of various graphene based materials used in water disinfection and their mechanism were briefly discussed under this section. The applications of various graphene based materials in water disinfection are given in supporting information Table S8. ${ }^{[171-186]}$ Akhavan et al. ${ }^{[172]}$ synthesized graphene oxide nanowells (GONWs) and reduced graphene oxide nanowells (RGONWs) and studied their antibacterial properties on E. coli (gram-negative) and Staphylococcus aureus (gram-positive). GONWs showed $74 \%$ and $59 \%$ antibacterial efficiency upon a direct contact to S. aureus and E. coli, respectively, in $1 \mathrm{~h}$. RGONWs showed $84 \%$ E. coli inactivation and $95 \%$ S. aureus inactivation within $1 \mathrm{~h}$. The prepared materials showed high antibacterial efficiency for S. aureus compared with E. coli. S. aureus contains a peptidoglycan layer (thickness between 20-80 nm) and does not have an external membrane; therefore, it has easy-to-break cell membrane by the sharp edges of nanowalls, whereas $E$. coli contains a thinner peptidoglycan layer (thickness between $7-8 \mathrm{~nm}$ ) and its contains extra outer membrane and thus it is difficult to break its cell membrane with the sharp edges of nanowalls. The RGONWs exhibited more antibacterial property than GONWs. The schematic illustration of cell membrane damage by graphene sheets is shown in Figure 10a. ${ }^{[18]}$

Carpio et al. ${ }^{[175]}$ synthesized graphene oxide functionalized with ethylenediamine triacetic acid (GO-EDTA) and investigated its antimicrobial activity. Its antimicrobial properties were studied using Cupriavidus metallidurans $\mathrm{CH} 4$ (gram-negative bacteria) and Bacillus subtilis (gram-positive bacteria) and the cytotoxicity was tested against human corneal epithelial cell line hTCEpi. GO-EDTA showed $99.1 \%$ and $92.3 \%$ antimicrobial activity against $C$. metallidurans $\mathrm{CH} 4$ and $B$. subtilis under direct contact for $3 \mathrm{~h}$ at $1000 \mu \mathrm{g} \mathrm{mL}^{-1}$ GO-EDTA concentration, whereas it showed no activity against human corneal epithelial cell line hTCEpi under direct contact in $24 \mathrm{~h}$. The pristine graphene oxide showed $92 \%$ and $82.2 \%$ antimicrobial activity against $C$. metallidurans $\mathrm{CH} 4$ and $B$. subtilis under direct contact for $3 \mathrm{~h}$ at $1000 \mu \mathrm{g} \mathrm{ml}^{-1}$ GO-EDTA concentration. The antimicrobial effect of GO-EDTA was due to the induction of oxidative stress in the bacterial cells. Since GO-EDTA did not show cytotoxicity against human cells, it can conveniently be used for the biomedical and water treatment purposes. Similarly, Cao et al. ${ }^{[178]}$ synthesized various combinations of $\mathrm{TiO}_{2} /$ graphene sheet nanocomposites and studied their antibacterial activity against $E$. coli under visible light. Among the prepared $\mathrm{TiO}_{2} /$ graphene sheet nanocomposites, $\mathrm{TiO}_{2}$ with $4.2 \mathrm{wt} \%$ graphene sheet nanocomposites $\left(\mathrm{TiO}_{2} / 4.2\right.$ wt $\%$ GSs) showed $90.5 \%$ antibacterial activity against $E$. coli in $12 \mathrm{~h}$ in visible light. The same composite did not exhibit any antibacterial property in the absence of light. The $\mathrm{TiO}_{2} / 1.4$ wt $\%$ graphene sheet nanocomposites showed about $75.2 \%$ antibacterial activity and 

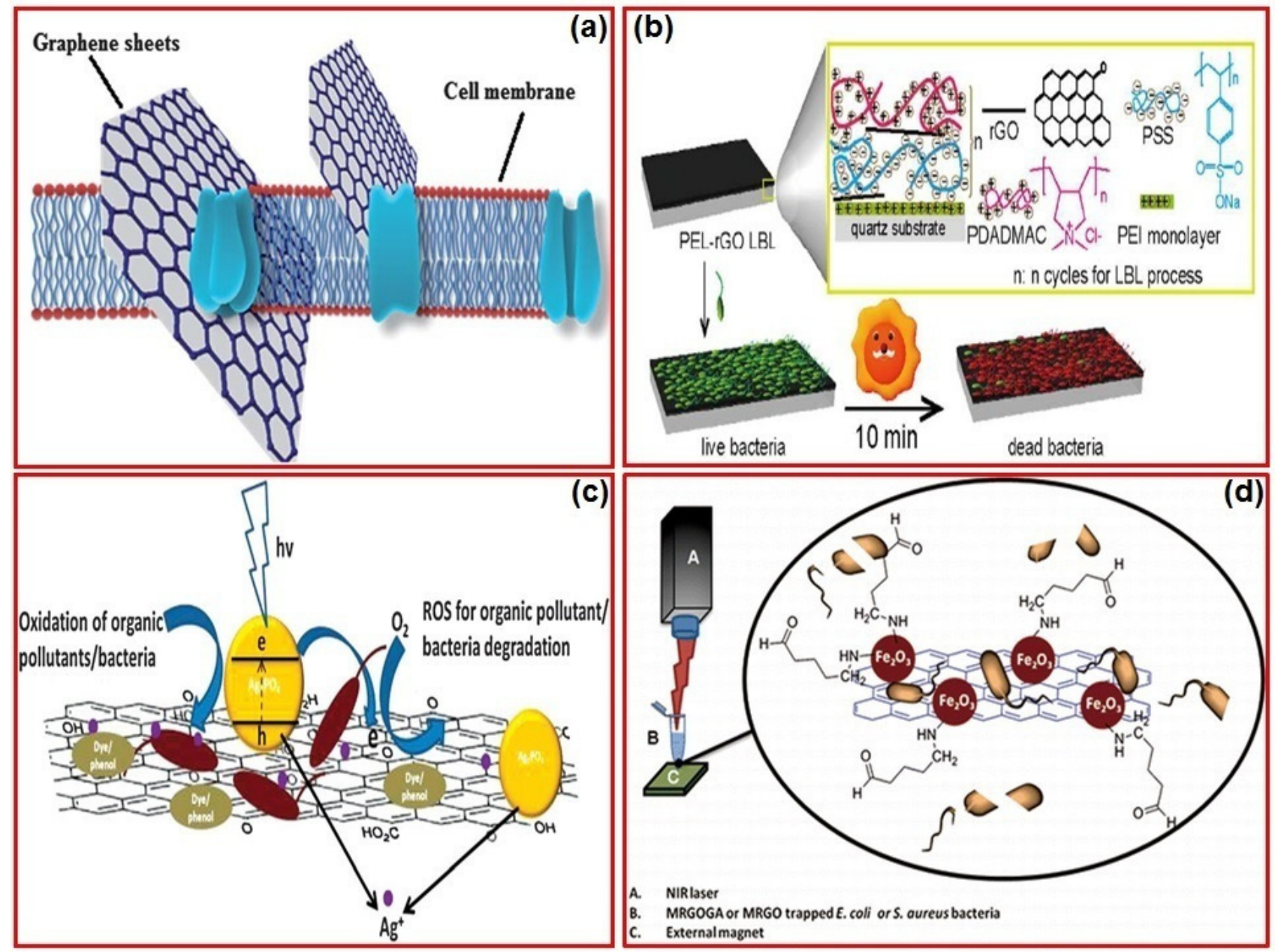

Figure 10. a) Schematic illustration of cell membrane damage by graphene sheets. Reproduced with permission. ${ }^{[18]}$ Copyright 2014 , Royal Society of Chemistry. b) Graphical illustration of the fabricated surface of the PEL-rGO LBL sheets and their airborne bacteria killing mechanism under solar irradiation. Reproduced with permission. ${ }^{[179]}$ Copyright 2015, American Chemical Society. c) Schematic illustration of the photocatalytic disinfection and dye degradation using the GO$\mathrm{Ag}_{3} \mathrm{PO}_{4}$ composite. Reproduced with permission. ${ }^{[181]}$ Copyright 2012, Royal Society of Chemistry. d) Schematic diagram of the batch-mode photothermal antibacterial process of MRGOGA. Reproduced with permission. ${ }^{[186]}$ Copyright 2013, American Chemical Society.

$\mathrm{TiO}_{2} / 7$ wt $\%$ graphene sheet nanocomposites showed $63.3 \%$ antibacterial activity under similar conditions only with $\mathrm{TiO}_{2} /$ graphene sheet nanocomposites. The pure $\mathrm{TiO}_{2}$ showed $8.8 \%$ bacterial inactivation performance in visible light. They reported very high bacterial inactivation performance of nanocomposites owing to the prolonged light absorption, enhanced charge separation, involvement of hydroxyl and super oxide radicals.

Hui et al. ${ }^{[179]}$ fabricated the polyelectrolyte-stabilized reduced graphene oxide sheets on a quartz substrate thin film (PEL-rGO LBL) and studied its antibacterial activity against $E$. coli and $B$. subtilis under solar irradiation. The graphical illustration of the fabricated surface of the PEL-rGO LBL sheets and their airborne bacteria killing mechanism under solar irradiation are shown in Figure 10b. The prepared material showed $>90 \%$ antibacterial activity against both bacteria in 10 min under solar irradiation. The high antibacterial activity of PEL-rGO LBL was attributed to solar radiation in the near-infrared region, which generated the rapid localized heating in the PEL-rGO LBL multilayer in a short time period. They reported that the PELrGO LBL multilayer can be conveniently used for disinfection of various biomedical devices and any other materials by few minutes long solar exposure. Jiang et al. ${ }^{[180]}$ fabricated the crumpled graphene-oxide-encapsulated Ag membrane (GOAg) and the crumpled graphene oxide (CGO) membrane and studied their antibacterial activity against $E$. coli. Both materials showed more than $97 \%$ antibacterial activity under direct contact in $2 \mathrm{~h}$. Similarly, Liu et al. ${ }^{[181]}$ synthesized graphene oxide (GO) enwrapped $\mathrm{Ag}_{3} \mathrm{PO}_{4}\left(\mathrm{GO}-\mathrm{Ag}_{3} \mathrm{PO}_{4}\right)$ and showed $100 \%$ antibacterial activity against $E$. coli under visible light in $2 \mathrm{~h}$. The schematic illustration of the photocatalytic disinfection and dye degradation using the $\mathrm{GO}-\mathrm{Ag}_{3} \mathrm{PO}_{4}$ composite is shown in Figure $10 \mathrm{c}$. Pham et al. ${ }^{[184]}$ fabricated blade-like graphene-based nanosheet films, i.e., graphene nanosmooth (GN-S) and graphene nanorough $(\mathrm{GN}-\mathrm{R})$ films for killing $P$. aeruginosa and $S$. aureus bacteria by direct contact. GN-S (500 nm size) showed 71.4 and $77.1 \%$ antibacterial activity against $P$. aeruginosa and $S$. aureus, respectively, under direct contact for $18 \mathrm{~h}$. GN-R (1.5 $\mu \mathrm{m}$ size) 


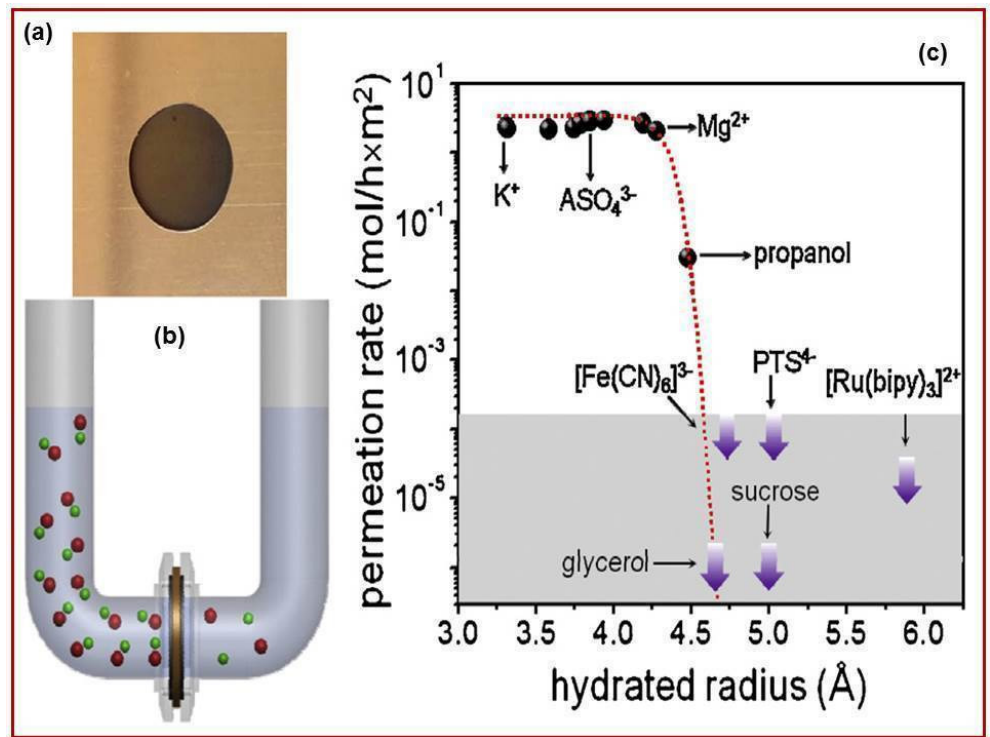

Figure 11. a) Micrometer thickness graphene oxide membrane glued into copper foil. b) Schematic of U-shaped filtration setup. c) Variation of permeation rate with respect to hydrated radius of species tested for separation. Reproduced with permission. ${ }^{[189]}$ Copyright 2014, Nature Publishing Group. showed $43.1 \%$ inactivation against $P$. aeruginosa and $87.6 \%$ inactivation against $S$. aureus under direct contact for $18 \mathrm{~h}$. The primary antibacterial behavior of the graphene nanosheets was attributed to thickness of graphene edges. Wu et al. ${ }^{[186]}$ fabricated magnetic reduced graphene oxide functionalized glutaraldehyde (MRGOGA) and studied their antibacterial activity. The schematic diagram of the batch-mode photothermal antibacterial process of MRGOGA is shown in Figure $10 \mathrm{~d}$. The prepared graphene-based material, MRGOGA, was studied for the effective killing of $S$. aureus and $E$. coli with an aid of near-infrared laser irradiation. MRGOGA showed more than $99 \%$ inactivation of $E$. coli and $S$. aureus in $10 \mathrm{~min}$. After the disinfection of bacteria, MRGOGA entrapped bacteria were easily separated using magnets from aqueous solution.

Graphene based materials showed an excellent application in water disinfection by direct contact and photoirradiation. Graphene nanomaterials (rods, wells, nanosheets, thin films) showed disinfection properties through direct contact towards different disease causing microorganism. Metal oxide-graphene materials also degrading the microorganism through the photoirradiation mechanism which is similar to the organic pollutant degradation. Among them, solar light induced photocatalytic disinfection methods have a potential practical application in the forthcoming days.

\section{Application of graphene based materials in water desalination}

In recent days, graphene based materials showed ground breaking applications in water desalination. Various techniques were reported for tailoring the pore size of graphene based surfaces/membranes. Graphene based aerogel electrodes were reported for the desalination of brackish water using capacitive deionization technique. Tailored graphene membranes widely reported for the removal of $\mathrm{NaCl}, \mathrm{KCl}, \mathrm{MgSO}_{4}$, and $\mathrm{MgCl}_{2}$ and various organic dyes using permeation, dead-end membrane filtration methods. In this section, we have reviewed the various reported graphene based materials used of the desalination and discussed their desalination feasibility and advantages. Various graphene based materials were used for water desalination and their detailed experimental conditions are shown in supporting information Table S9. The first vacuum tight graphene based membrane and its desalination properties were reported by Nair et al. ${ }^{[187]}$ The recent development of various graphene oxide membrane materials and their desalination applications were extensively reviewed by Joshi et al. ${ }^{[188]}$ They reported that graphene oxide membrane acts as a molecular sieve allowing all solute with hydrated radius less than $\sim 4.5 \AA .{ }^{[189]}$ They fabricated micrometer thickness graphene oxide membrane $(1 \mathrm{~cm})$ glued into copper foil and sealed in a $2.5 \mathrm{~cm}$ diameter U-shaped setup divided into two compartments by graphene oxide: feed and permeated compartments. The schematic picture of prepared membrane, $U$ shaped filtration setup and variation of permeation rate with respect to hydrated radius of species are shown in Figure 11a-c. The aqueous species of $\mathrm{K}^{+}, \mathrm{Na}^{+}, \mathrm{AsO}_{4}{ }^{3-}, \mathrm{Mg}^{+}$, propanol, etc. were passed through the feed compartment through a 5 micrometer thick GO membrane. Depending on the hydrated radius of species, their permeation rate varied. They reported that molecules dissolved in water with a hydrated species size up to $\sim 4.5 \AA$ could pass through GO membrane. The molecule hydrated species size more than $\sim 4.5$ were not able to pass through membrane. For example, the hydrated radius of $\left[\mathrm{Fe}(\mathrm{CN})_{6}\right]^{3-}$, glycerol, sucrose, $\left[\mathrm{Ru}(\mathrm{bipy})_{3}\right]^{2+}$ species were found to be more than $4.5 \AA$, so they did not pass through GO membrane. Further the electrical conductivity and chemical analysis of the permeate compartment was performed and confirmed the obtained results.

Wang et al. ${ }^{[191]}$ synthesized the functionalized reduced graphene oxide-resol nanocomposite (RGO-RF) and applied as an electrode material for the desalination of water via capacitive deionization (CDI) method. They reduced the graphene oxide 



Figure 12. a) Schematic diagram of the GO reduction process by titania under ultraviolet irradiation and RGO/TO hybrid membranes water purification process. Reproduced with permission. ${ }^{[192]}$ Copyright 2015, Nature Publishing Group. b) Schematic diagram of water desalination by GO nanosheet membrane. Reproduced with permission. ${ }^{[46]}$ Copyright 2013, American Chemical Society. c) Schematic illustration of the GO membrane and the transport of alkali and alkaline metal salts. Reproduced with permission. ${ }^{[195]}$ Copyright 2014, American Chemical Society. d) Computational stimulation of pores in a single layer graphene membrane and their water desalination mechanism. Reproduced with permission. ${ }^{[196]}$ Copyright 2012, American Chemical Society.

using the mixture of $\mathrm{Na}_{2} \mathrm{CO}_{3}$, resorcinol, and methanol as catalysts in a ratio of 1:200:400, respectively. Among the studied materials, RGO-RF showed a better desalination performance than RGO and activated carbon. The promising result indicated that the novel RGO-RF electrode has a potential application in water desalination in method. The electrosorptive removal performances of $\mathrm{NaCl}$ by RGO-RF, RGO, and activated carbon were found to be $3.2,1.8$, and $1.5 \mathrm{mg} / \mathrm{g}$, respectively, with $20 \mathrm{~mL}$ $\mathrm{min}^{-1}$ inflow of $65 \mathrm{mg} / \mathrm{L} \mathrm{NaCl}$ solution and $2.0 \mathrm{~V}$ applied electric field. The enhanced desalination of RGO-RF was attributed to the very specific surface area $\left(406.4 \mathrm{~m}^{2} \mathrm{~g}^{-1}\right)$, which resulted in high $\mathrm{NaCl}$ uptake. Sun et al. ${ }^{[192]}$ synthesized $\mathrm{RGO} / \mathrm{TiO}_{2}$ hybrid membranes via ultraviolet radiation and used for water purification by an ion permeation method. The prepared RGO/TO hybrid membranes with a composition of $\mathrm{GO}\left(0.1 \mathrm{mg} \mathrm{mL}^{-1}\right)$ and $\mathrm{TiO}_{2}\left(0.08 \mathrm{mg} \mathrm{mL}^{-1}\right)$ showed the salt rejection up to $95 \%$ under UV irradiation for three days, whereas the pristine GO/TO showed the salt rejection up to $\sim 60 \%$. The RGO/TO hybrid membranes exhibited very high desalination capability in the absence of external hydrostatic pressure. The schematic diagram of the GO reduction process by titania under ultraviolet irradiation and RGO/TO hybrid membrane water purification process is shown in Figure $11 \mathrm{a}$.

Surwade et al. ${ }^{[193]}$ fabricated nanoporous single-layer graphene and used it as a desalination membrane. They synthesized porous graphene single layers using chemical vapor deposition (CVD). The single layer graphene was placed on $5 \mu \mathrm{m}$ silicon nitride microchip hole. They created nanopores on a graphene single layer by plasma etching method. Among the prepared materials, the porous graphene/SiN pore with ID/IG = 0.6 showed $98.0 \% \mathrm{KCl}$ rejection in $24 \mathrm{~h}$, whereas pristine graphene/SiN did not show the filterability for $\mathrm{KCl}$. They reported that the produced nanoporous single-layer graphene exhibited excellent water desalination capacity from an aqueous solution of $\mathrm{Na}^{+}, \mathrm{K}^{+}, \mathrm{Li}^{+}$and $\mathrm{Cl}^{-}$ions. The nanoporous single-layer graphene membranes displayed a $100 \%$ rejection of $\mathrm{Na}^{+}, \mathrm{K}^{+}, \mathrm{Li}^{+}$ and $\mathrm{Cl}^{-}$ion and water passed through rapidly. Hu et al. ${ }^{[46]}$ synthesized graphene oxide cross-linked trimesoyl chloride, which 
was deposited on a polydopamine coated polysulfone membrane. They used the prepared membrane for the removal of $\mathrm{NaCl}, \mathrm{Na}_{2} \mathrm{SO}_{4}$, rhodamine WT, and methylene blue from water using a dead-end membrane filtration method. The schematic diagram of water desalination by the prepared membrane is shown in Figure $11 \mathrm{~b}$. The prepared membranes coated with 15 layers of $\mathrm{GO}$ on polydopamine-coated polysulfone support membranes showed 59 and $88 \%$ rejection of $\mathrm{NaCl}$ and $\mathrm{Na}_{2} \mathrm{SO}_{4}$, respectively. The same membrane also showed $95 \%$ rejection of rhodamine-WT and $66 \%$ rejection of methylene blue. It was observed that an increase of GO layers to 50 leads to a decrease in the desalination of water and the optimum 15 GO layers showed the maximum desalination efficiency. Similarly, Han et al. ${ }^{[194]}$ fabricated ultrathin graphene nanofiltration membranes (uGNMs) with a modified graphene oxide $\left(34.0 \mathrm{mg} \mathrm{m}^{-2}\right.$ ). The modified graphene was coated on mixed cellulose ester membrane. The thickness of the graphene oxide coating was found to be $\sim 22-53 \mathrm{~nm}$. The uGNMs was used for desalination of water. Ultrathin graphene nanofiltration membranes with $34.0 \mathrm{mg} \mathrm{m}^{-2}$ of GO content showed $99 \%$ rejection of dye namely direct red 81 and methyl blue in 30 min using a deadend filtration method. uGNMs showed 60, 43, 30, and 20\% rejection of $\mathrm{Na}_{2} \mathrm{SO}_{4}, \mathrm{NaCl}, \mathrm{MgSO}_{4}$, and $\mathrm{MgCl}_{2}$ within 30 min using a dead-end filtration method. The uGNMs exhibited tremendous performance and high dye removal caused by electrostatic interaction and physical separation. The salt rejection was controlled by Donnan exclusion of the ultrathin graphene membranes.

Sun et al. ${ }^{[195]}$ fabricated few layers of graphene oxide membranes and used for water desalination process. They studied the selective transmembrane transport of alkali and alkaline metal salt solutions using graphene oxide membranes. The schematic illustration of the prepared membrane and the transport of alkali and alkaline metal salts are shown in Figure $11 \mathrm{c}$. They reported that the transport behaviors of the selected metal ions $\left(\mathrm{K}^{+}, \mathrm{Mg}^{2+}, \mathrm{Ca}^{2+}\right.$, and $\left.\mathrm{Ba}^{2+}\right)$ highly depend on produced thermal motions and the interaction of metal ions on $\pi$ electron network of graphene oxide membranes. They reported that prepared graphene oxide membranes would be very useful as a filter material for the separation of many gases and liquids.

Cohen-Tanugi and Grossman ${ }^{[196]}$ reported computational stimulation of single layer nanopores in a graphene membrane for the effective desalination of water. Computational modeling of nanopores in a single layer graphene membrane and their water desalination mechanism is shown in Figure $11 \mathrm{~d}$. Computational stimulation study is very useful in understanding the next-generation graphene membranes for clean water technology.

Micrometer thickness graphene based materials showed extraordinary water desalination property. The novel graphene materials reported namely, micrometer thickness graphene oxide membrane, porous graphene/SiN pore, graphene oxide cross-linked polydopamine-coated polysulfone membranes, ultrathin graphene nano-filtration membrane were showed an excellent water desalination properties by controlling the pore size. The pore size controlled graphene materials not allowing any other ions ( $\mathrm{Na}$, dyes, As) to pass through it and it act as molecular sieve. On the other hand graphene materials/aerogel coated electrode showed good desalination capacity through capacitive deionization (CDI) process and supercapacitor based water filter. Design of future desalination technology process using tailored graphene materials is a fast growing filed and many research works is under progress in this field. The graphene based materials will show a huge impact on the future water desalination.

\section{Future challenges and prospects}

The applications of graphene materials in the field of water/ wastewater treatment are growing rapidly. The aggregation of graphene in aqueous solutions is the major technical bottlenecks in water purification. The aggregation of graphene layers reduces contaminants and the accessibility to the surface and limits their interaction. To overcome such technological bottlenecks, graphene based materials were modified with various functional groups. The hydrophilic functional groups (carboxyl, ketone, epoxy, and hydroxyl groups) on the graphene surface enhanced their dispersion and decreased their aggregation. The modified graphene materials are highly interactive with aqueous pollutants and can enhance their removal. During water purification process, separation of graphene nanomaterials requires membrane filters. To solve filtration problems, magnetic graphene based materials have been prepared. Magnetic particles prevent the aggregation of the graphene and can easily be separated from the solution using external magnetic field. The graphene composites degraded various types of organic pollutants with sun light, and the electrophotolysis-assisted technique showed great potential and can be applied to industrial water treatment. The reported graphene-based materials showed groundbreaking applications in the fields of water desalination and disinfection properties. They will have great impact on sea water desalination and will solve the drinking water problem all over the world and thus will be the alternative to reverse osmosis. The synthesis of graphene, GO, and rGO is still a challenging process, scientists will have to develop more simple, robust, and efficient preparation methods for graphene, GO, rGO, and their nanocomposites. For the complete understating of graphene-based materials, still exhaustive studies are required considering their structure, formation, size, viability, reproducibility, methods and properties. Currently, an extensive research work is being carried out in this area. On the other hand, commercial large scale production of graphene materials is challenging and further work to be addressed on their commercial production for the wide range of applications. The toxicity of graphene based materials for living things, human exposure and ecosystem must be extensively investigated and these issues have not been addressed to date. Graphene based materials have many advantages as well as limitations in water purifications, at the same time it is a most promising material for solving various environmental problems. We finally conclude that graphene and graphene-based composites will emerge as a mounting star in the water purification in near future. 


\section{Supporting Information}

Supporting Information is available from the Wiley Online Library or from the author. The complete classification of graphene based materials and comparison of different materials towards water purifications were given in the supporting information Table S1-S9. Supporting information contains the complete literature summary of various graphene-based materials used for water purification (adsorption, degradation, disinfection and desalination) with respect to removal capacity, reusability, temperature, $\mathrm{pH}$, surface area, size and time and other parameters.

\section{Acknowledgements}

One of the authors (S.V) wishes to express his gratitude to Dr. Vijayamohanan K. Pillai, Director, CSIR-Central Electrochemical Research Institute, Karaikudi, India for his continuous support and encouragement. The authors thank Mr S. Gunasekaran, KRC, CSIR-CECRI for design and layout of schematic the image in the wrapper page.

Keywords: adsorption - desalination · disinfection - graphene • water chemistry

[1] J. H. Warner, F. Schaffel, A. Bachmatiuk, M. H. Rummeli, Graphene: fundamentals and emergent applications, Elsevier, Amsterdam 2013, pp. 1-450.

[2] M. D. Stoller, S. Park, Y. Zhu, J. An, R. S. Ruoff, Nano Lett. 2008, 8, 3498-3502.

[3] Y. Zhu, S. Murali, W. Cai, X. Li, J. W. Suk, J. R. Potts, R. S. Ruoff, Adv. Mater. 2010, 22, 3906-3924.

[4] X. Huang, Z. Yin, S. Wu, X. Qi, Q. He, Q. Zhang, Q. Yan, F. Boey, H. Zhang, Small 2011, 7, 1876-1902.

[5] C. Lee, X. Wei, J. W. Kysar, J. Hone, Science 2008, 321, 385-388.

[6] A. A. Balandin, S. Ghosh, W. Bao, I. Calizo, D. Teweldebrhan, F. Miao, C. N. Lau, Nano Lett. 2008, 8, 902-907.

[7] K. L. Bolotin, K. J. Sikes, Z. Jiang, M. Klima, G. Funderberg, J. Hones, P. Kim, H. L. Stormer, Solid State Commun. 2008, 146, 351-355.

[8] S. Basu, P. Bhattacharyya, Sens. Actuators B Chem. 2012, 173, 1-21.

[9] Y. Zhu, S. Murali, W. Cai, X. Li, J. W. Suk, J. R. Potts, R. S. Ruoff, Adv. Mater. 2010, 22, 3906-3924.

[10] a) C. A. Ferrari, F. Bonaccorso, V. Fal'ko, K. S. Novoselov, S. Roche, P. Bøg gild, S. Borini, et al. Nanoscale 2015, 7, 4598-4810; b) X. Wang, G. Shi, Energy Environ. Sci. 2015, 8, 790-823; c) V. Georgakilas, M. Otyepka, A. B. Bourlinos, V. Chandra, N. Kim, K. C. Kemp, P. Hobza, R. Zboril, K. S. Kim, Chem. Rev. 2012, 112, 6156-6214.

[11] D. Li, M. B. Muller, S. Gilje, R. B. Kaner, G. G. Wallace, Nat. Nanotechnol. 2008, 3, 101-105.

[12] R. Sitko, B. Zawisza, E. Malicka, TrAC Trends Anal. Chem. 2013, 51, 33-43.

[13] F. Perreault, A. Fonseca de Faria, M. Elimelech, Chem. Soc. Rev. 2015, 44, 5861-5896.

[14] G. K. Ramesha, A. V. Kumara, H. B. Muralidhara, S. Sampath, J. Colloid Interface Sci. 2011, 361, 270-277.

[15] a) M. Yusuf, F. M. Elfghi, S. A. Zaidi, E. C. Abdullah, M. A. Khan, RSC Adv. 2015, 5, 50392-50420; b) J. G. S. Moo, B. Khezri, R. D. Webster, M. Pumera, ChemPhysChem 2014, 15, 2922-2929; c) W. Z. Teo, M. Pumera, ChemPlusChem 2014, 79, 844-849.

[16] O. C. Compton, S. T. Nguyen, Small 2010, 6, 711-723.

[17] S. Wang, H. Sun, H. M. Ang, M. O. Tadé, Chem. Eng. J. 2013, 226, 336-347.

[18] R. K. Upadhyay, N. Soin, S. S. Roy, RSC Adv. 2014, 4, 3823-3851.

[19] H. Chang, H. Wu, Energy Environ. Sci. 2013, 6, 3483-3507.

[20] S. Daer, D. Kharraz, A. Giwa, S. A. Hasan, Desalination 2015, 367, 37-48.
[21] K. S. Novoselov, A. K. Geim, S. V. Morozov, D. Jiang, Y. Zhang, S. V. Dubonos, I. V. Grigorieva, A. A. Firsov, Science 2004, 306, 666-669.

[22] V. Singh, D. Joung, L. Zhai, S. Das, S. I. Khondaker, S. Seal, Prog. Mater. Sci. 2011, 56, 1178-1271.

[23] C. Schafhäutl, J. Prakt. Chem. 1840, 21, 129-157.

[24] B. C. Brodie, Trans. R. Soc. 1859, 149, 249.

[25] L. Staudenmaier, Ber. Dtsch. Chem. Ges. 1898, 31, 1481-1487.

[26] a) W. S. Hummer's Jr, R. E. Offeman, J. Am. Chem. Soc. 1958, 80, 1339; b) J. Chen, B. Yao, C. Li, G. Shi, Carbon 2013, 64, 225-229; c) E. J. Frankberg, L. George, A. Efimov, M. Honkanen, J. Pessi, E. Levänen, Fullerencs, Nanotubes, Carbon Nanostruct. 2015, 23, 755-759; d) J. H. Kang, T. Kim, J. Choi, J. Park, Y. S. Kim, M. S. Chang, H. Jung, K. T. Park, S. J. Yang, C. R. Park, Chem. Mater. 2016, 28, 756-764; e) S. Abdolhosseinzadeh, H. Asgharzadeh, H. S. Kim, Sci. Rep. 2015, 5, 10160, doi:10.1038/srep10160.

[27] D. C. Marcano, D. V. Kosynkin, J. M. Berlin, A. Sinitskii, Z. Sun, A. Slesarev, L. B. Alemany, W. Lu, J. M. Tour, ACS Nano 2010, 4, 4806-4814.

[28] R.M. Frazier, D. T. Daly, R.P. Swatloski, K.W. Hathcock, C. R. South, Recent Pat. Nanotechnol. 2009, 3, 164-176.

[29] K. A. Worsley, P. Ramesh, S. K. Mandal, S. Niyogi, M. E. Itkis, R. C. Haddon, Chem. Phys. Lett. 2007, 445, 51-56.

[30] W. Choi, I. Lahiri, R. Seelaboyina, Y. S. Kang, Crit. Rev. Solid State Mater. Sci. 2010, 35, 52-71.

[31] V. Dhand, K. Y. Rhee, H. J. Kim, D. H. Jung, J. Nanomater. 2013, 2013, $1-14$.

[32] J. Choi, H. Lee, K. Kim. B. Kim, S. Kim, J. Phys. Chem. Lett. 2010, 1, 505-509.

[33] C. Berger, Z. Song, X. Li, X. Wu, N. Brown, C. Naud, D. Mayou, T. Li, J. Hass, A. N. Marchenkov, E. H. Conrad, P. N. First, W. A. de Heer, Science 2006, 312, 1191-1196.

[34] W. A. de Heer, C. Berger, X. Wu, P. N. First, E. H. Conrad, X. Li, T. Li, M. Sprinkle, J. Hass, M. L. Sadowski, M. Potemski, G. Martinez, Solid State Commun. 2007, 143, 92-100.

[35] G. Zhao, T. Wen, C. Chen, X. Wang, RSC Adv. 2012, 2, 9286-9303.

[36] H. Song, L. Hao, Y. Tian, X. Wan, L. Zhang, Y. Lv, ChemPlusChem 2012, 77, 379-386.

[37] D.-H. Yoo, T. V. Cuong, V. H. Luan, N. T. Khoa, E. J. Kim, S. H. Hur, S. H. Hahn, J. Phys. Chem. C 2012, 116, 7180-7184.

[38] V. Chandra, J. Park, Y. Chun, J. W. Lee, I.-C. Hwang, K. S. Kim, ACS Nano 2010, 4, 3979-3986.

[39] S. Zhang, Y. Shao, H. Liao, M. H. Engelhard, G. Yin, Y. Lin, ACS Nano 2011, 5, 1785-1791.

[40] W. F. Chen, L. F. Yan, Nanoscale 2011, 3, 3132-3137.

[41] T. Kuilla, S. Bhadra, D. Yao, N. H. Kim, S. Bose, J. H. Lee, Prog. Polym. Sci. 2010, 35, 1350-1375.

[42] W. Zhang, X. Shi, Y. Zhang, W. Gu, B. Li, Y. Xian, J. Mater. Chem. A 2013, 1, 1745-1753.

[43] L. Fan, C. Luo, M. Sun, H. Qiu, J. Mater. Chem. 2012, 22, 24577-24583.

[44] L. Fan, C. Luo, M. Sun, X. Li, H. Qiu, Colloid Surf. B Biointerfaces 2013, 103, 523-529.

[45] Y. Wang, S. Liang, B. Chen, F. Guo, S. Yu, Y. Tang, PLoS One 2013, 8, e65634, doi:10.1371/journal.pone.0065634.

[46] M. Hu, B. Mi, Environ. Sci. Technol. 2013, 47, 3715-3723.

[47] J. R. Potts, D. R. Dreyer, C. W. Bielawski, R. S. Ruoff, Polymer 2011, 52, 5-25.

[48] H. Shen, L. Zhang, M. Liu, Z. Zhang, Theranostics 2012, 2, 283-294.

[49] C. Hu, T. Lu, F. Chen, R. Zhang, J. Chinese Adv. Mater. Soc. 2013, 1, 21-39.

[50] Q. Zhuo, Y. Ma, J. Gao, P. Zhang, Y. Xia, Y. Tian, X. Sun, J. Zhong, X. Sun, Inorg. Chem. 2013, 52, 3141-3147.

[51] C. Zhao, S.-L. Chou, Y. Wang, C. Zhou, H.-K. Liu, S.-X. Dou, RSC Adv. 2013, 3, 16597-16603.

[52] S. Yu, Q. Liu, W. Yang, K. Han, Z. Wang, H. Zhu, Electrochimica Acta 2013, 94, 245-251.

[53] I. S. Cho, Z. Chen, A. J. Forman, D. R. Kim, P. M. Rao, T. F. Jaramillo, X. Zheng, Nano Lett. 2011, 11, 4978-4984.

[54] L. Peng, T. Xie, Y. Lu, H. Fan, D. Wang, Phys. Chem. Chem. Phys. 2010, 12, 8033-8041.

[55] X. Liu, H. Zheng, Y. Li, W. Zhang, J. Mater. Chem. C 2013, 1, 329-337.

[56] Y. Hou, X. Li, Q. Zhao, G. Chen, Appl. Catal. B: Environ. 2013, 142-143, $80-88$. 
[57] Y. Yan, S. Sun, Y. Song, X. Yan, W. Guan, X. Liu, W. Shi, J. Hazard. Mater. 2013, 250-251, 106-114.

[58] F. Wang, K. Zhang, J. Mol. Catal. A: Chem. 2011, 345, 101-107.

[59] S. Ameen, M. S. Akhtar, H.-K. Seo, H. S. Shin, Mat. Lett. 2013, 100, 261-265.

[60] J. Cheng, H. Xin, H. Zheng, B. Wang, J. Power Sources 2013, 232, 152-158.

[61] S. D. Perera, A. D. Liyanage, N. Nijem, J. P. Ferraris, Y. J. Chabal, J. K. J. Balkus, J. Power Sources 2013, 230, 130-137.

[62] G. Xie, K. Zhang, B. Guo, Q. Liu, L. Fang, J. R. Gong, Adv. Mater. 2013, $25,3820-3839$.

[63] G. Blanita, M. D. Lazar, Micro Nanosystems 2013, 5, 138-146.

[64] X. Huang, F. Boey, H. Zhang, Cosmos 2010, 6, 159-166.

[65] N. A. Luechinger, N. Booth, G. Heness, S. Bandyopadhyay, R. N. Grass, W. J. Stark, Adv. Mater. 2008, 20, 3044-3049.

[66] M. Wang, Q. Liu, H. Sun, E. A. Stach, H. Zhang, L. Stanciu, J. Xie, Cabron 2012, 50, 3845-3853.

[67] C. Du, Z. Yao, Y. Chen, H. Bai, L. Li, RSC Adv. 2014, 4, 9133-9138.

[68] W. Hong, H. Bai, Y. Xu, Z. Yao, Z. Gu, G. Shi, J. Phys. Chem. C 2010, 114, 1822-1826.

[69] B. Wang, S. Li, J. Liu, M. Yu, Mater. Res. Bull. 2014, 49, 521-524.

[70] H. Porwal, S. Grasso, M. J. Reece, Adv. Appl. Ceram. 2013, 112, 443-454.

[71] M. Zhou, T. Lin, F. Huang, Y. Zhong, Z. Wang, Y. Tang, H. Bi, D. Wan, J. Lin, Adv. Funct. Mater. 2013, 23, 2263-2269.

[72] L. S. Walker, V. R. Marotto, M. A. Rafiee, N. Koratkar, E. L. Corral, ACS Nano 2011, 5, 3182-3190.

[73] Y. Lou, G. Liu, S. Liu, J. Shen, W. Jin, Appl. Surf. Sci. 2014, 307, 631-637.

[74] P. Wu, H. Lv, T. Peng, D. He, S. Mu, Sci. Rep. 2014, 4, 3968, doi:10.1038/ srep03968.

[75] J. Liu, H. Yan, M. J. Reece, K. Jiang, J. Euro. Ceram. Soc. 2012, 32, 4185-4193.

[76] C. Ramírez, S. M. Vega-Diaz, A. Morelos-Gómez, F. M. Figueiredo, M. Terrones, M. I. Osendi, M. Belmonte, P. Miranzo, Carbon 2013, 57, 425-432.

[77] Y. Fan, L. Wang, J. Li, J. Li, S. Sun, F. Chen, L. Chen, W. Jiang, Carbon 2010, 48, 1743-1749.

[78] S. Watcharotone, D. A. Dikin, S. Stankovich, R. Piner, I. Jung, G. H. B. Dommett, G. Evmenenko, S.-E. Wu, S.-F. Chen, C.-P. Liu, S. T. Nguyen, R. S. Ruoff, Nano Lett. 2007, 7, 1888-1892.

[79] Z.-H. Huang, X. Zheng, W. Lv, M. Wang, Q.-H. Yang, F. Kang, Langmuir 2011, 27, 7558-7562

[80] G. Zhao, J. Li, X. Ren, C. Chen, X. Wang, Environ. Sci. Technol. 2011, 45, 10454-10462.

[81] P. Bhunia, G. Kim, C. Baik, H. Lee, Chem. Commun. 2012, 48, 9888-9890.

[82] C. J. Madadrang, H. Y. Kim, G. Gao, N. Wang, J. Zhu, H. Feng, M. Gorring, M. L. Kasner, S. Hou, ACS Appl. Mater. Interfaces 2012, 4, 1186-1193.

[83] H-.P Cong, X-.C. Ren, P. Wang, S-.H. Yu, ACS Nano 2012, 6, 2693-2703.

[84] M. Liu, C. Chen, J. Hu, X. Wu, X. Wang, J. Phys. Chem. C 2011, 115, 25234-25240.

[85] H.-L. Ma, Y. Zhang, Q.-H. Hu, D. Yan, Z.-Z. Yu, M. Zhai, J. Mater. Chem. 2012, 22, 5914-5916.

[86] Y. Leng, W. Guo, S. Su, C. Yi, L. Xing, Chem. Eng. J. 2012, 211-212, 406-411.

[87] O. Sayar, K. Mehrani, F. Hoseinzadeh, A. Mehrani, O. Sadeghi, Microchim. Acta 2014, 181, 313-320.

[88] X. Luo, C. Wang, L. Wang, F. Deng, S. Luo, X. Tu, C. Au, Chem. Eng. J. 2013, 220, 98-106.

[89] Z. Li, F. Chen, L. Yuan, Y. Liu, Y. Zhao, Z. Chai, W. Shi, Chem. Eng. J. 2012, 210, 539-546.

[90] a) X. Mi, G. Huang, W. Xie, W. Wang, Y. Liu, J. Gao, Carbon 2012, 50, 4856-4864; b) Y. Ye, D. Yin, B. Wang, Q. Zhang, J. Nanomaterials 2015, 2015, 1-6; c) Z. Han, Z. Tang, S. Shen, B. Zhao, G. Zheng. J. Yang, Sci Rep. 2014, 4, 5025, doi:10.1038/srep05025.

[91] Y. Ren, N. Yan, J. Feng, J. Ma, Q. Wen, N. Li, Q. Dong, Mater. Chem. Phys. 2012, 136, 538-544.

[92] X. Luo, C. Wang, S. Luo, R. Dong, X. Tu, G. Zeng, Chem. Eng. J. 2012, $187,45-52$.

[93] S. Chen, J. Hong, H. Yang, J. Yang, J. Environ. Radioact. 2013, 126, 253-258.

[94] Y. Ren, N. Yan, Q. Wen, Z. Fan, T. Wei, M. Zhang, J. Ma, Chem. Eng. J. 2011, 175, 1-7.

[95] S. Vasudevan, J. Lakshmi, RSC Adv. 2012, 2, 5234-5242.
[96] J. Lakshmi, S. Vasudevan, Environ. Sci. Pollut. Res. 2013, 20, 5114-5124.

[97] a) A. S. K. Kumar, S.-J. Jiang, RSC Adv. 2015, 5, 6294-6304; b) M. Barathi, A. S. K. Kumar, C. U. Kumar, N. Rajesh, RSC Adv. 2014, 4, 53711-53721; c) A. S. K. Kumar, S. S. Kakan, N. Rajesh, Chem. Eng. J. 2013, 230, 328-337; d) A. S. K. Kumar, N. Rajesh, RSC Adv. 2013, 3, 2697-2709.

[98] L. Fan, C. Luo, X. Li, F. Lu, H. Qiu, M. Sun, J. Hazard. Mater. 2012, 215-216, 272-279.

[99] C. Wang, C. Feng, Y. Gao, X. Ma, Q. Wu, Z. Wang, Chem. Eng. J. 2011, 173, 92-97.

[100] L. Ai, C. Zhang, Z. Chen, J. Hazard. Mater. 2011, 192, 1515-1524.

[101] S.-T. Yang, S. Chen, Y. Chang, A. Cao, Y. Liu, H. Wang, J. Colloid Interface Sci. 2011, 359, 24-29.

[102] L. Ai, J. Jiang, Chem. Eng. J. 2012, 192, 156-163.

[103] L. Fan, C. Luo, M. Sun, H. Qiu, X. Li, Colloids Surf. B: Biointerfaces 2013, 103, 601-607.

[104] a) J. Li, F. Wang, C. Liu, J. Colloid Interface Sci. 2012, 382, 13-16; b) Z. Min, W. Wen-Long, B. Xue-Dong, Chin. Phys. B 2013, 22, 098105, doi: 10.1088/1674- 1056/22/9/098105; c) Z. Zhao, X. Wang, J. Qiu, J. Lin, D. Xu, C. Zhang, M. Lv, X. Yang, Rev. Adv. Mater. Sci. 2014, 36, 137-151; d) S. Kabiri, D. N.H. Tran, T. Altalhi, D. Losic, Carbon 2014, 80, 523-533; e) D. N. H. Tran, S. Kabiri, T. R. Sim, D. Losic, Environ. Sci.: Water Res. Technol. 2015, 1, 298-305; f) H. Guo, T. Jiao, Q. Zhang, W. Guo, Q. Peng, X. Yan, Nanoscale Res. Lett. 2015, 10, 1-10; g) J. Ma, M. Yang, F. Yu, J. Zheng, Sci. Rep. 2015, 5, Article number: 13578, doi: 10.1038/ srep13578.

[105] X. Yang, J. Li, T. Wen, X. Ren, Y. Huang, X. Wang, Colloids Surf. A: Physicochem. Eng. Asp. 2013, 422, 118-125.

[106] S. Zeng, N. Gan, R. Weideman-Mera, Y. Cao, T. Li, W. Sang, Chem. Eng. J. 2013, 218, 108-115.

[107] Y.-P. Chang, C.-L. Ren, J.-C. Qu, X.-G. Chen, Appl. Surf. Sci. 2012, 261, 504-509.

[108] L. Li, L. Fan, M. Sun, H. Qiu, X. Li, H. Duan, C. Luo, Int. J. Biol. Macromol. 2013, 58,169-175.

[109] Q. Wu, G. Zhao, C. Feng, C. Wang, Z. Wang, J. Chromatogr. A 2011, 1218, 7936-7942.

[110] M. Seredych, T. J. Bandosz, Micropor. Mesopor. Mater. 2012, 150, 55-63.

[111] Y. Lin, S. Xu, L. Jia, Chem.Eng. J. 2013, 225, 679-685.

[112] Y. Gao, Y. Li, L. Zhang, H. Huang, J. Hu, S. M. Shah, X. Su, J. Colloid Interface Sci. 2012, 368, 540-546.

[113] Y. Tang, H. Guo, L. Xiao, S. Yu, N. Gao, Y. Wang, Colloids Surf. A: Physicochem. Eng. Asp. 2013, 424, 74-80.

[114] X. Hu, L. Mu, J. Wen, Q. Zhou, J. Hazard. Mater. 2012, 213-214, 387-392.

[115] S. M. Maliyekkal, T. S. Sreeprasad, D. Krishnan, S. Kouser, A. Kumar Mishra, U. V. Waghmare, T. Pradeep, Small 2013, 9, 273-283.

[116] O. G. Apul, Q. Wang, Y. Zhou, T. Karanfil, Water Res. 2013, 47, 1648-1654.

[117] P. Sharma, N. Hussain, D. J. Borah, M. R. Das, J. Chem. Eng. Data 2013, $58,3477-3488$

[118] J. Xu, L. Wang, Y. Zhu, Langmuir 2012, 28, 8418-8425.

[119] B. Beless, H. S. Rifai, D. F. Rodrigues, Environ. Sci. Technol. 2014, 48, 10372-10379.

[120] W. Fan, W. Gao, C. Zhang, W. W. Tjiu, J. Pan and T. Liu, J. Mater. Chem. 2012, 22, 25108-25115.

[121] N. A. Travlou, G. Z. Kyzas, N. K. Lazaridis, E. A. Deliyanni, Langmuir 2013, 29, 1657-1668

[122] G. Xie, P. Xi, H. Liu, F. Chen, L. Huang, Y. Shi, F. Hou, Z. Zeng, C. Shaob, J. Wang, J. Mater. Chem. 2012, 22, 1033-1039.

[123] Z. Sui, Q. Meng, X. Zhang, R. Ma, B. Cao, J. Mater. Chem. 2012, 22, 8767-8771.

[124] S. S. Gupta, I. Chakraborty, S. M. Maliyekkal, T. A. Mark, D. K. Pandey, S. K. Das, T. Pradeep, ACS Sustainable Chem. Eng. 2015, 3, 1155-1163.

[125] D. Koushik, S. S. Gupta, S. M. Maliyekkal, T. Pradeep , J. Hazard. Mater. 2016, 308, 192-198.

[126] F. Liu, J. Zhao, S. Wang, P. Du, B. Xing, Environ. Sci. Technol. 2014, 48, 13197-13206.

[127] J. Li, S. Zhang, C. Chen, G. Zhao, X. Yang, J. Li, X. Wang, ACS Appl. Mater. Interfaces 2012, 4, 4991-5000.

[128] X. Yang, C. Chen, J. Li, G. Zhao, X. Rena, X. Wang, RSC Adv. 2012, 2, 8821-8826.

[129] W. Gao, M. Majumder, L. B. Alemany, T. N. Narayanan, M. A. Ibarra, B. K. Pradhan, P. M. Ajayan, ACS Appl. Mater. Interfaces 2011, 3, 1821-1826. 
[130] J.-H. Deng, X.-R. Zhang, G.-M. Zeng, J.-L. Gong, Q.-Y. Niu, J. Liang, Chem. Eng. J. 2013, 226, 189-200.

[131] L. J. Xu, W. Chu, L. Gan, Chem. Eng. J. 2015, 263, 435-443.

[132] S. Thangavel, N. Raghavan, G. Kadarkarai, S. -J. Kim, G. Venugopal, UItrason. Sonochem. 2015, 24, 123-131.

[133] Y. Yao, Y. Cai, F. Lu, F. Wei, X. Wang, S. Wang, J. Hazard. Mater. 2014, 270, 61-70.

[134] Y. Yao, C. Xu, S. Miao, H. Sun, S. Wang, J. Colloid Interface Sci. 2013, 402, 230-236.

[135] P. Shi, X. Dai, H. Zheng, D. Li, W. Yao, C. Hu, Chem. Eng. J. 2014, 240, 264-270.

[136] C. Li, L. Li, L. Sun, Z. Pei, J. Xie, S. Zhang, Carbon 2015, 89, 74-81.

[137] S. Liu, W. Peng, H. Sun, S. Wang, Nanoscale 2014, 6, 766-771.

[138] H. Sun, S. Liu, G. Zhou, H. M. Ang, M. O. Tadé, S. Wang, ACS Appl. Mater. Interfaces 2012, 4, 5466-5471.

[139] Y. Yao, C. Xu, S. Yu, D. Zhang, S. Wang, Ind. Eng. Chem. Res. 2013, 52, 3637-3645.

[140] H. Sun, Y. Wang, S. Liu, L. Ge, L. Wang, Z. Zhu, S. Wang, Chem. Commun. 2013, 49, 9914-9916.

[141] W. Peng, S. Liu, H. Sun, Y. Yao, L. Zhi, S. Wang, J. Mater. Chem. A 2013, 1 5854-5859.

[142] B. Ai, X. Duan, H. Sun, X. Qiu, S. Wang, Catal. Today 2015, 258, 668-675.

[143] S. Morales-Torres, L. M. Pastrana-Martínez, J. L. Figueiredo, J. L. Faria, A. M. T. Silva, Appl. Surf. Sci. 2013, 275, 361-368.

[144] J. Li, S. Zhou, G.-B. Hong, C.-T. Chang, Chem. Eng. J. 2013, 219, 486-491.

[145] E. Lee, J.-Y. Hong, H. Kang, J. Jang, J. Hazard. Mater. 2012, 219-220, $13-18$

[146] G. Jiang, Z. Lin, C. Chen, L. Zhu, Q. Chang, N. Wang, W. Wei, H. Tang, Carbon 2011, 49, 2693-2071.

[147] L. M. Pastrana-Martínez, S. Morales-Torres, A. G. Kontos, N. G. Moustakas, J. L. Faria, J. M. Doña-Rodríguez, P. Falaras, A. M. T. Silva, Chem. Eng. J. 2013, 224, 17-23.

[148] T.-D. Nguyen-Phan, V. H. Pham, E. W. Shin, H.-D. Pham, S. Kim, J. S. Chung, E. J. Kim, S. H. Hur, Chem. Eng. J. 2011, 170, 226-232.

[149] S. Anandan, T. N. Rao, M. Sathish, D. Rangappa, I. Honma, M. Miyauchi, ACS Appl. Mater. Interfaces 2013, 5, 207-212.

[150] Z. Ai, W. Ho, S. Lee, J. Phys. Chem. C 2011, 115, 25330-25337.

[151] V. Štengl, D. Popelková, P. Vláčil , J. Phys. Chem. C 2011, 115, 25209-25218.

[152] T. Kamegawa, D. Yamahana, H. Yamashita, J. Phys. Chem. C 2010, 114, 15049-15053.

[153] a) P. Wang, Y. Ao, C. Wang, J. Hou, J. Qian, Carbon 2012, 50, 5256-5264 b) T. Jiao, H. Zhao, J. Zhou, Q. Zhang, X. Luo, J. Hu, Q. Peng, X. Yan, ACS Sustainable Chem. Eng. 2015, 3, 3130-3139.

[154] S. Ghasemi, S. R. Setayesh, A. Habibi-Yangjeh, M. R. Hormozi-Nezhad, M. R. Gholami, J. Hazard. Mater. 2012, 199-200, 170-178.

[155] K. Li, T. Chen, L. Yan, Y. Dai, Z. Huang, J. Xiong, D. Song, Y. Lv, Z. Zeng, Colloids Surf. A: Physicochem. Eng. Asp. 2013, 422, 90-99.

[156] Y. Tang, S. Luo, Y. Teng, C. Liu, X. Xu, X. Zhang, L. Chen, J. Hazard. Mater. 2012, 241-242, 323-330.

[157] N. P. Herring, S. H. Almahoudi, C. R. Olson, M. S. El-Shall, J. Nanopart Res. 2012, 14, 1-13.

[158] B. Neppolian, A. Bruno, C. L. Bianchi, M. Ashokkumar, Ultrason. Sonochem. 2012, 19, 9-15.

[159] Z. Wang, Y. Du, F. Zhang, Z. Zheng, X. Zhang, Q. Feng, C. Wang, Mater. Chem. Phys. 2013, 140, 373-381.

[160] X. Zhang, X. Chang, M. A. Gondal, B. Zhang, Y. Liu, G. Ji, Appl. Surf. Sci. 2012, 258, 7826-7832.

[161] N. Farhangi, R. R. Chowdhury, Y. Medina-Gonzalez, M. B. Ray, P. A. Charpentier, Appl. Catal. B: Environ. 2011, 110, 25-32.

[162] Q. Hao, Y. Zhang, Int. J. Electrochem. Sci. 2016, 11, 1496-1511.

[163] C. Zhai, M. Zhu, F. Ren, Z. Yao, Y. Du, P. Yang, J. Hazard. Mater. 2013, 263, 291-298.
[164] G. Zhang, Y. Zhou, F. Yang, J. Electrochem. Soc. 2015, 162, H357-H365.

[165] T. Duan, Q. Wen, Y. Chen, Y. Zhou, Y. Duan, J. Hazard. Mater. 2014, 280, 304-314.

[166] C. Zhai, M. Zhu, Y. Lu, F. Ren, C. Wang, Y. Du, P. Yang, Phys. Chem. Chem. Phys. 2014, 16, 14800-14807.

[167] D. Wang, X. Li, J. Chen, X. Tao, Chem. Eng. J. 2012, 198-199, 547-554.

[168] C. Zhai, M. Zhu, D. Bin, H. Wang, Y. Du, C. Wang, P. Yang, ACS Appl. Mater. Interfaces 2014, 6, 17753-17761.

[169] P. Wang, Y. Ao, C. Wang, J. Hou, J. Qian, J. Hazard. Mater. 2012, 223-224, 79-83.

[170] L. Yang, Z. Li, H. Jiang, W. Jiang, R. Su, S. Luo, Y. Luo, Applied Catalysis B: Environ. 2016, 183, 75-85.

[171] H. R. Pant, B. Pant, H. J. Kim, A. Amarjargal, C. H. Park, L. D. Tijing, E. K. Kim, C. S. Kim, Ceram. Int. 2013, 39, 5083-5091.

[172] O. Akhavan, E. Ghaderi, ACS Nano 2010, 4, 5731-5736.

[173] O. Akhavan, E. Ghaderi, A. Esfandiar, J. Phys. Chem. B 2011, 115, 6279-6288.

[174] O. Akhavan, M. Choobtashani, A. Esfandiar, J. Phys. Chem. C 2012, 116, 9653-9659.

[175] I.E. M, Carpio, J. D. Mangadlao, H. N. Nguyen, R. C. Advincula, D. F. Rodrigues, Carbon 2014, 77, 289-301.

[176] J. Liu, L. Liu, H. Bai, Y. Wang, D. D. Sun, Appl. Catal. B: Environ. 2011, 106, 76-82.

[177] P. Gao, J. Liu, D. D. Sun, W. Ng, J. Hazard. Mater. 2013, 250-251, 412-420.

[178] B. Cao, S. Cao, P. Dong, J. Gao, J. Wang, Mater. Lett. 2013, 93, 349-352.

[179] L. Hui, J. T. Auletta, Z. Huang, X. Chen, F. Xia, S. Yang, H. Liu, L. Yang, ACS Appl. Mater. Interfaces 2015, 7, 10511-10517.

[180] Y. Jiang, W.-N. Wang, D. Liu, Y. Nie, W. Li, J. Wu, F. Zhang, P. Biswas, J. D. Fortner, Environ. Sci. Technol. 2015, 49, 6846-6854.

[181] L. Liu, J. Liu, D. D. Sun, Catal. Sci. Technol. 2012, 2, 2525-2532.

[182] S. Liu, M. Hu, T. H. Zeng, R. Wu, R. Jiang, J. Wei, L. Wang, J. Kong, Y. Chen, Langmuir 2012, 28, 12364-12372.

[183] T. Kavitha, A.I. Gopalan, K.-P. Lee, S.-Y. Park, Carbon 2012, 50, 2994-3000.

[184] V. T. H. Pham, V. K. Truong, M. D. J. Quinn, S. M. Notley, Y. Guo, V. A. Baulin, M. A. Kobaisi, R. J. Crawford, E. P. Ivanova, ACS Nano 2015, 9 8458-8467.

[185] O. Akhavan, E. Ghaderi, J. Phys. Chem. C 2009, 113, 20214-20220.

[186] M.-C. Wu, A. R. Deokar, J.-H. Liao, P.-Y. Shih, Y.-C. Ling, ACS Nano 2013, 7, 1281-1290.

[187] R. R. Nair, H. A. Wu, P. N. Jayaram, I. V. Grigorieva, A. K. Geim, Science 2012, 335, 422-444.

[188] R. K. Joshi, S. Alwarappan, M. Yoshimura, V. Sahajwalla, Y. Nishina, Appl. Mater. Today 2015, 1, 1-12.

[189] R. K. Joshi, P. Carbone, F. C. Wang, V. G. Kravets, Y. Su, I. V. Grigorieva, H. A. Wu, A. K. Geim, R. R. Nair, Science 2014, 343, 752-754.

[190] A. K. Mishra, S. Ramaprabhu, Desalination 2011, 282, 39-45.

[191] Z. Wang, B. Dou, L. Zheng, G. Zhang, Z. Liu, Z. Hao, Desalination 2012, 299, 96-102.

[192] P. Sun, Q. Chen, X. Li, H. Liu, K. Wang, M. Zhong, J. Wei, D. Wu, R. Ma, T. Sasaki, H. Zhu, NPG Asia Mater. 2015, 7, e162; doi:10.1038/am.2015.7

[193] S. P. Surwade, S. N. Smirnov, I. V. Vlassiouk, R. R. Unocic, G. M. Veith, S Dai, S. M. Mahurin, Nat. Nanotechnol. 2015, 10,459-464.

[194] Y. Han, Z. Xu, C. Gao, Adv. Funct. Mater. 2013, 23, 3693-3700.

[195] P. Sun, F. Zheng, M. Zhu, Z. Song, K. Wang, M. Zhong, D. Wu, R. B. Little, Z. Xu, H. Zhu, ACS Nano 2014, 8, 850-859.

[196] D. Cohen-Tanugi, J. C. Grossman, Nano Lett. 2012, 12, 3602-3608.

Submitted: June 7, 2016

Accepted: September 1, 2016 